PNL- 4286

$1>$

NUREG/CR-2766

PNL-4286

\title{
Design Basis for the NRC Operations Center
}

Prepared by M. K. Lindell, J. A. Wise, B. N. Griffin/HARC

A. E. Desrosiers, W. D. Meitzler/PNL

Battelle Human Affairs Research Centers

Pacific Northwest Laboratory

Prepared for

U.S. Nuclear Regulatory

Commission 


\section{NOTICE}

This report was prepared as an account of work sponsored by an agency of the United States Government. Neither the United States Government nor any agency thereof, or any of their employees, makes any warranty, expressed or implied, of assumes any legal liability of responsibility for any third party's use, or the results of such use, of any information, apparatus, product or process disclosed in this report, or represents that its use by such third party would not infringe privately owned rights.

\section{Availability of Reference Materials Cited in \\ 1. The NRC Public Document Room, 1717 H Street, N.W. Washington, DC 20555 \\ 2. The NRC/GPO Sales Program, U.S. Nuclear Regulatory Commission, Washington, DC 20555 \\ 3. The National Technical Information Service, Springfield, VA 22161}

Most documents cited in NRC publications will be available frorn one of the following sources:

Although the listing that follows represents the majority of documents cited in NRC publications, it is not intended to be exhaustive.

Referenced documents available for inspection and copying for a fee from the NRC Public Document Room include NRC correspondence and ir.ternal NRC memoranda; NRC Office of inspection and Enforcement bulletins, circulars, information notices, inspection and investigation notices; Licensee Event Reports; vendor reports and correspondence; Commission papers; and applicant and licensee documents and correspondence.

The following documents in the NUREG series are available for purchase from the NRC/GPO Sales Program: formal NRC staH and contractor reports, NRC-sponsored conference proceedings, and NRC booklets and brochures. Also available are Regulatory Guides, NRC regulations in the Code of Federal Regulations, and Nuclear Regulatory Commission /ssuanses.

Documents available from the National Technical Information Service include NUREG series reports and technical reports prepared by other federal agencies and reports prepared by the Atomic Energy Commission, forerunner agency to the Nuclear Regulatory Commission.

Documents available from public and special technical libraries include all open literature items, such as books, journal and periodical articles, and transactions. Federal Register notices, federal and state legislation, and congressional reports can usually be obtaine $d$ from these libraries.

Documents such as theses, dissertations, foreign reports and tra hslations, and non-NAC conference proceedings are available for purchase from the organization sporsoring the publication cited.

Single copies of NAC draft reports are available free upon written request to the Division of Technical Information and Document Control, U.S. Nuclear Regulatory Commission, Washington, DC 20555

Copies of industry codes and standards used in a substantive manner in the NRC regulatory process are maintained at the NRC Library, 7920 Norfolk Avenue, Bethesda, Maryland, and are available there for reference use by the public. Codes and standards are usually copyrighted and may be purchased from the originating organization or, if they are American National Standards, from the American National Standards Institute, 1430 Broadway, New York, NY 10018. 
NUREG/CR-2766

PNL-4286

HARC- $400 / 82 / 005$

\section{Design Basis for the NRC Operations Center}

Manuscript Completed: March 1982

Date Published: May 1983

Prepared by

M. K. Lindell, J. A. Wise, B. N. Griffin/Battelle Human Affairs Research Centers

A. E. Desrosiers, W. D. Meitzler/Pacific Northwest Laboratory

Battelle Human Affairs Research Centers

4000 N.E. 41 st Street

Seattle, WA 98105

Pacific Northwest Laboratory

Richland, WA 99352

\section{Prepared for}

Division of Emergency Preparedness and Engineering Response

Office of Inspection and Enforcement

U.S. Nuclear Regulatory Commission

Washington, D.C. 20555

NRC FIN B2182 
3092901294904

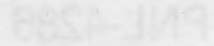

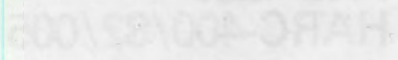


ABSTRACT

This report documents the development of a design for a new NRC Operations Center (NRCOC). The project was conducted in two phases: organizational analysis and facility design. Three sources of information were used in the process of conducting the organizational analysis: (1) review of NRC incident response plans and procedures, (2) interviews with NRC personnel and (3) observations of the activation and functioning of the existing NRCOC during an energency exercise. Following the identification of the adjacencies and environmental conditions required to facilitate effective performance, the layout and equipment of the existing NRCOC were examined to what changes were needed to accommodate the flows of verbal, numeric and graphic information and the flow of material throughout the NRCOC.

In order to control the amount of traffic, congestion and noise within the facility, it is recommended that information flow in the new NRCOC be accomplished by means of an electronic Status Information Management System. Functional requirements and a conceptual design for this system are described.

An idealized architectural design and a detailed design program are presented that provide the appropriate amount of space for operations, equipment and circulation within team areas. The overall layout provides controlled access to the facility and, through the use of a zoning concept, provides each team within the NRCOC the appropriate balance of ready access and privacy determined from the organizational analyses conducted during the initial phase of the project. 



\section{CONIENTS}

$\underline{\text { Page }}$

$\begin{array}{lll}1.0 \text { Introduction } & 1\end{array}$

2.0 Organizational Structure and Functions 3

2.1 Interteam Analysis 3

2.2 Intrateam Analysis 6

2.2.1 Response Coordination Team 6

2.2.2 Current Status Team 7

2.2.3 Reactor Safety Team 8

2.2.4 Protective Measures Team 11

2.2.5 Safeguards Team 14

2.2.6 Executive Team 15

2.2.7 Liaison Team 18

$\begin{array}{ll}3.0 \text { Required Ad jacencies } & 19\end{array}$

3.1 Adjacencies for Activation Modes 19

3.1.1 Verbal Information 20

3.1.2 Numeric Information 20

3.1.3 Graphic Information 20

3.1.4 Materials 24

3.1.5 Sumary of Activation Mode Adjacencies 24

4.0 Analysis of the Design of the Existing NRCOC 27

4.1 Interteam Analysis $\quad 27$

4.2 Intrateam Analysis 29

4.2.1 Response Coordination Team 29

4.2.2 Current Status Team 31

4.2.3 Reactor Safety Team 31

4.2.4 Protective Measures Team 32

4.2.5 Safeguards Team 33

4.2.6 Executive Team 33

4.2.6.1 Briefing Process 34

4.2.6.2 Deliberative Process 34

4.2.7 Liaison Team 35 
5.0 Status Information Management System 36

5.1 Purpose 36

$\begin{array}{lll}5.2 & \text { Functional Requirements } & 36\end{array}$

$\begin{array}{lll}5.3 & \text { Conceptual Design } & 38\end{array}$

5.3.1 General Discussion 38

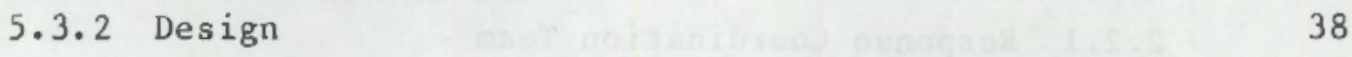

5.4 Desıgn Guidelines for Visual Display Terminals (VDTs) 39

5.4.1 Workplace Positioning and Placement 40

5.4.2 Ambient Task Lighting 41

5.4.3 Noise and Ventilation 42

5.4.4 Koom Elements in the Visual Field 42

6.0 Architectural Design $\quad 43$

6.1 Functional Zoning 43

6.2 Circulation Restrictions $\quad 44$

6.3 Utilities (Ducting and Wiring) 45

6.4 Space Analysis $\quad 45$

6.5 Ideal Configuration $\quad 46$

6.6 Dual Use Considerations $\quad 49$

7.0 Design Program 50

7.1 General Design Requirements 50

7.1.1 Illumination 50

7.1.2 Acoustics 51

7.1.3 Thermal and Air Quality 51

7.1.4 Security, Symbolic and Special 52

7.2 Detail Design Programs 54

7.2.1 Executive Team Briefing Room 54

7.2.1.1 Executive Secretary Workstation $\quad 54$

7.2.1.2 Status Officer Workstation 56

7.2.1.3 Briefing Area 58

7.2.2 Executive Team Meeting Chamber 60

7.2.3 Liaison Tean Room 62

7.2.4 Analysis Team Directors' Workspace 63

$\begin{array}{lll}7.2 .5 & \text { Operations Room } & 66\end{array}$ 


\section{CONTENTS (Cont.)}

$\underline{\text { Page }}$

7.2.5.1 General Requirements 66

7.2.5.2 Communications Support Area 67

7.2.5.3 Current Status Area 70

7.2.6 Reactor Safety Team Room 71

7.2.7 Safeguards Team Room 73

7.2.8 Protective Measures Team Space 74

7.2.8.1 General Requirements $\quad 74$

7.2.8.2 Radiological Analysis Team Area $\quad 75$

7.2.8.3 Protective Action Aralysis Team Area 76

7.2.9 Response Coordination and Reception Areas 77

7.2.9.1 Functional Narrative 77

7.2.9.2 Detail Description 78

$\begin{array}{ll}7.2 .10 \text { Ready Room } & 80\end{array}$

7.2.10.1 Functional Narrative $\quad 80$

$\begin{array}{ll}\text { 7.2.10.2 Detail Description } & 81\end{array}$

$\begin{array}{ll}\text { 7.2.11 Support Spaces } & 83\end{array}$

7.2.11.1 Copy/Fax Room 83

7.2.11.2 Phone Room $\quad 84$

7.2.11.3 Restrooms $\quad 84$

7.2 .11 .4 Computer Room 85

7.2.11.5 Hallways and Circulation Areas 85

7.2.11.6 Reception Area 86

$\begin{array}{ll}\text { References } & 87\end{array}$

Appendix

vii. 


\section{Figures}

Page

Figure 1 Team level analysis 5

Figure 2 Current status 9

Figure 3 Reactor safety 12

$\begin{array}{lll}\text { Figure } 4 & \text { Protective measures } & 13\end{array}$

$\begin{array}{lll}\text { Figure } 5 \text { Safeguards } & 16\end{array}$

$\begin{array}{lll}\text { Figure } 6 & \text { Executive team } & 17\end{array}$

$\begin{array}{lll}\text { Figure } 7 & \text { Verbal information } & 21\end{array}$

Figure 8 Numeric information 22

$\begin{array}{lll}\text { Figure } 9 \text { Graphic information } & 23\end{array}$

Figure 10 Materials 25

$\begin{array}{ll}\text { Figure } 11 \text { Adjacency summary } & 26\end{array}$

Figure 12 Circulation in existing operations center 28

$\begin{array}{ll}\text { Figure } 13 \text { Floor plan } & 47\end{array}$

Figure 14 Furniture layout 55

\section{$\underline{\text { Tables }}$}

Table 1 Instrumentation \& Control Electrical Reactor Functions 10

$\begin{array}{lll}\text { Table } 2 \text { Adjacency requirement codes } & 19\end{array}$

$\begin{array}{lll}\text { Table } 3 & \text { Space analysis sumary } & 46\end{array}$ 
DESIGN BASIS FOR THE NRC OPERAT IONS CENTER

\subsection{Introduction}

The smooth functioning of organizational response to an emergency requires that a number of resources be brought to bear. Primary among these are personnel, equipment, information and material. The effective use of these resources, in turn, necessitates the provision of work spaces that support, rather than thwart, the intended functions of the organization.

In the case of the NRC, an Operations Center is needed that will provide for the routine monitoring of normal activities at 1 icensed nuclear facilities, yet serve as the initial focus of the agency's response to an emergency at a licensed nuclear facility or during transport of nuclear materials. These extremes of activity, which correspond to the Normal and Initial Activation modes of operation described in NUKEG-0728 are associated with a number of specific functions that must be accomplished. These functions include the acquisition and analysis of information on incident and plant status; evaluation and advice and evaluation concerning licensee actions, liaison with federal, state and local agencies; provision for public information and recommendations for protective actions for the public.

Achievement of such functions is accomplished by means of a response organization composed of specialized teans which differ in their tasks, equipment and information needs. In order to assure that the NRC responds to the incident conditions in an appropriate and timely manner, the workspace within which each of the teams operates must meet two basic criteria: it must be in a suitable location and it must provide environmental conditions that facilitate performance.

The first criterion can be assessed by consideration of the required adjacencies of the teams. Teams that have frequent, or if not frequent, at leagt important, interchanges of personnel, information, or materials should be close together. This may be because an individual is a "linking pin" between two or more teams and therefore must meet or check with those in two different areas. Team directors, for example function as "members" of two different groups, their own analysis teams and the Executive Team. Other members of analysis teams may be "linking pins" not because they coordinate two different levels of an organizational hierarchy, but because they mediate sequential dependencies in the flow of work. In an organization that processes information, such lateral links may appear among teams that collect the information and those that perform different types of analyses on the data subsequent to it's collection. Interchanges of material in such organizations are most frequently "paper flows" of status reports, analyses and the like. 
The second criterion, environmental conditions that facilitate performance, is indicated by the size, spatial configuration, and ambient qualities associated with the space assigned to each work group. The size of a work group's location is determined by the requirements for operational space for personnel and equipment. Circulation space for the unimpeded flow of traffic within the area is also required. Operational space for equipment, it should be noted, must take into account any requirements for access during preventive or corrective maintenance. Spatial configuration, which is reflected in the aspect ratio ( $A R=$ length/width), influences the interactions that take place within that area: a square $(A R=1.0)$ provides the minimum perimeter per unit of area but provides maximum access within the space. More rectangular spaces provide greater perimeter but more sharply restrict access.

Required ambient qualities, such as illumination, acoustics, temperature, and air quality, may differ from task to task. Closely linked activities which require significantly different ambient conditions can produce problems. For example, monitoring a visual display terminal (VDT) and inspecting maps or diagrams can require very different light intensities. This would affect the type of lighting in an area if the same person or two people who were assigned adjacent areas needed to perform these tasks.

The purpose of this report is to document the analyses of the structure and functioning of the teams that operate within the NRC Operations Center and to translate the interactions among teans into a set of required adjacencies. The required adjacencies will, in turn, be used as a framework to describe current conflicts between the design of the organization and the design of the space within which the organization functions. All of these will be addressed in sections 2.0 through 4.0 .

Subsequent sections of this report will describe an electronic status display system that will improve the dissemination of information througout the NRCOC, and present architectural drawings and a design program that provide the adjacencies and environmental conditions required to facilitate each team in the performance of its functions. 


\subsection{Organizational Structure and Functions}

\subsection{Interteam analysis}

Prior to designing a physical structure, it was necessary to assess the organizational structure and functioning of the response teams. This assessment made use of written materials, interviews and performance observations. Review of NRC emergency plans and procedures included NUREG-0728 (NRC Incident Response Plan) and NUREG-0845 (Agency Procedures for the Incident Response Plan). Other sources of written information included reports on emergency communications and reactor data acquisition (NUREG-0729, NUREG-0730, NUREG/CR-1739). NKC staff were interviewed to incorporate their judgments about design features required for the new facility. Finally, observations were made during an emergency exercise to gain further insight into staffing and equipment needs and their impact on alternative spatial arrangements.

These sources indicated that operational functions had been assigned to seven different functional entrties, the Executive Team, a Liaison Team, three analysis teams (Reactor Safety, Protective Measures and Safeguards) a communications team (Current Status) and a support team (Response Coordination). Functions to be performed by each of these teans can be briefly sumnarized as follows. The Executive Team provides advice or direction to the 1 icensee, recommends protective actions to offsite authorities and interprets or sets NRC policy related to an incident. The Liaison Team provides a means by which authoritative information concerning the status of the incident, the status of the licensee, state and local response, and NRC actions can be disseminated to federal and state agencies, the Congress and the public. The Reactor Safety Team monitors the status of reactor and safety systems involved in an incident and is responsible for assessing current plant status and projecting plant prognosis. The Protective Measures Team uses reactor data and together with meteorological and hydrological data producer projections of exposures of the residents in the vicinity of the incident to radiological releases. These projections are used as a basis for recommending protective actions for the public. The Safeguards Team provides a coordinated flow of information concerning safeguards aspects of an incident involving sabotage or unauthorized access to special nuclear material (SNM). The Current Status Team monitors two dedicated Iines from a nuclear reactor (the Emergency Notification System, ENS, and the Health Physics Network, HPN), prepares status reports and enters status information into video displays. The Response Coordination Team provides communications support by operating the switchboard and monitoring ENS lines to unaffected reactors. In addition, this team provides administrative and logistical support to the other teams in the NRCOC.

The way in which the mission of the NRCOC is accomplished cannot be understood solely by consideration of the assignment of specialized functions to teams. It is also necessary to understand the number of personnel that are required to perform these functions and to understand the sequencing of the tasks performed by these teams. Required staffing 
levels are obviously an important consideration since it affects the size of the team areas and, subsequently, the size of the overall facility. This requirement will be discussed below, in the presentation of the analyses of intra-team functioning.

Performance sequencing must, however, be discussed at both the intraand inter-team levels. This term refers to the temporal ordering of the activities of the teams, which ray be either simultaneous, sequential or asynchronous. In practice, it is difficult to classify activities as falling unambiguously into only one of these categories, since some of the activities of a team may be simultaneous, other activities sequential and still others asynchronous with respect to the activities of another team.

Assurance of a satisfactory level of coordination of the sequential tasks requires an understanding of the flow of work which should consider separately the flows of materials and information. In an organization like the NRCOC, the flow of materials is much less significant than the flow of information. Information flow can itself be broken down into three types, verbal, numeric, and graphic information.

The most clearly defined flow of information among the work teams in this center is that of incoming technical data from the reactor site through the Current Status Team to the analysis teams who process the information and foward recommendations and supporting analyses to the Executive Team. The latter group resolves policy issues and gives advice or direction, if necessary, to the licensee management. Advisory messages on the status of the incident, the status of licensee, state and local response to the incident and the NRCs evaluation of the actions of other organizations especially the licensee--are disseminated by means of the Liaison Team. This flow, diagrammed in Figure 1, includes verbal, numeric, and graphic information.

A second, perhaps less obvious and certainly less standardized flow of information moves in a reverse direction from the Executive Team to the analysis teams in the form of directions for additional analyses and reports of decisions made. There is also a backflow of information from the analysis teams to the Current Status Team. This takes the form of requests for clarification or additional information from the reactor site. Members of the Liaison Team contribute to a secondary flow of information to the Executive Team. The liaisons transmit requests for statements which they receive from outside organizations with which they are in contact. Last, any of the teams may initiate a request to the Response Coordination Team for administrative or logistical support. Since these backflows follow the same paths as the forward flows, they are not diagrammed separately.

At the present time, information is transmitted from Current Status to the analysis teams primarily by means of standardized message forms that describe reactor parameters, emergency classes, meteorological and 
hydrological data and radiation measurements taken from field surveys. analysis team members are made aware of telephone communications between the reactor site and the communicators in the Current Status Team by means of an audio monitor. Communication among the analysis teams is primarily face to face although the results of analyses conducted by one team that have been prepared for briefings of the Executive Team are available to the other team(s). The members of the Executive Team and the Liaison Team receive information by means of oral briefings from the analysis team directors and by means of standardized forms that describe the results of analyses by the teams. Video displays describing the "status of the incident" and "status of the response" are generated by the Current Status Team. These displays are available in the analysis team rooms and the Executive Team room where the Executive Team and most of the Liaison Team are currently located. Backflows of information, since they deal primarily with directions for additional analyses, and requests for clarification or further information, are primarily verbal.

\subsection{Intrateam analysis}

The following discussion will describe each of the work teams in turn. Following a brief summarization of the team's function will be a listing of the personnel assigned to the team and the team members. This narrative will include mention of the major communications and analytic activities and present a flow chart that describes the performance sequencing within the team.

\subsubsection{Response Coordination Team}

The RC Team activates the Operations Center, makes initial notifications to key organizations, provides administrative and logistic support to the other teams and provides communications support for the Operations Center.

\author{
Logistic Support \\ Director \\ Member
}

\section{Personnel}

\begin{tabular}{l} 
Communications Support \\
\hline Duty Officer \\
Phone Operator \\
Asst. Phone Operator
\end{tabular}

Following the initial activation of the center and notification of key agencies, the activities of the Logistic Support group consist primarily of the provision of needed services to other teams within the NRCOC. The workload for this group is highly variable and the variations in workload are generally unpredictable. In order to respond promptly to requests from other teams, it is necessary for the members of this group to be readily available, and in most cases, to circulate from area to area. Some of the tasks must be handled at a specific workstation, but others need not. The members of this group are drawn from the staff of the Incident Response Branch which is located in the Operations Center area during normal operations. Thus the size of the Logistic Support group can vary with the size of the workload during periods of high demand. 
The Logistic Support group has approximately equal levels of comnunications contact with all of the other teams in the NRCOC. Because of this consideration, as well as the fact that most of the contacts consist of nonroutine requests, an information flow diagram would be uninformative and is not presented.

The other group, Communications Support, operates the switchboard and monitors the ENS lines to all plants not involved in the incident. The Duty officer receives the initial call from the affected plant, makes emergency notifications, and transfers communications control to the two emergency operations phone operators. He subsequently moves from the primary telephone console to an alternate console in order to continue monitoring the ENS for all plants not involved in the incident.

The phone operators receive outside calls and route these to the proper NRCOC staff.

\title{
2.2.2 Current Status Team
}

The CS Team monitors the dedicated 1 ines (Emergency Notification System, ENS, and the Health Physics Network, HPN), enters status information for the video displays and prepares status reports for the analys is teams.

\author{
Personnel \\ Director \\ Deputy Director \\ ENS external communicator \\ ENS internal communicator \\ HPN external communicator \\ HPN internal communicator \\ Status Board operator
}

CS Team operations begin with the activity of either the Health Physics Network or Emergency Notification System external communicators, who operate in parallel. These individuals receive information via dedicated voice lines from communicators at the affected site. The HPN handles information primarily useful to the Protective Measures Team. The ENS handles information primarily useful to the Reactor Safety Team.

The external communicators have sufficient technical training to ask clarifying questions of the callers. This information is used to formulate entries to update two status boards which display the status of the incident and the status of the response. The respective internal communicators are also monitoring the lines, and transcribe data onto prepared forms. These forms are duplicated and distributed to the analysis teams.

The CS Director or Deputy Director monitors both ENS and HPN external communicators, sometimes initiating questions to the caller through the appropriate communicator. The CS Director and Deputy Director play somewhat interchangeable roles in that they need to monitor both ENS and HPN 
lines simultaneously, but with selective attention. The Current Status Director/Deputy Director also must be available to confer with the analysis team directors. Thus, the Director/Deputy Director need to be able to coordinate their activities, operate with one monitoring while the other confers.

The Status Board Operator receives instructions personally from the CS Director in the form of written material to be added to the status board. The Status Board Operator inputs this material through the keyboard at the personal VDT workstation. From this point of entry, the material is available on video monitors at selected places throughout the NRCOC. Information flaw for the CS Team is displayed in Figure 2.

\title{
2.2.3 Reactor Safety Team
}

The RS Team monitors the status of reactor and safety systems involved in an incident. Team members also monitor licensee and NRC actions necessary to control the incident. They are responsible for assessing current plant status and projecting future changes. The RS Team personnel functions involve:

\author{
Personnel \\ Team Director \\ Deputy Director \\ Core Physics \\ Containment \\ Instrumentation and Control \\ Heat Transfer \\ Electrical Systems \\ Reactor Systems (3)
}

In addition there are standby people for Mechanical \& Auxiliary, Structural, and Materials who may be called into the team space if needed. These individuals are additions, not substitutions to the team.

The RS Team can be understood in terms of the reactor functions which are addressed by its nembers. The assignment of personnel to functions is displayed in Table 1. The reactor functions themselves overlap as follows :

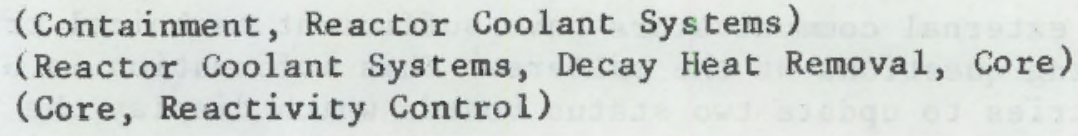

Piping and instrumentation diagrams (P\&IDs) are utilized primarily by the personnel in Instrumentation \& Control, Electrical Systems, and Reactor Systems. The P\&IDs are in 17 in. $x 11$ in. pages in the FSAR stored in the central file room of the NRCOC. 
HPN

External

Cormunicator
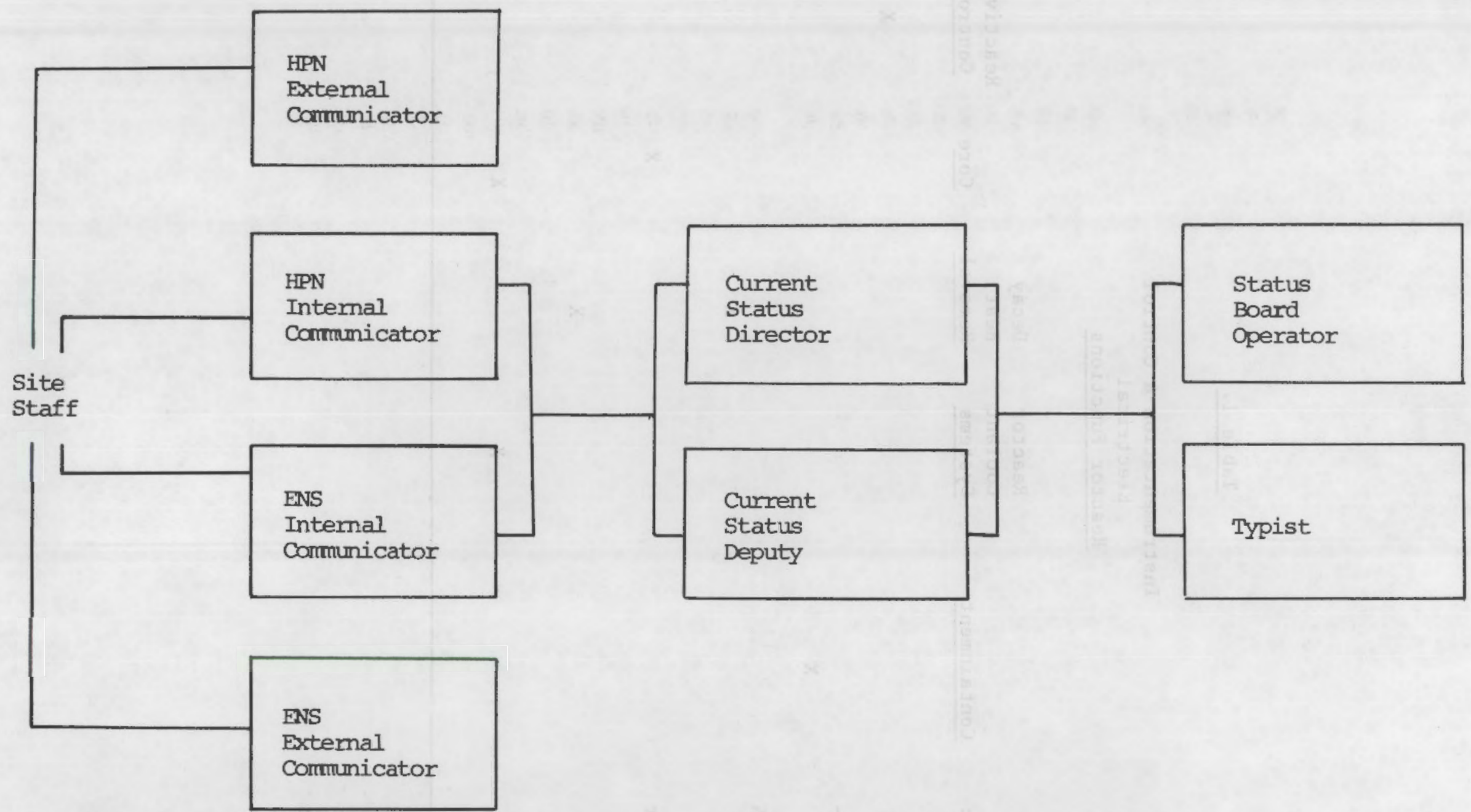

Figure 2 Current Status 


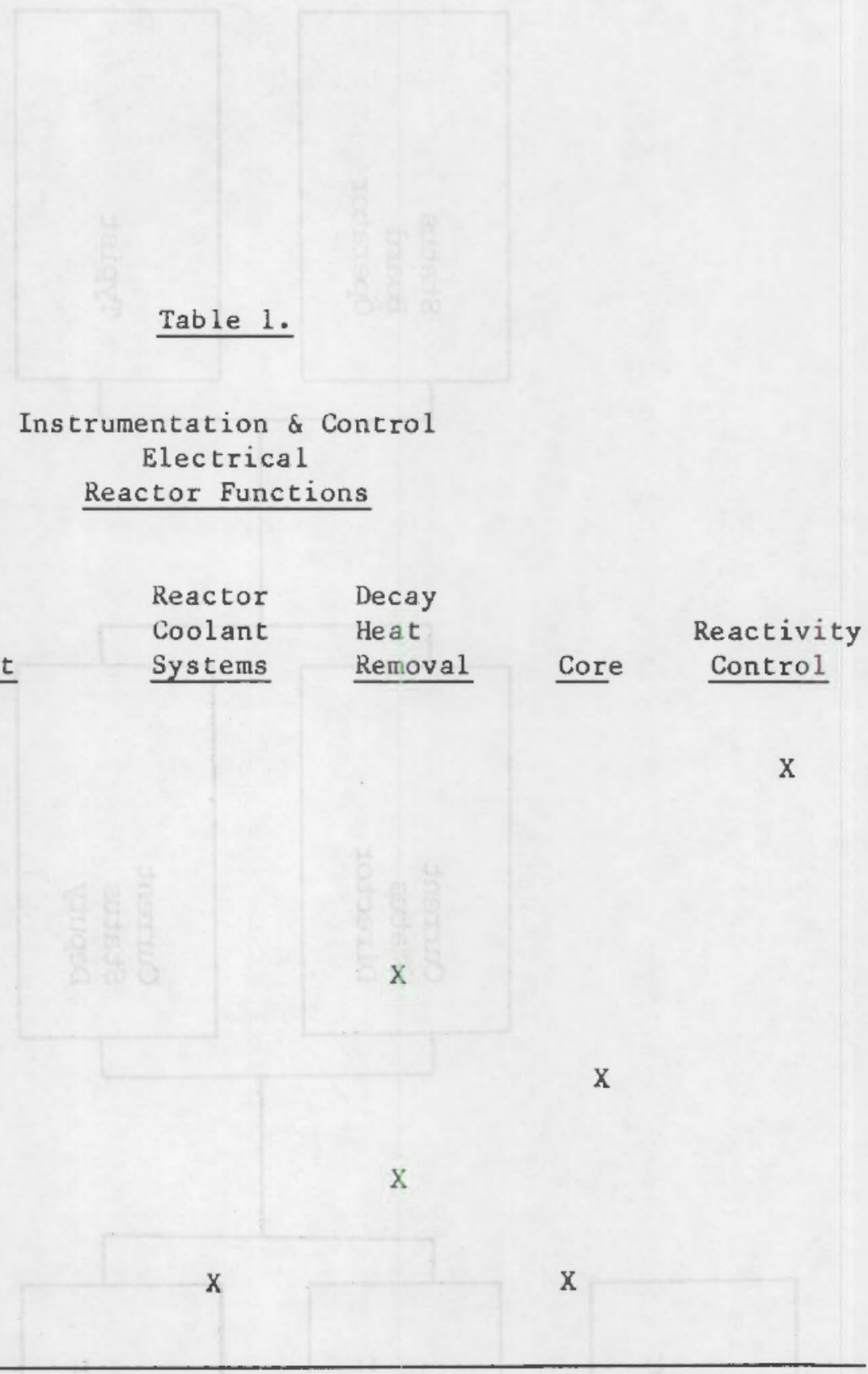

Team

Members:

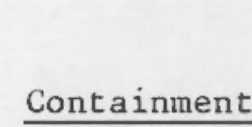

Core

Physics

Containment

Instr \&

Control

Heat

Transfer

Elect.

Systems

\section{X}

Reactor

Sys tems

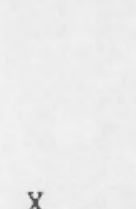


The RS Team spends considerable time in joint discussion. RS Team members work both singly and in small groups, with the Reactor Systems, Instrumentation \& Control, and Electrical analysts working in particularly close cooperation. The absence of a prescribed flow of information within the RS Team is indicated in Figure 3 by the location of all team members within a single box.

The RS Team does not currently utilize or appear to need computer assistance. Team members operate mainly with printed materials, construction charts, and schematic diagrams. In its work, the RS Team uses pages from the Final Safety Analysis Report (FSAR) of the affected plant, and other construction drawings and schematic diagrams as required. All team members refer frequently to the audio (ENS) and video (status of incident and status of response) monitors.

The Deputy Director does not (and should not) remain at a fixed workstation. This person directs and coordinates team members' activities, and is in constant contact with these other individuals. The RS Team Director divides his time between activities such as those of the RS Deputy, and providing briefings in the Executive Team briefings room.

\subsubsection{Protective Measures Team}

The Protective Measures (PM) Team monitors and coordinates the collection of environmental data at the incident's site and region. The team also maintains summaries of current, cumulative, and projected radiological impacts on people and the environment.

The PM Team is broken into two subteams, one of which deals with dose calculations-the Radiological Analysis Team. The other deals with the problems of determination of appropriate protective action--the Protective Action Analysis Team. Compositions of the teams are listed below. The flow of information is presented in Figure 4.

\author{
Radiological \\ Analys is Team \\ Team Leader \\ Effluent Control \& On- \\ site Health Physics \\ Source Term \\ Dose Assessment (2) \\ Meteorologist (2) \\ of fsite Environmental \\ Analysis \\ Hydrology
}

\section{Personnel Team Director Deputy Director}

\section{Protective Action Analys is Team}

Team Leader HP Analysts/Technical State Liaisons (2)

Protective Action Analysts (2) 


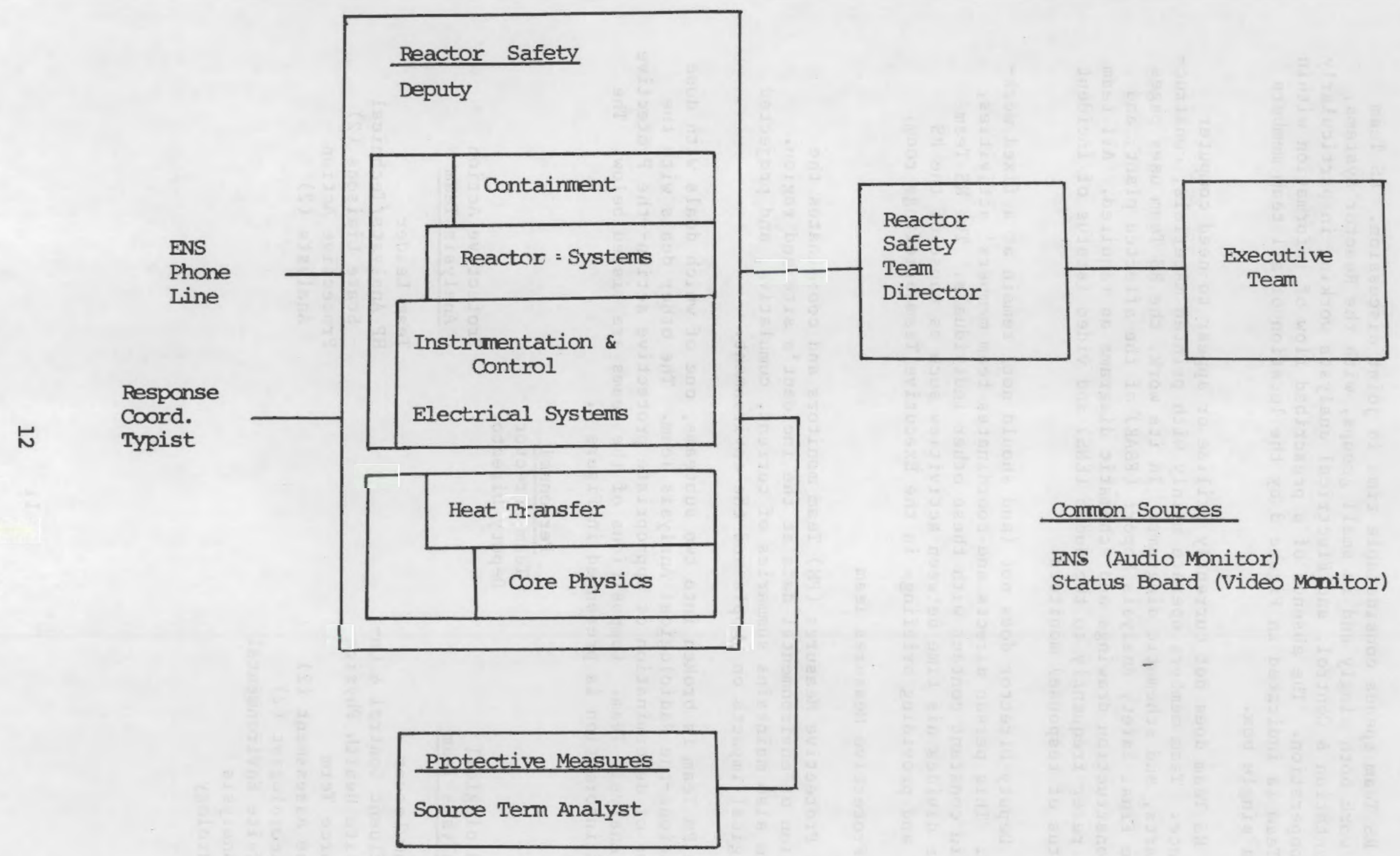

Figure 3 Reactor Safety 


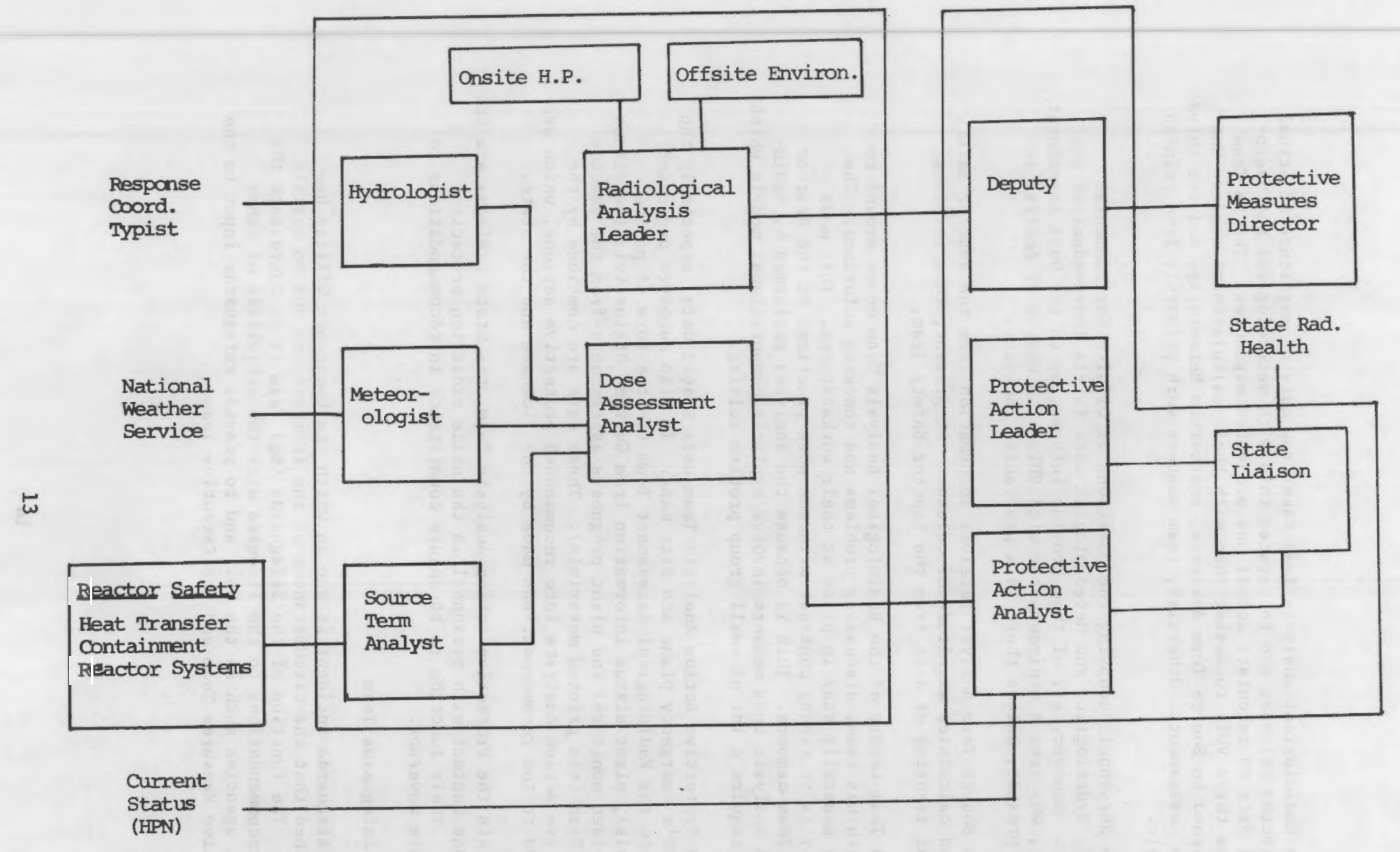

Figure 4 Protective Measures 
The Radiological Analysis Team takes raw data on magnitude of actual or projected releases and integrates this with meterological and hydrological data to calculate actual and projected exposures. The RA Team will use three VDTs to assist them with their calculational needs. One is assigned to Source Term Analysis, another to Meteorology and the third to Dose Assessment. Otherwise, team members work primarily from printed materials.

The personnel occupying the positions of offsite Environmental Analyst, Hydrologist, and Meteorologist work fairly independent of one another. However, all of them provide information to the Dose Assessment Analyst, who uses a mini-computer with VDT. The Onsite HP Analyst is rarely present, unless there is a protracted incident.

The Source Term Analyst receives information from the Reactor Safety Team and calculates magnitude of release. At present, this involves personal transfer of data from the Reactor Safety Team.

The Team Leader of the Radiological Analysis Team moves around to meet with his team, discussing problems and checking solutions. The members generally stay in place at their workstations. This mode of activity is in strong contrast with the work practices of the Reactor Safety Team members. This is because the analyses performed by Radiological analysis team members involve explicit computational models which do not require a lot of small group problem solving.

The Protective Action Analysis Team uses static data, especially the licensee's emergency plans and site maps. It also receives processed data from the Radiological Assessment Team (in the form of printed materials), plant status information from Current Status (via the status board video monitors) and plant prognosis assessments from the Reactor Safety Team (via printed materials). These data are combined by the Protective Action Analysts into recommended protective actions, which are compared to the recommendations made by the licensee and the state.

Within the Protective Action Analysis Team, the State Liaisons are in telephone contact with personnel in the state radiation protection agency. Their function is to ensure consistency in recommendations to the State Governor.

\subsubsection{Safeguards Team}

A safeguards incident is one in which the Emergency officer has determined that the circumstances of the incident are due to hostile action. The function of the Safeguards $(\mathrm{Sg}) \mathrm{Tean}$ is to coordinate the NRC's recommendations to the licensee with the activities of other Federal agencies such as the FBI, and to provide safeguards input to the Protective Measures Team and the Executive Team. 


\author{
Personne 1 \\ Director \\ Deputy Director \\ Safeguards Analysts (2) \\ Safeguards Coordinator
}

During most safeguards incidents, only the $\mathrm{Sg}_{\mathrm{g}}$ and PM Teams will be operating. However, there are special conditions which may make it necessary for the RS Team to also become operational. In a case of sabotage, the need for safeguards expertise would become increasingly apparent as the emergency developed. In a direct attack on a plant the $\mathrm{Sg}$ Team would play a more prominent role from the outset.

The $\mathrm{Sg}$ Director plays the same role as the director of other teams, briefing the Executive Team as needed. The Deputy Director acts as coordinator for the groups' activities. Activities are best characterized as small group discussion with frequent multiple overlapping phone calls to other parties. For this reason, no explicit flow of information is diagrammed in Figure 5. The $\mathrm{Sg}$ Team does not prepare graphic material for Ex Team presentation. Briefings are done verbally more than pictorially.

\title{
2.2.6 Executive Team
}

The functions of the Ex Team are to advise the Chair of the NRC with respect to advice or direction to the licensee and to recommend protective actions on- and offsite.

\author{
Personnel \\ Chair, NRC (Director of Executive Team) \\ Executive Director of Operations (Deputy Director) \\ Director of Inspection and Enforcement \\ Director of Nuclear Reactor Regulation \\ Director of office of MMSS
}

The staff of the Ex Team are displayed in Figure 6. All are permanently assigned to the Executive Team workspace. In addition, there are a Status officer and an Executive Secretary permanently assigned to this area and three liaisons who are currently located within or adjacent to the Ex Team room.

The Ex Team receives almost all of the information that it utilizes in its deliberations from the analysis team directors. This information is in the form of personal briefings. The Ex Team receives additional information from the video monitors which display the status of the incident and the status of the response.

The Ex Team also receives requests for statements through the three liaisons. The Chair of the NRC must also have the capability to initiate or respond to external phone calls placed by individuals like the President, a State Governor, members of Congress, heads of other federal agencies, and the like. 


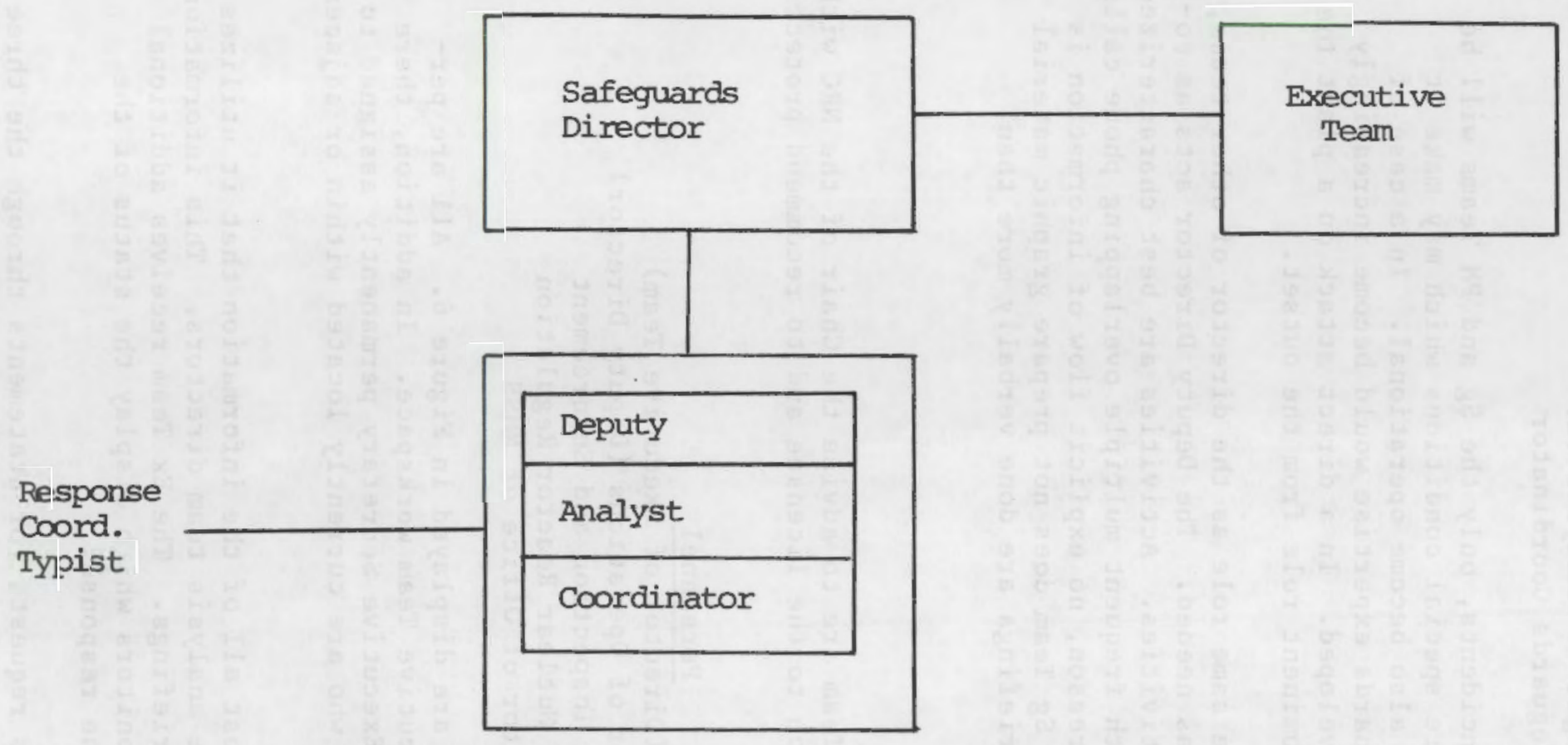

Figure 5 Safeguards 


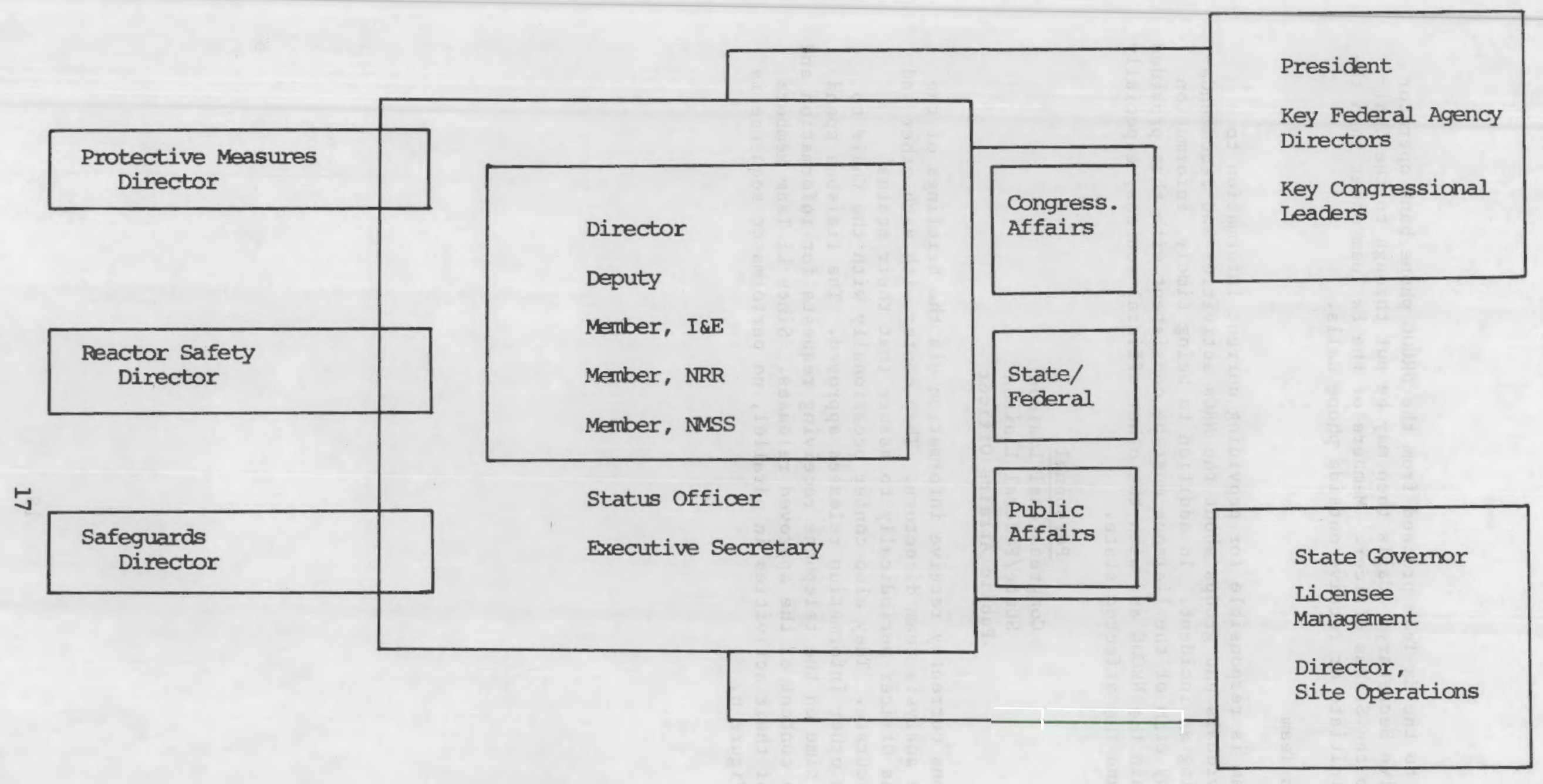

\section{Figure 6 Executive Team}


All calls to the Ex Team proceed from the NRCOC phone bank operator to the Executive Secretary. Calls then may be put through to the Chair or referred to the Status officer. Members of the Ex Team other than the Chair do not initiate or receive outside phone calls.

\subsubsection{Liaison Team}

The $\mathrm{Li}$ Team is responsible for providing current information to external individuals and groups about the NRCs activities and recommendations concerning an incident. In addition to being timely, information disseminated by each of the liaisons must be consistent with that provided by others within the NRCOC and with the other official sources, especially the licensee and the affected state.

\section{Personne 1 \\ Congressional Liaison \\ State/Federal Liaison \\ Public Affairs officer}

The liaisons currently receive information via the briefings of the Ex Team by the analysis team directors. They confer with each other and with the Status officer periodically to assure that their status reports are accurate. They also confer occasionally with the Chair to have press and other information releases approved. The liaisons spend most of their time on the telephone receiving requests for information and discussing the content of the approved releases. Since Li Team members perforn most of their activities in parallel, no performance sequence is indicated in Figure 6. 


\subsection{Required Adjacencies}

\subsection{Adjacencies for activation modes}

The information flow diagrams presented and described in the preceding pages give a sufficient description of the organizational processes that operate in the NRCOC. They do not, however, provide a satisfactory basis for architectural design. For this purpose, adjacency matrices are more appropriate. In the following sections, matrices will be presented that describe the strength of the adjacency requirement implied by flows of verbal, numeric and graphic information and by flows of materials. These will be followed by a summary adjacency matrix that will simultaneously display the requirements of all four of the individual flows.

Each of the four adjacency matrices will indicate the strength of the requirement by means of a code indicating strong, moderate, or weak adjacency requirements between each of the teams. A strong adjacency is based on major transfers of information or materials. A moderate adjacency is the result of moderately significant transfers. Adjacency requirements are weak when these are minimal or no transfers between groups. A more specific explanation of what is meant by a strong or moderate adjacency requirement for each of the categories of information or materials is listed in the following table.

Table 2.

Adjacency requirement codes

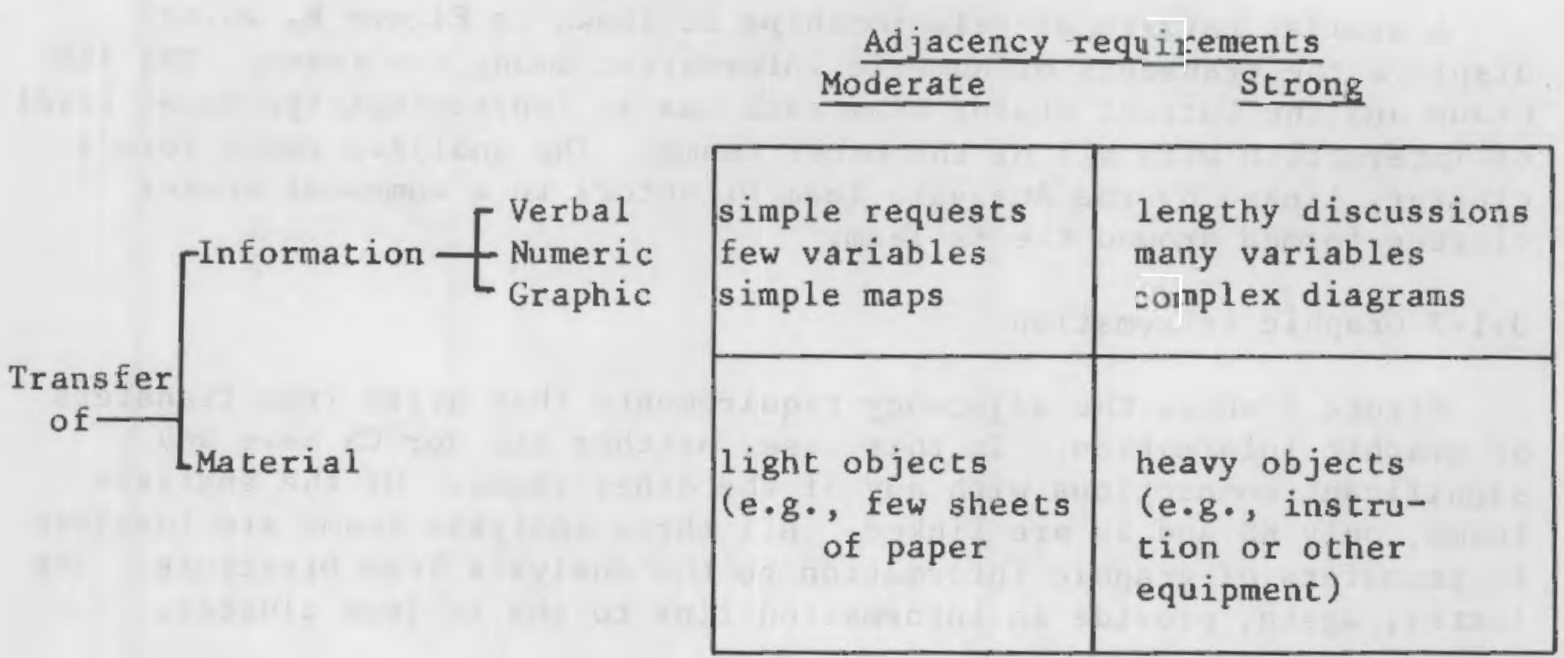




\subsubsection{Verbal Information}

Figure 7 describes the adjacency implications for transfers of verbal information. This figure shows the lower off-diagonal elements of a square, symmetric matrix. Each column should be interpreted as indicating the strength of the adjacency requirement of the indicated team with each of the remaining teams within the NRCOC. Thus, the first column indicates that the Administrative and Logistic Support (ALS) Group of the Response Coordination Team has major transfers of information and, thus, a strong adjacency requirement with each of the other teams within the operations center. Communications Support has only moderately significant transfers of information with the analysis teams (Reactor Safety, Protective Measures, and Safeguards), with the Executive Support Team (Status Officer and Executive Secretary) and with the Liaison Team. This team has essentially no verbal contact with the Current Status Team, and with the Analysis Team Directors and with the Executive Team.

The adjacency matrix indicates that ALS does not need to be any closer to one team than to any other team because its contacts are equally strong with all teams. A similar pattern holds for the CS Team. There are, however, two clusters that emerge from this analysis. The analysis teams form one cluster; the Ex Team, Ex Support Team, and Li Team form the second cluster. The rightmost three elements of row six, which indicate the major transfers of information between the analysis teams and the team directors, and the three elements of column seven, which indicate major transfers of information between the Analysis Team Directors and the second cluster, provide a graphic illustration of the "linking pin" concept discussed in Section 1.0. The Analysis Team Directors provide a link between two differentiated clusters of teams within the operations center.

\subsubsection{Numeric information}

A similar pattern of relationships is shown in Figure 8, which displays the transfers of numeric information among the teams. The ALS Group and the Current Status Team each has an (approximately) equal level of interaction with all of the other teams. The analysis teams form a cluster, linked by the Analysis Team Directors to a somewhat weaker cluster formed around the Ex Team.

\subsubsection{Graphic information}

Figure 9 shows the adjacency requirements that arise from transfers of graphic information. In this case, neither ALS nor CS have any significant connections with any of the other teams. Of the analysis teams, only RS and $\mathrm{Sg}$ are linked. All three analysis teams are involved in transfers of graphic information to the Analysis Team Directors. The latter, again, provide an information link to the Ex Team cluster. 


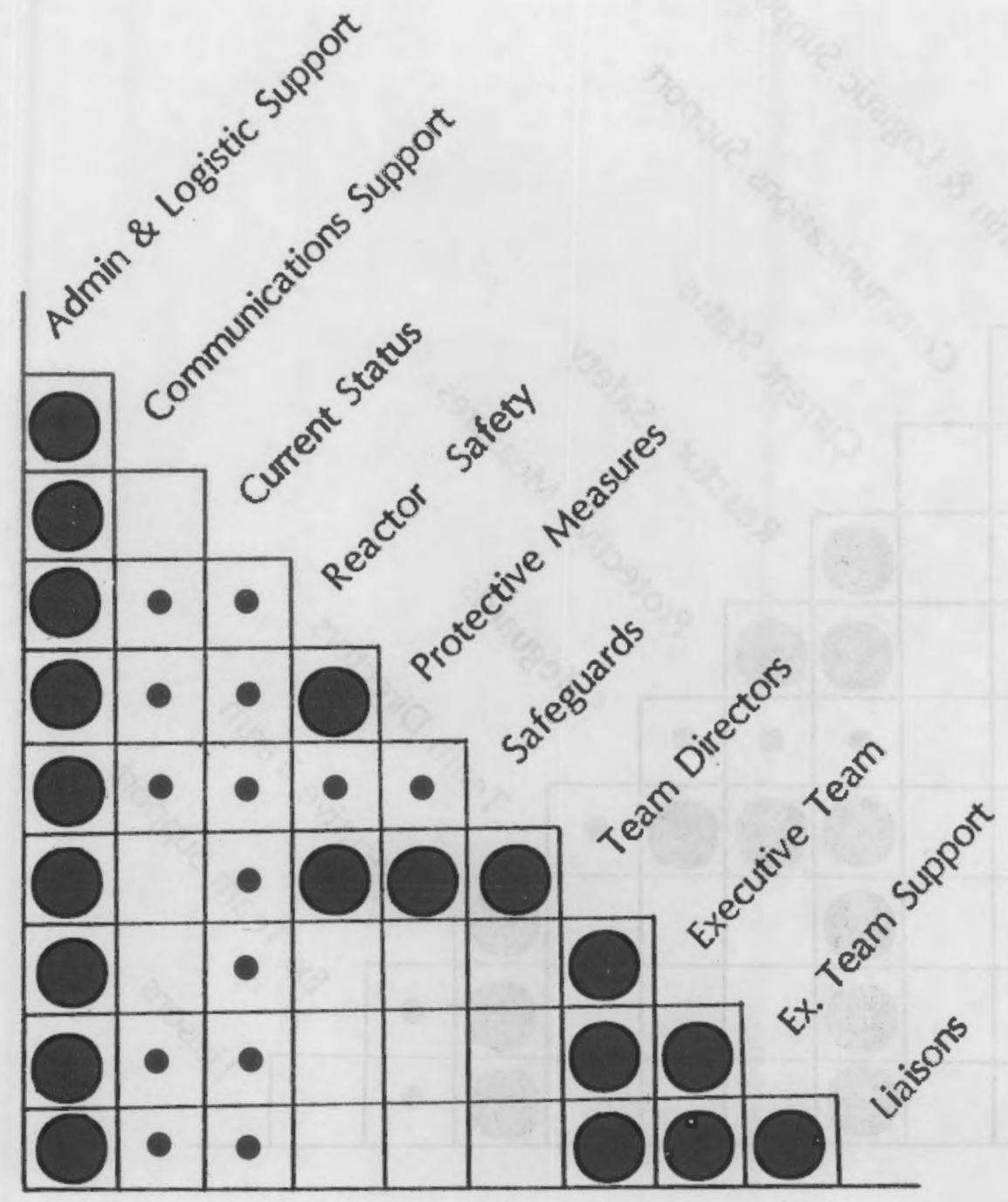

Strong Adjacency

Moderate Adjacency

Weak Adjacency

Figure 7 Verbal Information 

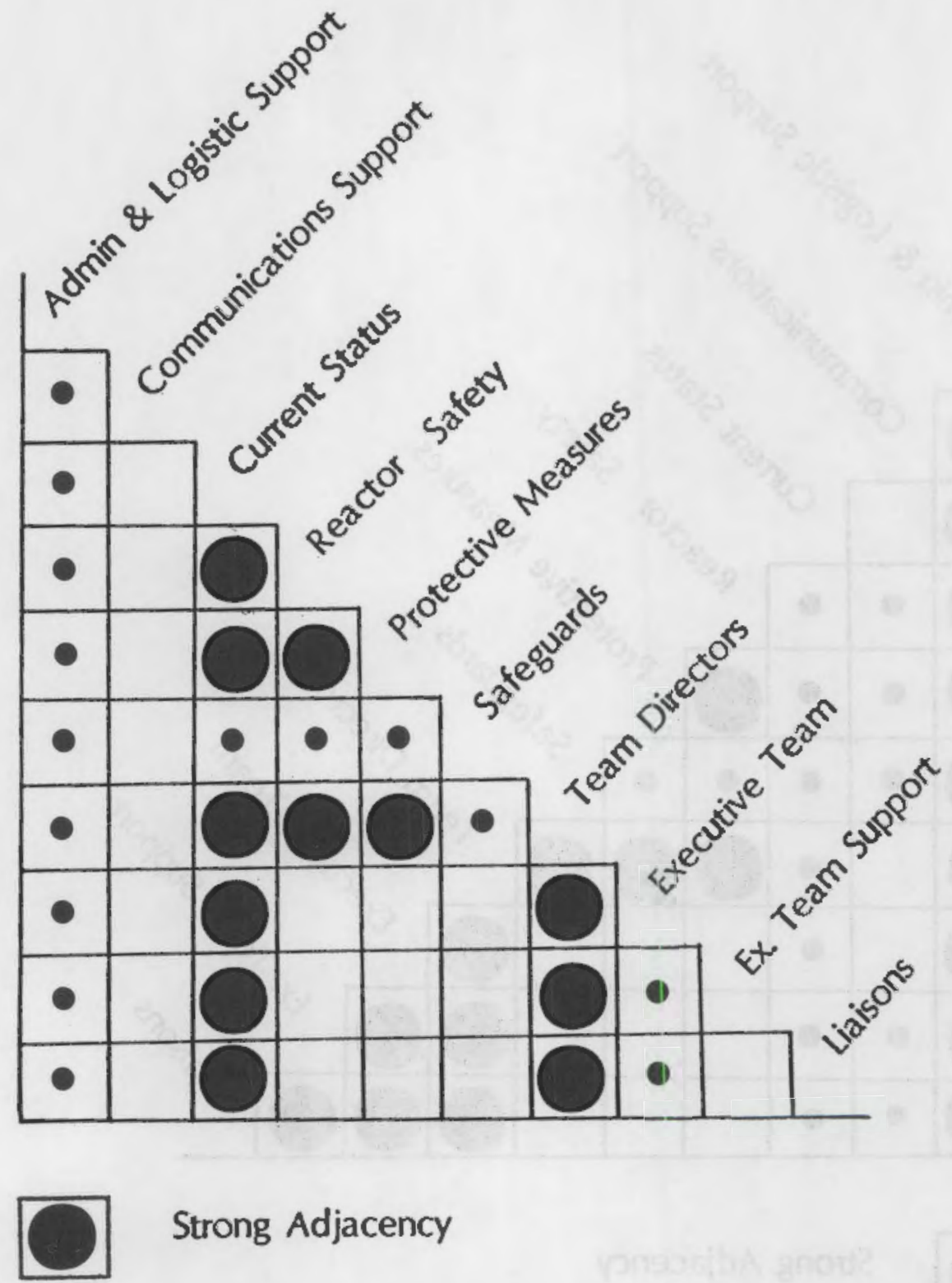

Strong Adjacency

- Moderate Adjacency

Weak Adjacency

Figure 8 Numeric Information 

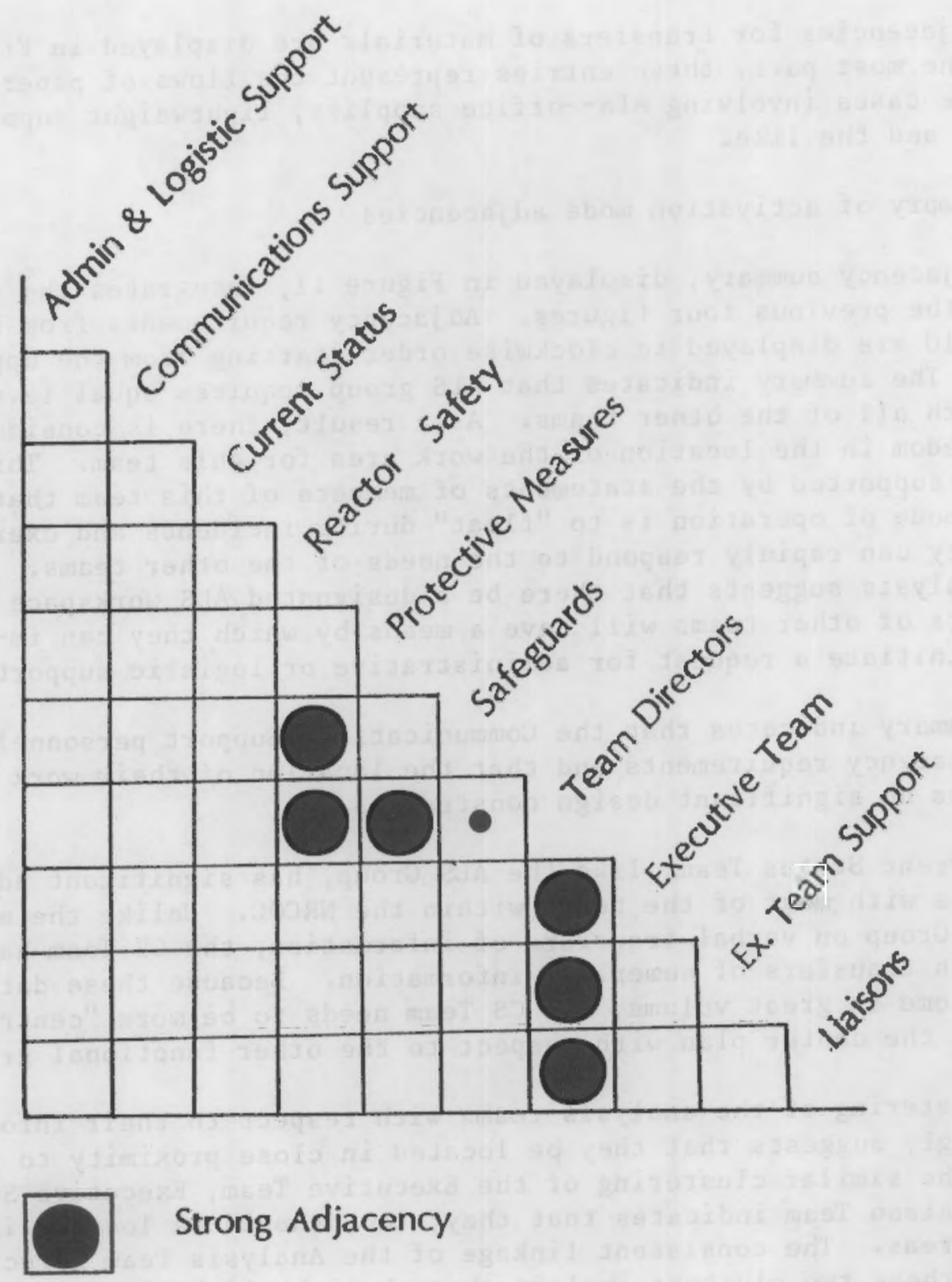

Strong Adjacency

- Moderate Adjacency

Weak Adjacency

Figure 9 Graphic Information 


\subsubsection{Materials}

The adjacencies for transfers of materials are displayed in Figure 10. For the most part, these entries represent the flows of paper work and--in the cases involving ALS--office supplies, lightweight support equipment, and the like.

\subsubsection{Sumary of activation mode adjacencies}

The adjacency summary, displayed in Figure 11, integrates the informa$t$ ion from the previous four figures. Adjacency requirements from Figures 7 through 10 are displayed in clockwise order starting from the upper left quadrant. The summary indicates that ALS group requires equal levels of contact with all of the other teams. As a result, there is considerable design freedom in the location of the work area for this team. This conclusion is supported by the statements of members of this team that their preferred mode of operation is to "float" during incidents and exercises so that they can rapidly respond to the needs of the other teams. The present analysis suggests that there be a designated ALS workspace so that members of other teams will have a means by which they can immediately initiate a request for administrative or logistic support.

The summary indicates that the Communications Support personnel have minimal adjacency requirements and that the location of their work area, too, imposes no significant design constraints.

The Current Status Team, like the ALS Group, has significant adjacency requirements with most of the teams within the NRCOC. Unlike the emphasis of the ALS Group on verbal transfers of information, the CS Team has major concern with transfers of numerical information. Because these data transfers come in great volume, the CS Team needs to be more "centrally located" in the center plan with respect to the other functional groups.

The clustering of the analysis teams with respect to their information flows strongly suggests that they be located in close proximity to one another. The similar clustering of the Executive Team, Executive Support Team and Liaison Team indicates that they, too, should be located in adjoining areas. The consistent linkage of the Analysis Team Directors to each of these two clusters implies that they should be located in an area "midway" between the analysis teams and the Executive Team. 


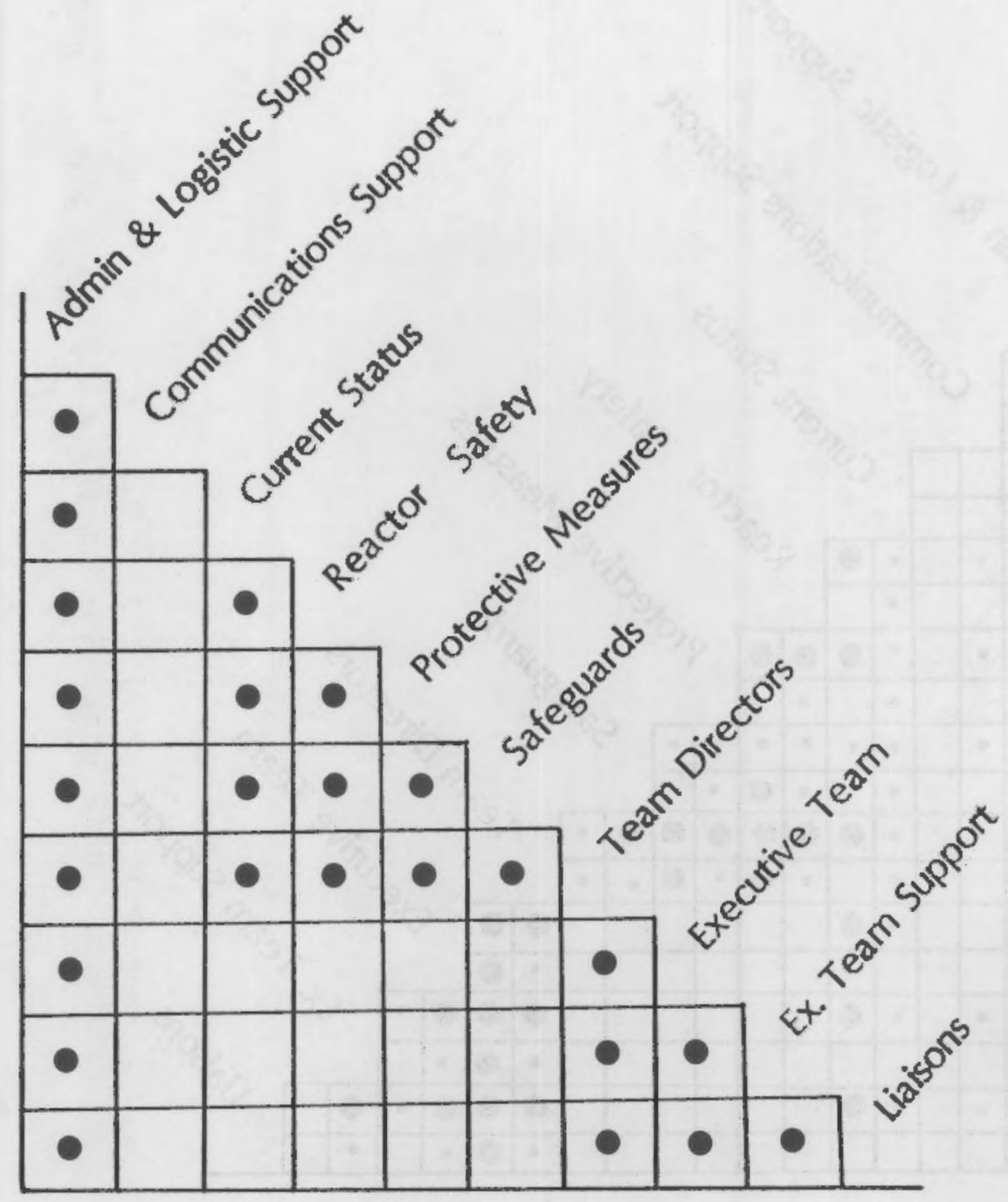

Strong Adjacency

- Moderate Adjacency

Weak Adjacency

Figure 10 Materials 

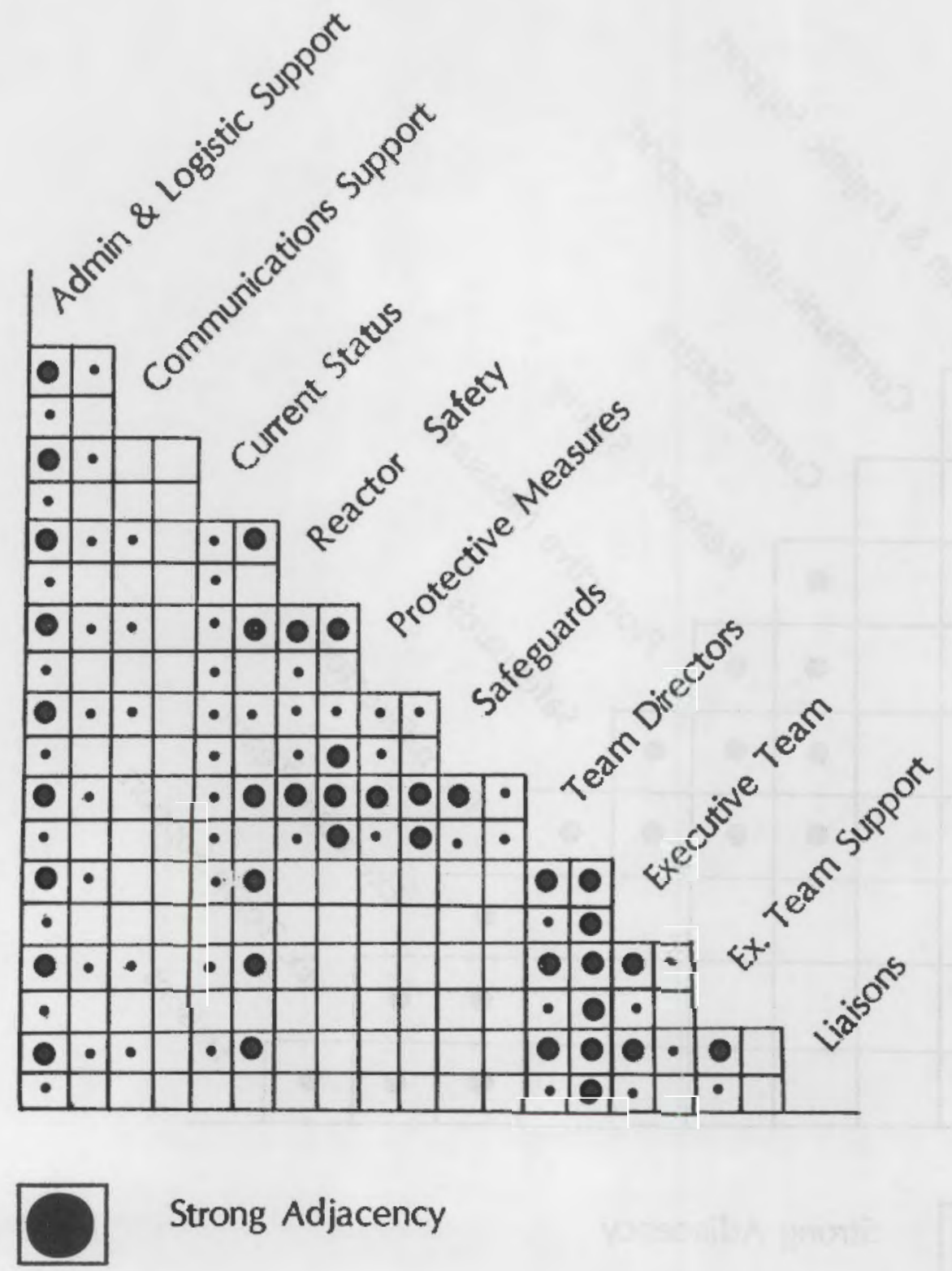

Strong Adjacency

- Moderate Adjacency

Weak Adjacency

Figure 11 Adjacency Summary 


\subsection{Analysis of the Design of the Existing NRCOC}

Comparison of the performance objectives of the work teams with the spatial layout and equipment resources shows that significant discrepancies exist in a number of areas. These discrepancies, identified by application of human factors analytic principles and observations at an emergency exercise, can be summarized as indicating that the functioning of the NRCOC is unduly influenced by an architectural design that tends to impede rather than facilitate performance. Following the organization of the previous section of this report, the following discussion will first focus on interactions among teams and, subsequently, on more detailed treatment of the interpersonal interactions and machine utilization within teams.

\subsection{Interteam analysis}

Inspection of Figures 1 and 11 (team level analysis of information flow and the summary adjacency matrix) suggests that the analys is team areas should be adjacent to one another and that both should be adjacent to the Current Status area. In addition, the Response Coordination Team should be in close proximity to those with whom they most frequenty interact. Figure 12, which displays the floor plan of the current Operations Center, shows that these needed proximities have been met.

Figure 1 shows that the information flow goes from the Current Status Team through the analysis teams to the Executive Team. The layout of the current Operations Center is not consistent with this flow. Figure 12 shows that the analysis teams are located on the south side of the Operations Room which contains the Communications Support Group and the Current Status Team. The Executive Team is located on the north side of this room. Because infornation is transmitted face to face or by means of paper copy transmitted by hand, the information flow produces a traffic flow from the analysis team rooms to the Executive Team room through the Operations room. This creates noise that has a particularly adverse effect on those who need to monitor phones (which is, in fact, the major activity in this area). There is also a problem of personnel in transit intruding upon the circulation of the staff of the Current Status and Response Coordination Teams within their own areas. Moreover, the area just outside the south door of the Executive Team room would be expected (and, in fact, was observed) to become a de facto waiting room for those waiting to go into--or meet someone coming out of--the Executive Team room. The tendency for such a space to become a caucus area is particularly unfortunate since this space is immediately adjacent to the phone operator's station. Worse, this area is between the phone operator and support equipment such as the multi-channel recorder. In summary, the present design passes a very busy "hallway" right through the middle of the Communications Support and Current Status Team areas. 


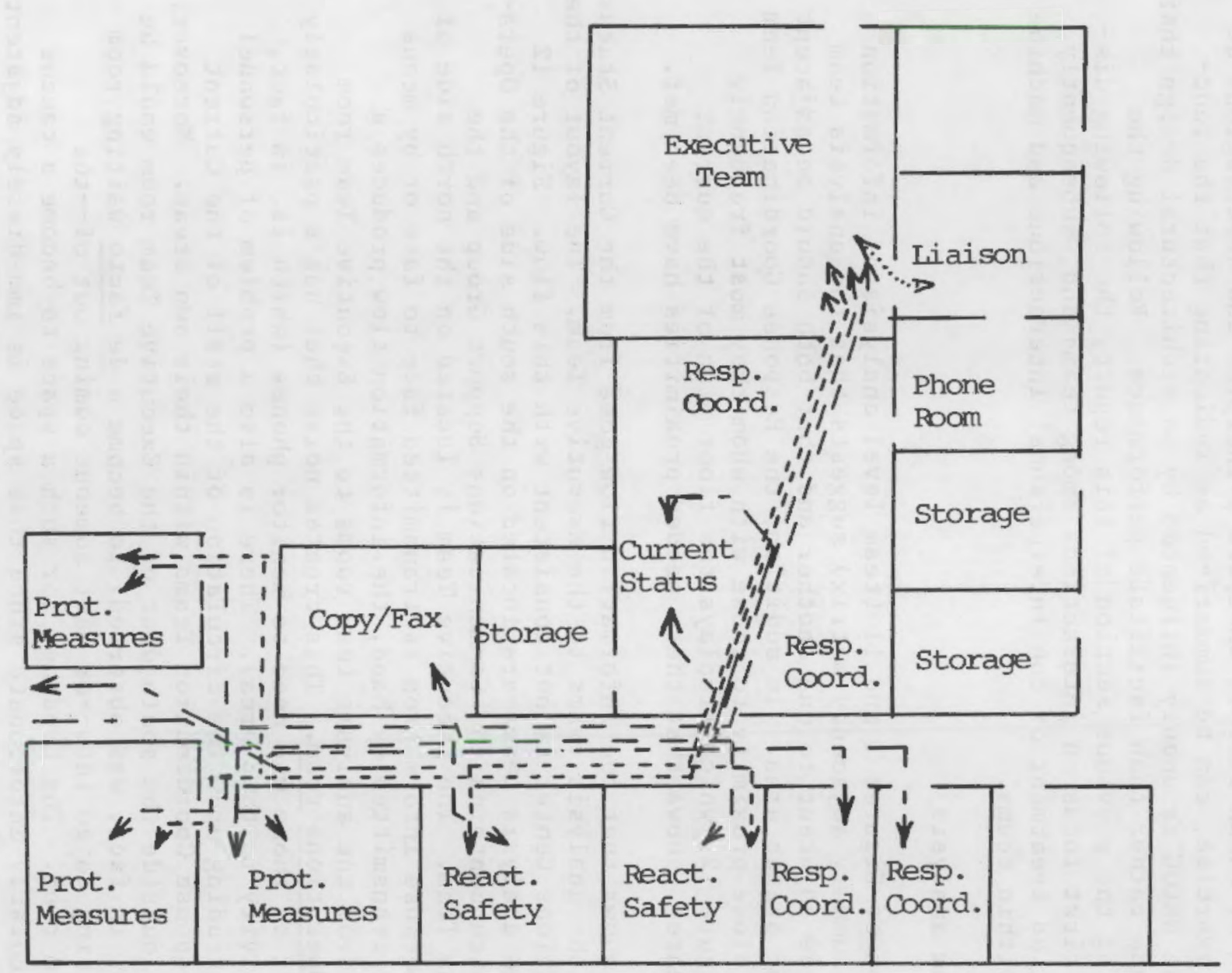

Figure 12 Circulation in Existing Operations Center 
Also significant, but of less importance is the placement of the telecopier and storage areas (which are support facilities) in a more central location than the analysis team rooms. While not as negative an effect as the previous factors, this does represent an inefficient utilization of space. Last, the Liaison Team is split between the Ex Team room and an auxiliary space adjacent to it. Although the liaisons should be in close proximity to the Ex Team room, they generate too much telephone noise to be in it.

The basic problem with the overall layout is that the aspect ratio is too high (i.e. too rectangular). Although the layout is L-shaped in its geometry, the flow pattern is like that of a long rectangular space connected by a central corridor. The information flow starts in the middle, and goes one direction to the analysis teams. It then must go from one end of the rectangle to the other for presentation to the Ex Team and liaisons. A more appropriate layout would have a unidirectional flow of information and a lower aspect ratio in order to satisfy the required adjacencies among the teams.

The poor routing of traffic flow is unnecessarily exacerbated by the reliance on face to face conversations and hand-carried copies of standardized forms for information transmission. Expansion of the status information display system would also address this problem. Not only would an electronic system for status information significantly reduce traffic and noise, it would significantly increase the speed with which information is disseminated throughout the operations center. It would also facilitate the preparation of more informative data displays such as time trends, and could provide at least a modest graphics capability.

\subsection{Intrateam analys is}

The following sections will present the analysis of each of the team workspaces. Specific areas of evaluation include overall space availability, layout, and workstation ergonomics.

\subsubsection{Response Coordination Tean}

As was noted in the previous section, the current layout of the NRCOC effectively passes a corridor through the center of the Communications Support Team space. This makes it more difficult for team members to communicate across this "corridor" and makes it nearly impossible for the Duty officer to provide backup support for the phone operator. Also, the phone operators, who are emergency personnel, cannot easily call upon the Duty officer for any assistance with temporary equipment problems, even though the Duty Officer would have been the last one to use the equipment before they arrived. Finally, vigilance tasks and the ability to respond efficiently should multiple emergencies occur require a workstation that is extremely familiar and acceptable to the operator. By switching the Duty officer to a new workstation entirely, such familiarity is lost because the Duty officer does not normally perform there. In conclusion, all relevant factors indicate that the Duty officer should not be required to switch workstations when the center goes into emergency mode. 
The Duty Officer workstation consists of a standard size ( 30 in. $x 60$ in.) desk with typing height return on the right side. The chair of the Duty officer is selected from those available in the operations area. Some duty officers use low leather executive chairs taken from the Ex Team room; others choose the upholstered fiberglass buckets located in the communications area.

Normal mode equipment consists of a standard desk telephone, cassette recorder and annunciator switchboard on the right typing return. There are also an indicator panel set atop the junction of the Duty officer's desk and the phone operator's desk on the Duty Officer's extreme right, telephone number lists, and NRC manuals stored atop this desk.

At present, the DO does not have enough horizontal work surface at the normal mode workstation. During the observation period under low workload, he had to place some manuals on his lap in order that they could be consulted at the same time as others that filled the available desk space. Some of the Duty Officer's tasks require consulting information from various sources in near simultaneous display; there should be sufficient work surface for this to be done.

The LS1, which indicates which plant is calling, is placed so that the Duty Officer has to get up out of the chair in order to read some of the information. It is also too far away, too far to the right, and too high relative to the seating position of the Duty officer. The Duty Officer needs to be able to read the plant name, phone number and circuit number from this panel without having to get up and be seated again.

The annunciator switchboard on the right return of the Duty Officer is too high and too deep for comfortable and efficient use. Either this piece of equipment should be placed on a lower height surface or the equipment should be replaced with one that has a smaller vertical format. The Duty officer presently has to reach too far up and over to use the buttons on the top rear of the switchboard.

The desk chair of the Duty officer, as chosen from those available, can only exacerbate the faults in layout and work surface. The chairs from the Ex Team room are too low for desk work, and the seated eyeheight of the Duty officer is insufficient for him to monitor the LSI or work the switchboard. The fiberglass bucket chairs have arms that are too long to allow the Duty officer to pull the chair close enough to the desk to have back support while working on the desk top. The recliner mechanism on the Ex Team room chairs is too extreme for desk use, and the reclining feature of the fiberglass bucket utilizes a pivot about the center bottom of the chair, which tends to raise the feet of a shorter Duty officer off the floor when in use.

There is no desk lamp at the workstation, and the illumination from the overhead fluorescents is below the recommended 50 foot-candle minimum for seated reading work. 


\subsubsection{Current Status Team}

The section on interteam analysis (4.1) noted that the main "corridor" of the NRCOC also passes through the CS Team space, a problem that is compounded by the use of two audio monitors (ENS and HPN) in close proximity. Isolation of this team from through traffic would significantly reduce noise and would improve the quality of communication within this team as well as between this team and the in-plant communicators on the ENS and HPN lines.

The locations of personnel within the CS Team area are generally satisfactory for the type of communication system available at present. However, reliance on a flow of message forms to disseminate information throughout the operations center is undesirable. Paper copy must be carried by hand. This makes it slow and generates traffic, and noise. Although individual message forms provide an acceptable record of individual conversations, they give an incomplete representation of the overall situation. Finally, transfer of data by means of paper copy inhibits the development of trending and other data displays. Entry of current status data into a computer-based data system would provide increased speed and accuracy of data distribution to the other teams in the NRCOC. Recommendations concerning this system will be made in a subsequent section of this report $(5.0)$.

\subsubsection{Reactor Safety Team}

The nature of the flow of information within the RS Team suggests that a single room is needed that permits team members to communicate with each other as needed to diagnose the current state of the reactor and to make projections concerning future status. The present design of the RS Team space does not support this. The space is divided into two rooms are connected only by an external corridor (see Figure 8). Because the RS Tean spends considerable time in joint discussion, there is no need for visual/acoustical barriers among RS Team workstations. In fact, there seems to be a need to avoid them. It is important to avoid explicitly assigning team members to workstation locations, or other formalized work setting arrangements that might impede the free interchange among team members.

The team members need horizontal work surfaces (tables rather than desks) for seated-height work. The central working group (Reactor Systems, Electrical, Instrumentation \& Control) could be accommodated drafting-level-height work surfaces with comfortable stools. Within this group there is a particularly frequent movement back and forth, with standing inspection of P\&IDs.

The present workspace lacks an adequate number of chairs. These should be armless and easily moved about the space, in order to accommodate on-demand small-group work seated at tables. Tackable vertical surfaces should be provided that are immediately visible and accessible to RS Team members such as the Instrumentation \& Control and Electrical Systems Analysts. Approximately $24 \mathrm{ft}^{2}$ of surface is desirable. 
The proposed Nuclear Data Link (NDL) will supplement current status information for the RS Team. The requisite VDT space should be allocated to the RS Team now. The VDT operator will field requests from various team members for information on reactor parameters, and should be placed centrally in the RS space. There is no necessity for direct connection between the VDT for the NDL and the inspection of the P\&IDs.

There is a minimal need for telephones in the RS space, three lines at most. One is for the Deputy Director, and the other two can be used largely as intercoms to the Source Term Analyst (on the Radiological Analysis sub-team of the Protective Measures Team) from the Containment Analyst and the Heat Transfer Analyst positions. In addition, the RS Team space should maintain its audio monitor for the ENS 1 ine.

\subsubsection{Protective Measures Team}

The members of the PM Team are currently assigned to three different rooms in the extreme southwest corner of the Operations Center. Unlike the situation with the RS Team, the division of the PM Team into three separate workspaces is not an extremely serious design flaw. On the other hand, this design is considerably less than ideal for the data processing system outlined in NUREG/CR-2371.

Proximities of the members of teams should generally follow their needs for face to face communication with other members of their team. This rule would dictate that members of the Radiological Assessment Group would be located close together and that those in State Liaison and Protective Action Analysis should be in their own area. Close proximities for the Meteorology, Source Term and Dose Assessment Analysts are further reinforced by the fact that all will be utilizing minicomputer stations. Needs for special lighting would be more readily accomodated in a single location. Moreover, a common location would facilitate continued operations in the event of failure of one or more of the units. Analysts who are routinely assigned to areas immediately adjacent to one another wouId be able to readily shift their operations to another workstation.

There is a need for two voice grade telephone lines to the Radiological Analysis Group for intermittent conversations. This is for backup communications for Hydrology, Meteorology, and Source Term personnel. In addition, there is a need to have an audio monitor for the HPN.

The Source Term Analyst receives information from the Reactor Safety Team and calculates magnitude of release. At present, this involves personal transfer of materials from the Reactor Safety Team. In the future, this information may be transmitted electronically, but it is likely that a need for direct interpersonal interaction will be maintained, if only to provide a satisfactory "back-up" capability. The Source Term workstation, then, should be the one most accessible to the Reactor Safety Team, and it should be possible for the RS Team members to interact with the Source Term Analyst without interfering with the other activities of the Radiological Analysis Team. 
The Protective Action Analysts and State Liaisons need to caucus with their team leader. They also need to be able to use tackable vertical display surfaces for site maps. The Protective Action Analysts and the State Liaisons should be in the same general workspace.

\subsubsection{Safeguards Team}

Most Safeguards work is such that it should take place around one or two large work tables where maps and binders may be spread out. There is need for a variety of telephone lines:

- A dedicated line to the FBI.

- A comercial 1 ine between the Safeguards staff within the NRCOC and another Safeguards evaluation group outside the center.

- A commercial 1 ine to reach other individuals within the NRC.

- An open commercial line.

There should be room for a working group of 5-8 within the Safeguards workspace.

\subsubsection{Executive Team}

Activities of the Ex Team can be divided into two major groups, those related to the briefing process and those in the deliberative process. At present, neither the architecture of the workspace nor the Emergency $P l a n$ and its associated procedures supports the distinction between these two types of activities. Provision of extensive visual aid equipment (slide projectors, overhead projector, maps, VDTs, etc.) and communication devices has facilitated access of the Ex Team to verbal, numeric, and graphic information. In fact, the Ex Team is virtually inundated with information. What is lacking are means for the flow of incoming information so that its significance can be deliberated, alternative course of action discussed and decisions made.

Administrative procedures to provide increased time for deliberation would encompass formalized rules that would pace the briefings schedule. One such set of rules might be:
a. Briefings take place every " $x$ " minutes.
b. Briefings can take place with change in event status (such as a change in emergency class).
c. Briefings can be initiated at the Chair's request. 
Briefings would be limited presentations by the appropriate analysis team directors and not protracted discussions that result in loss of control of the deliberative process by the Chair. The Chair needs the option to end the briefing process by retiring with his committee to an undisturbed, extremely private space, where sensitive discussion can take place.

For this reason the Ex Team workspace should be divided into two separate rooms--a briefing room and a meeting chamber. The remainder of the functional narrative for the briefing room is intended to specify this as a separate room. The meeting chamber is discussed in depth under "Deliberative Process" (4.2.6.2).

\subsubsection{Briefing process}

This room needs to accommodate the Ex Team, two or three presentors, the Executive Secretary, Status Officer (and a possible assistant), possibly three liaisons, and potentially 3-5 visitors. The briefing room needs to immediately connect to the meeting chamber, and serve as an anteroom to the chamber. Although there are "formal" briefings, the activities within the briefings room are necessarily much less formal and closely controlled than are the deliberations within the meeting chamber.

The briefing room should serve as the permanent workstation assignments of the Executive Secretary and the Status Officer. The Executive Secretary should be positioned so as to exercise visual control over all entries to the briefing room, and direct physical control over all entries to the Meeting Chamber. The Status officer and the Executive Secretary need to be in voice and visual range of each other, although the Status officer's workstation should be positioned and treated so that he may have telephone conversations while briefings are in progress in the room.

Briefings may commence with entry of the Ex Team into the briefing room from their more private meeting chamber. It is expected that other individuals from outside the Ex Team (e.g. Analysis Team Directors, liaiaons, visitors, etc.) will be assembled in the briefing room prior to commencement of the briefings.

The briefing room should be equipped with tackable surfaces, requisite current status monitors, and slide and overhead projection equipment.

\subsubsection{Deliberative process}

Within this room sensitive deliberations are undertaken that directly result in public actions taken by the NRC in the event of an emergency. In the deliberation process, the NRC Chair has full decision-making authority. Subsequent actions are not the result of consensus or votes among the Ex Team members. It is the Chair's perogative and responsibility to make decisions, seeking the advice of team members at his own discretion. 
The layout and detailing of this room needs to reflect this administrative reality. This will be discussed further under Meeting Chamber Details $(7.2 .2)$. In addition, the room needs to have a private telephone for the Chair.

\subsubsection{Liaison Team}

The function of the State/Federal Liaison is to provide coordination with a party actively involved in the management of the incident--the affected state. This raises a potential problem of coordination with the Protective Action Analysis Group in the Protective Measures Team. The PAA Group must maintain coordination with members of a corresponding team of protective action analysts in the affected state (or states) to ensure that any potential discrepancies in protective action recommendations are resolved as rapidly as possible. Because the State Protective Action Analysts will be in the same location (the State EOC) as the Emergency Services personnel that the State/Federal liaison is conferring with, it is important that careful coordination between the State/Federal Liaison and the Protective Action Analysis Team be established and maintained. This indicates that the State/Federal Liaison be assigned to the PAA Team area where he can become actively involved in the coordination of technical and "political" communications with the state.

The Congressional Affairs and Public Affairs Liaisons, on the other hand, provide information releases to parties outside the NRC who are not actively involved in the incident. Although they need accurate information, they need not confer with each other, the Status office and with the NRC Chair on anything more than a periodic basis. For this reason they may be accomnodated close to the Briefing Room.

In addition to their high volume of communication with Congress and the media, these two liaisons confer with the Congressional Af fairs and Public Affairs offices. Thus, their space must be acoustically shielded from the Briefing Room, preferably by a separate entrance.

There is also a need to support the drafting of press releases and the coordination activities within the liaison workspace. At least one typewriter or word processor station should be provided for the Liaison workspace. Each liaison needs a separate phone 1 ine. 


\subsection{Status Information Management System}

\subsection{Purpose}

The general purpose of the SIM System is to make information which exists at the operations center easily accessible to the NRCOC staff so that the most appropriate recommendations are made to the licensee concerning corrective actions for the facility and to offsite authorities concerning protective actions for the public. Overall this system will assist in managing the center's information and resources. More specifically, the computer is to automate the transfer of information and requests among the NRCOC functional teams and to assist in logging data from the site of the incident, requests initiated by NRCOC staff for information from the site, and data resulting from analyses performed by NRCOC staff. Besides fulfilling the information needs of the staff, the system must be easy to use and flexible.

\subsection{Functional requirements}

The SIM System is accessed at a workstation located near the user's normal work area. The user inputs system requests via the workstation keyboard. The system responds to requests or provides status information on the display unit which is an integral part of the workstation. These workstations are the major interface between the SIM System and the NRCOC staff. Thus a workstation should be located near each user's work area. The following paragraphs describe the basic functions provided by the information system.

- Message/Request Transmittal. A message or request may be entered in one workstation and sent to any other workstation. When sending a message, the operator may designate that the message be sent to a person, a group of people, or a specific workstation. If desired, one may enter a message on a given workstation for someone who will be at that same workstation on a different shift. In short, a person can send a message to any person or workstation at any time or from any workstation.

- Message/Request Management. Once a message or request is transmitted, both the sender and message receiver must be able to manage the request. The sender must be able to query the status of the message to determine if the receiver has viewed it and when. Also the sender should be able to view the priority of the message in the receiver's action-required queue. The receiver must be able to set priorities for each request in a queue and to respond to requests. A response could be that the receiver is taking action, but will not have an answer until a specified time.

- Display Alerting. Anytime the status board is updated, a response to processing of a request is complete, or a new message is received a blinking symbol will appear on the user's display. A unique symbol will appear on the display regardless of what the user is currently doing; the user's current task could be continued uninterrupted if desired. 
- General Status Board. A status board consisting of one or more special displays can be created and maintained. These displays can be requested and viewed at any workstation. The status board will contain all the information necessary to determine the general status of an event. Once displayed, the status board will update continuously until another request is made through the keyboard. The status board display is hierarchical in structure. The top level, which is initially displayed, would depict the summary status of the event. Greater levels of detail would be available upon request.

- User Status Board. Since each team focuses on different parts of the emergency process, a user-definable status board would be made available to each user. The user may format and select the parameters to be displayed on his own status board.

- Information Logging. The information system will time stamp and date all information entered or requests made. Likewise the information will have a tag which indicates who entered the information into the system.

- Online User Instruction. In order to use the information system, one need not memorize commands or procedures. Whenever in doubt on what to do next, the user presses the key on the workstation labeled HELP. The system will respond with instructions on the options currently available to the user. If more detail is required, the HELP function key is pressed again. Thus, an experienced user can operate the system efficiently and not be penalized for this online user instruction function. Inexperienced personnel can use the systern, by requesting assistance when required.

- Historical Data Recall. Any data or requests logged by the system may be recalled by any workstation. This information may be accessed via a number of approaches. Recalled information may be categorized by time of day, subject matter, or author. For example, a request might be made to display all the information received from the incident site on a given day including the time and name of person who entered each piece of information. As another example, a user could request the last five entries.

- Graphical Display. Data retrieved by a user may be displayed using a number of methods. One may simply display a list of the readings. Alternatively, one may plot the readings on a two-dimensional graph, or bar chart. 


\subsection{Conceptual design}

\subsubsection{General Discussion}

The SIM System design is based on the functional requirements described in Section 5.2. These requirements could be expanded or reduced to fit the operational needs of the center. For example, the scope could be increased so that the information system includes all of the generalpurpose computing resources required at the center. Then all modeling, dose estimates, and interfaces to other computing resources could be handled by the information system. This conceptual design for the information system focuses on a turnkey system dedicated to the exchange and management of data and requests.

\subsubsection{Design}

The SIM System consists of a dedicated minicomputer and connected workstations. A computer workstation is placed in each person's work area where system access is needed. The minicomputer is housed in an enclosed area in the operation center--the SIM System computer room. Access to this computer room will be restricted to maintenance personne 1 and an operator who may have to change magnetic tapes. Frequency of access should be weekly or monthly, depending on system use.

The computer workstation consists of a computer terminal including keyboard and graphic display, and a hard copy device which could be embedded in the terminal. This workstation, which may be placed on any desk or table, occupies approximately two square feet of surface. The workstation requires an office environment, $120 \mathrm{Volt}$ ( $\mathrm{AC}$ ) electrical power (normal electrical outlet) and a dedicated line to the computer system. The terminal is quiet, except when a person is pressing keys or making a hard copy of the display. 
The computer system is housed in the computer room. Since there is no need for physical contact with the computer, it can be located in a secluded area. The computer room must provide hearing, ventilation and air conditioning (HVAC), electrical power, lighting for personnel entering the room, and fire protection. A false floor is not required for this computer system. The computer room may contain more than just this computer; however, a restricted access area is strongly recommended.

The computer system should consist of a computer with 1 Mbyte of memory, one magnetic tape drive, a 300 Mbyte mass storage device and workstation interfaces. The configuration of the computer system should be such that workstations can be easily added, deleted, or moved, and that expansion of memory or mass storage is easily attainable. A block diagram of the computer configuration follows:

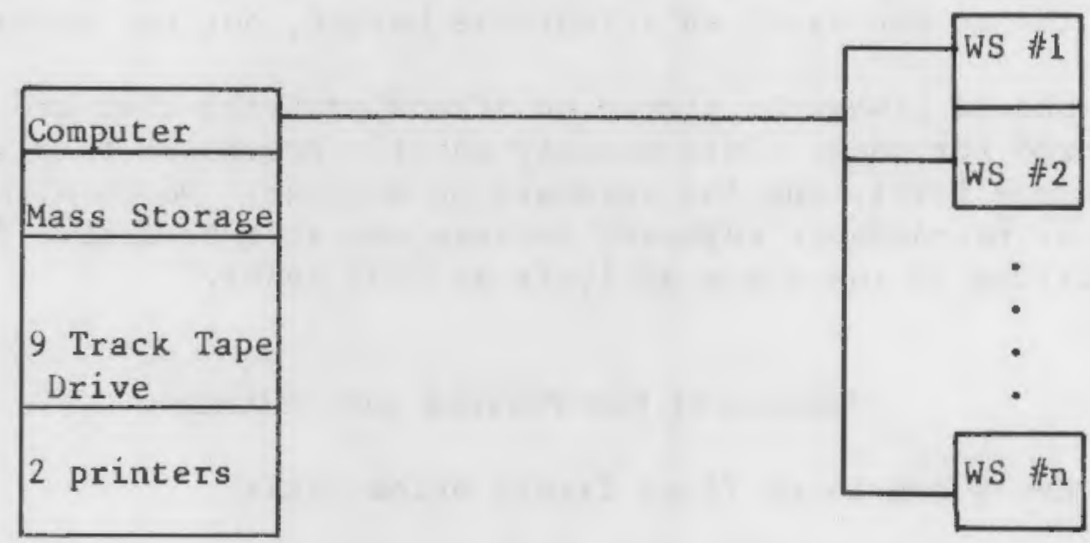

The computer vendor will supply the development software tools needed to construct the turnkey SIM system. These tools include the operating system, high level computer languages, editors, and file maintenance utilities. Using the supplied software, a custom turnkey system can be developed. Once completed, even a system user who lacks computer programming or engineering skills may use all the features of the system.

\subsection{Design Guidelines for Visual Display Terminals (VDTs)}

Much of the analytical work performed in the NRCOC will utilize VDTs. Experience throughout the office industry in recent years has shown that the introduction of VDTs into unprepared office settings can lead to a variety of problems for human operators. Among these are:

- Focus problems for bifocal wearers

- Back problems (these normally constitute $50 \%$ of all ailments associated with VDTs).

- Disability glare from the screen surface, because of reflections of room lights off the screen. This often causes eyestrain and headaches. 
Fatigue of neck, arms and wrists, because of improper positioning of keyboard, inappropriate chairs, and poor relative positioning of the hard copy and the VDT.

Any of these problems can greatly degrade personnel's ability to perform efficiently and accurately during a protracted emergency. However, many of these ailments can be avoided through careful attention to workplace positioning and placement, ambient and task 1 ighting, noise and ventilation, and, finally, room elements in the visual field.

\subsubsection{Workplace Positioning and Placement}

VDT work and typing are not the same thing. Terminals should not be placed on desks or stands designed for typewriters, as this usually puts the display screen at too low a height. When a terminal is placed on a desktop, the screen is at an acceptable height, but the keyboard is not.

VDTs should always be placed on stands or desks that are specifically manufactured for them. This usually entails provision to place the VDT screen on one level, and the keyboard on another. Desks with recessed worktops or retractable keyboard shelves may also be used. These have been specified in the space analysis as "VDT desks."

\section{CHECKLIST FOR POSTURE AND HEIGHTS ${ }^{1}$}

\section{Heels can touch floor firmly below chair}

2. Clearance between front edge of chair and thighs about 1 in. (25 mm)

3. Knees bent at $90^{\circ}$ angle

4. Trunk tilted back slightly

5. Arms vertical

6. Forearms horizontal

7. With right index finger on $\mathrm{J}$ key, wrist is straight $\pm 10^{\circ}$

8. Chair elbow rest at (or just below) desk surface

9. Chair elbow length permits bringing seat close to desk

10. Wrist supports provided near keys for momentary resting

$\mathbf{l}_{\text {This }}$ checklist was provided by Dr. Richard A. Olsen. 
CHECKLIST FOR POSTURE AND HEIGHTS (Cont.)

- 11. Head balanced, natural erect position; neck straight

12. Line of sight to center of display is $15^{\circ} \pm 5^{\circ}$

below eye level (up to $10^{\circ}$ lower with bifocals)

13. Adjustable chair height or foot rests available to fit user and shoe dimensions

14. Adjustable keyboard support surface height to match user and seat variations

15. Adjustable display support surface height to match user and seat variations.

16. Adjustments can be made as user desires for change of pace

17. Elbow rests are selectable by operator

18. Chair backrest support adjustable in height and fore-aft direction

19. Display face tiltable to control glare: $5^{\circ}$ toward operator through $15^{\circ}$ away

20. Distance from eye to display is variable, $30 \mathrm{in} .(760 \mathrm{~mm})$ or less as user desires

21. Display can be rotated to fit task and glare control needs

22. Keyboard position on surface is adjustable fore and aft and in keyboard tilt

\subsubsection{Ambient Task Lighting}

Most VDT problems attributable to lighting occur because the setting is too brightly lit. This causes reflections off the screen, and contrast glare when the operator shifts his/her eyes to another point in the setting.

To avoid reflections, ceiling luminaires can be shielded with "egg-crate" type diffusers. Special fluorescent tubes with built-in parabolic reflectors can also be used. One brand name for the latter is "Verta-Ray." This type of tube (or equivalent) should be specified for installation in those locations where reflected glare might be a problem. In order to reduce contrast glare: 
The area around the VDT should have ambient illumination not to exceed $50 \mathrm{fc}$.

- The VDT should be placed so that the operator sees neither windows nor window reflections in the screen.

- The work surface should be neither shiny nor light-colored.

- The VDT should be placed so that ceiling luminaires are parallel with the operator's sight 1 ine.

- Walls or partitions around the operator should be given a darker surface tone than regular workstations. This helps avoid contrast between the dark screen and the 1 ight walls

\subsubsection{Noise and Ventilation}

Excessive noise can be produced by printers associated with VDTs. It is usually best to place the printer a few feet behind the operator. In this location, the printer can be sound shielded by bringing absorptive partitions up closely on three sides. These should have a noise reduction coefficient (NRC) of at least .85 .

If a VDT is placed in a very small workspace, ventilation should be adjusted so that the workstation temperature does not exceed $72^{\circ} \mathrm{F}$.

\subsubsection{Room Elements in the Visual Field}

As mentioned above, extremely reflective or light-colored surfaces in the operator's range of vision should be avoided.

Operator eye rest can be aided by providing interesting fixation points (such as larger pictures) at various places in the visual field. 


\subsection{Architectural Design}

The adjacency summary presented in Figure 12 describes how teams should be assigned to locations within the NRCOC. Teams that have strong adjacency requirements should be close together; teams that have weak adjacencies can be placed further apart. In translating the adjacency requirements into a floor plan, however, a number of constraints must be recognized. First, it may not be possible to satisfy all of the adjacency requirements because of building geometry. It would not be easily possible, for example, to locate ten teams immediately adjacent to another unless one resorted to a radial floor plan--an unusual configuration. Second, adjacency problems are compounded by consideration of required floor areas. If teans need large workspaces, this can also produce deviations from the desired plan for a given building. Third, the need for special circulation within work areas may limit the layout between work areas. Finally, local building codes may prohibit certain plan management, regardless of their functionality, because of building safety requirements.

In arriving at an "ideal" configuration for the NRCOC, all of these aspects were taken into account to arrive at a design most likely to fit available building stock. The restrictiveness of all of these factors was reduced in some measure by utilizing an electronic means of communication (the Status Information Management system) rather than face to face communication or standardized paper forms to relay information. However, the need for redundancy via these "backup" systems if the electronic system were to fail required that the plan possess such added demand flexibility.

The development of the ideal configuration rests specifically on three design factors. These are: functional zoning, circulation restrictions, and location of utilities, such as ducting and wiring. Each of these factors is described below.

\subsection{Functional zoning}

The basic support functions of the NRCOC were divided into five types. The first was technical analysis/support, which includes the analysis teams and the Administrative and Logistic Support group of the Response Coordination Team. Storage was a related function. This included the need for analysis team members to store specialized equipment during normal operations and for members of the Incident Response Branch to store their work during activation modes. Circulation is a third function which is comprised of entry/emergency egress, security, equipment servicing, and interaction during emergencies. Location of utilities is a fourth function dealing with maintenance of equipment, and the ability of the building ambient support system to perform its tasks. The last function is briefing/decisionmaking.

The fundamental concern in developing a design for the NRCOC was to stratify the uses of space within the operations center into zones that represented compatible uses. This resulted in a basic concept in which zones were sequenced in the order: 


\begin{tabular}{|c|}
\hline Technical analysis/support \\
\hline Storage \\
\hline Circulation \\
\hline Utility core \\
\hline Briefing/decisionmaking \\
\hline
\end{tabular}

This conceptualization permits growth or contraction along the zoning bands. Changes are accommodated especially easily if the partitions between areas within a zone are nonload bearing and, thus, can be moved on demand.

\subsection{Circulation restrictions}

Although the functional zoning concept provides for most circulation along the major axis of the Operations Center, there are other needs for circulation that must be addressed as well. First, there must be access through the storage zone to permit entry to the technical analysis/support zone and similarly, through the utility zone to obtain entry to the briefing/decisionmaking zone. Access to technical analysis areas does not require any "processional" considerations in the design. Access to the briefing/decisionmaking zone, however, presents quite a different situation since this is the location of the Executive Team. Special treatment, such as an oversized corridor, should be used to help insulate the activities of the Ex Team from those of the rest of the Operations Center. Such a corridor would have the added advantage of accommodating demanding secondary flows of personnel among the Analysis Team Directors, the Liaison Team, Executive Support Team, and the Administrative and Logistics Support group of the Response Coordination Team. The corridor should be sized to allow two pairs of individuals, walking abreast, to pass each other in opposite directions without interference.

Other important circulation restrictions include the primary level of selectivity--access control--at the point of entry to the NRCOC and a service entry at a point opposite the primary access point. Together these provide a "front door" and "back door" access to the NRCOC that can be used as volume and privacy demands. These concepts are described graphically in the following way. 


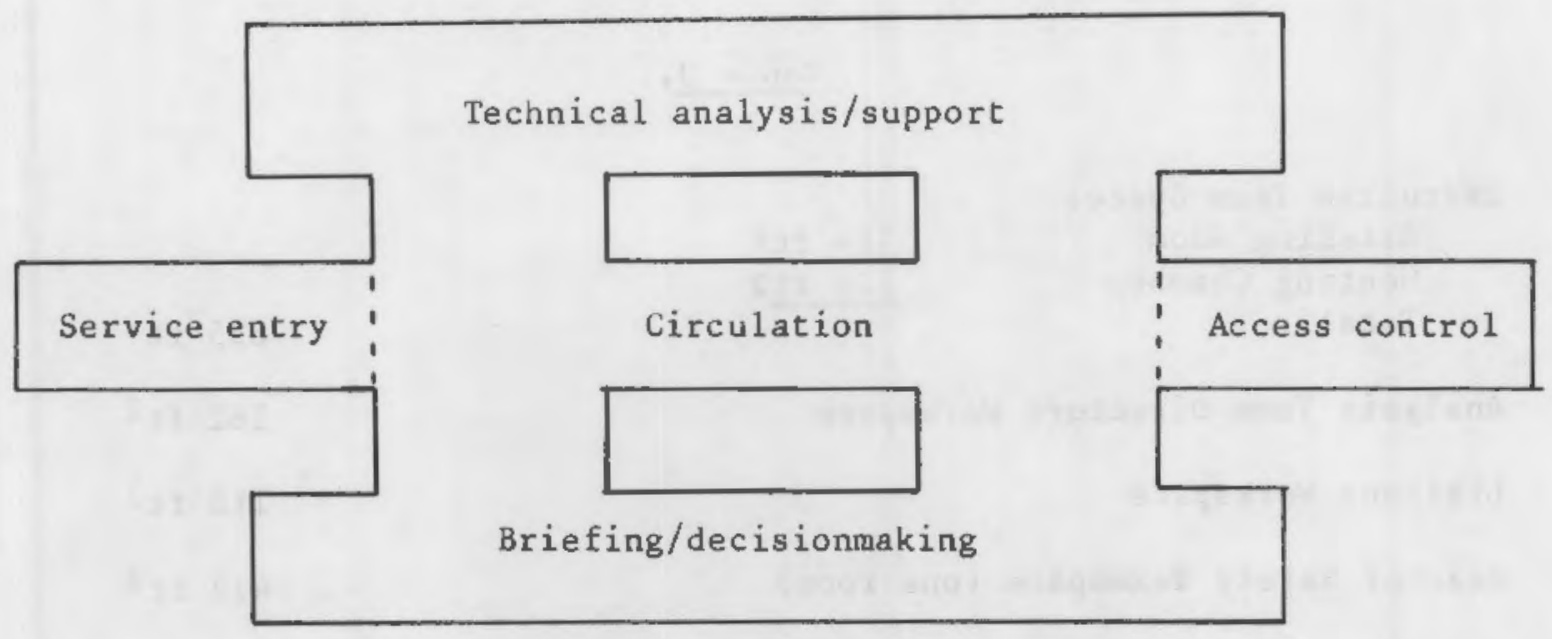

\subsection{Utilities (ducting and wiring)}

Provision for needed utilities, especially ducting for HVAC and wiring for electric power and electronic communications is made by means of an overhead chase that is superimposed upon the storage and utility zones with connecting links across the circulation zone. This concept is depicted in the schematic below.

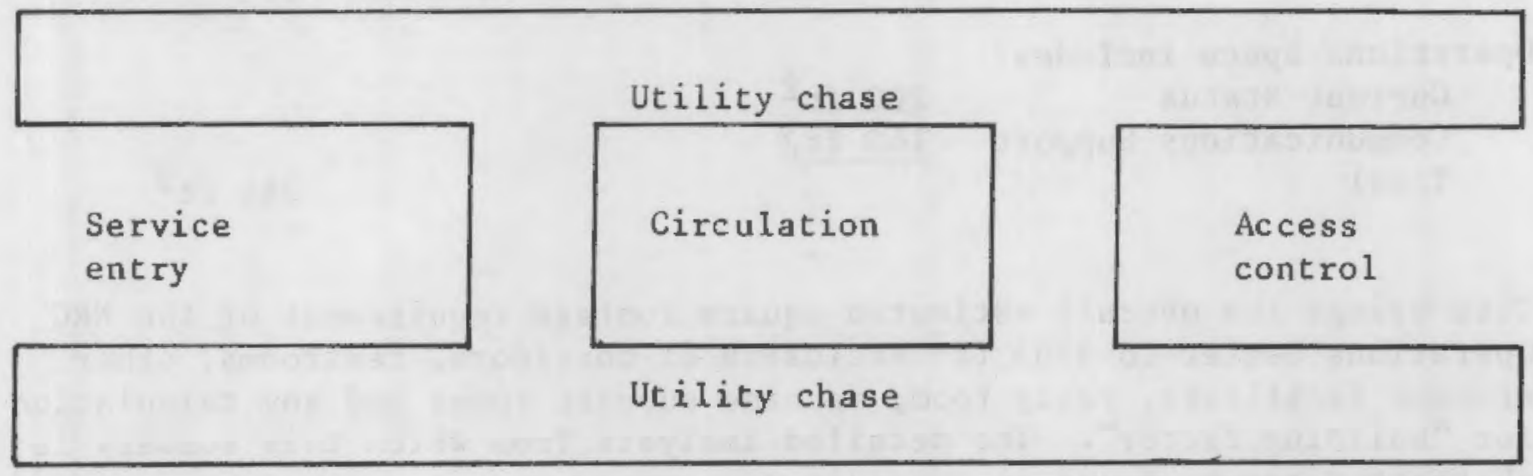

This chase organizes the utilities, allowing easy access for maintenance, repair, and updating of the systems it services. It also permits needed repairs to take place without impinging on the analysis or Executive Team areas, allowing their work to continue unimpeded during an emergency.

\subsection{Space analysis}

Analysis of the tasks assigned to members of the functional teams within the NRCOC was used to determine the amount of space that would be required at each of the workstations. Space for required operations, equipment and circulation were aggregated for each of the teams to produce an overall workspace requirement. These results of the space analysis are displayed in the following table. 


\section{Table 3.}

Executive Team Space:

Briefing Room

$714 \mathrm{ft}^{2}$

Meeting Chamber

$\underline{121 \mathrm{ft} 2}$

Total

$835 \mathrm{ft}^{2}$

Analysis Team Directors Workspace

$162 \mathrm{ft}^{2}$

Liaisons Workspace

$118 \mathrm{ft}^{2}$

Reactor Safety Teamspace (one room)

$412 \mathrm{ft}^{2}$

Protective Measures Teamspace (two interconnecting rooms)

$530 \mathrm{ft}^{2}$

Safeguards Teamspace (one room that may interconnect with the Reactor Safety Teamspace)

Response Coordination Teamspace (one room)

Operations Space includes: Current Status

This brings the overall estimated square footage requirement of the NRC Operations Center to $3355 \mathrm{ft}^{2}$ exclusive of corridors, restrooms, other storage facilities, ready room, machine support rooms and any calculation for "building factor". The detailed analysis from which this summary is abstracted can be found in Appendix A.

\subsection{Ideal configuration}

Integration of the requirements for adjacency, workspace area, circulation and utilities can be accommodated by means of the design presented in Figure 13. This design incorporates a number of distinctive features. In keeping with the adjacency requirements, all of the Analysis Teams are located in close proximity to one another. Storage areas are provided that open onto the analysis team areas to provide space that is restricted to use by the Analysis Teams during activation modes. Additional storage is provided that opens out into the main corridor for common access during normal or activation modes. The storage zone, incidentally, provides "swing" space for the doors so that they do not intrude into the team areas or pose a safety hazard in the main corridor. 


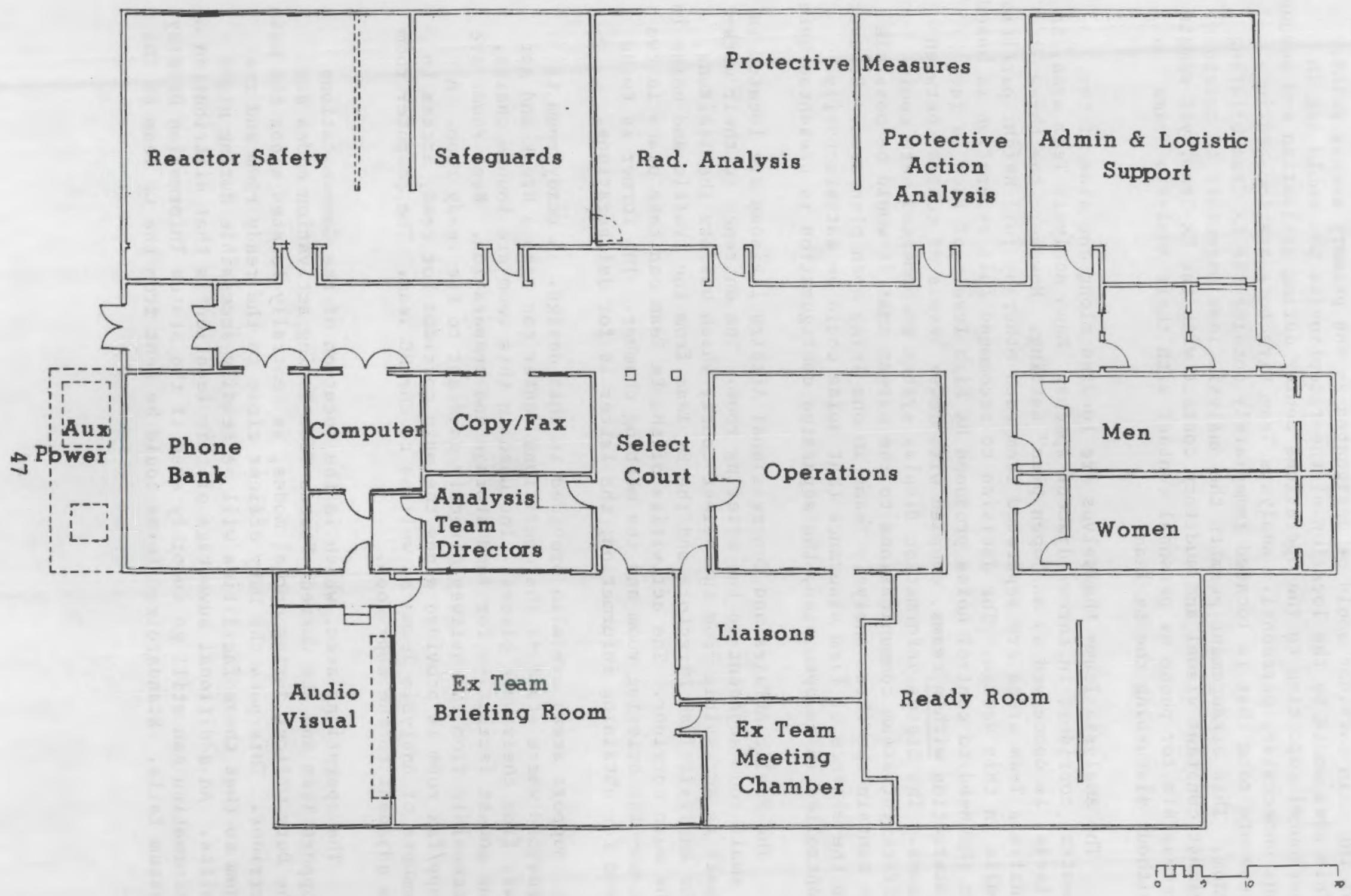

Figure 13 Floor Plan 
The main corridor has a service entry at one end. This entry could be used primarily for bringing in oversized equipment, but can be equipped with emergency exits ("panic doors") for fire safety. The opposite end of the main corridor would be designated as the primary access point. This area would be the location of the receptionist who would $\log$ in personnel reporting to the operations center during activation and screen out unnecessary personnel. Analysis Team Directors are located in a separate room that is located immediately outside the Ex Team briefing room. This arrangement permits the Analysis Team Directors to maintain almost constant visual and auditory contact with the Ex Team, yet remain accessible for phone or personal contact with their Analys is Teams without disturbing the Ex Team.

The Analysis Teams themselves are located along one side of the central corridor, in three adjacent spaces. Each Analysis Team area, in itself, is conceived as an "open plan" setting. However, the three Analysis Team areas are separated from each other by full height partition walls in this design. The decision to recommend full separation is based on the need to control noise produced by high levels of face to face interaction within teams, coupled with lower levels of contact between teams. The Status Information Display system recommended here could affect intrateam communications to the extent that it would be possible to contain the three Analys is Teams in one large open plan area. However, in the absence of firm assurance that noise could be satisfactorily controlled in an open plan, the separated configuration is presented here.

The Public Affairs and Congressional Affairs liaisons are located in a small room adjacent to the briefing room. The entrance to their workspace is accessible from the select court, which buffers the liaisons, the Analysis Team Directors and the Ex Team from the traffic and noise in the main corridor. The activities of the Ex Team can take place in two rooms--the briefing room and the meeting chamber. The former is to be used for obtaining information; the latter is for deliberations.

Support areas are also provided in this design. A ready room is provided where staff of the operations center can take a break and get away from their work places. Included in this room are lounge chairs, and modest facilities for food storage and preparation. Rest rooms are accessible from the hallway directly adjacent to the ready room. A copy/fax room is provided along the main corridor for ready access to members of Analysis Teams as well as to the RC Team. The computer room is adjacent to the copy room.

The operations area, which is the location of the Communications Support Team and the Current Status Team during activation modes and the Duty officer during normal modes, is centrally located along the main corridor. This puts the Duty officer close to the ready room and rest room so that these facilities will be readily accessible during night shifts. An additional advantage of this location is that distribution of information can still go smoothly even if the Status Information Display system fails. Standardized forms could be sent from the CS Team to the 
copier and distributed to the Analysis Teams without disruption to other teams within the NRCOC. Similarly, results of analyses could be taken from the Analysis Team rooms to the Analysis Team Directors' room and the Ex Team briefing room without creating congestion and noise for Communications Support and Current Status personnel.

\subsection{Dual-use considerations}

The need for efficient utilization of space dictates that as much space as possible be usable during normal mode operations. Some spaces are, by virtue of their primary use, unsuitable for dual use. Equipment rooms, such as the phone room, computer room, and copy/fax room cannot be used for other functions although they can be used for the same purpose in both normal and activation modes. The Ex Team meeting chamber also should be classified as a single purpose space. It is inappropriate for use as office space, although it can be utilized as a small conference room at anytime.

At least five of the rooms within the operations center are suitable for dual use.

- The Ex Team briefing room can serve during normal operations as a conference room in support of the Division of Emergency Preparedness.

- The Analysis Team rooms and the Response Coordination room can be used during normal mode operations as office space for members of the Incident Response Branch. The available space in these rooms (that is, total space less VDT workstation space) can be divided into open plan office areas. The number of personnel to assign to office space within each of the team areas should conform to the greatest degree possible with workstation space allowances and the need for ready activation. The rooms have been "oversized" in this design in order to accommodate dual-use configurations.

- The Liaison Team room is also suitable for office space during routine operations. It has been oversized to allow it to also function as a Resource Room for the Operations Area (see Appendix A for details on storage facilities). 


\subsection{Design Program}

\subsection{General Design Requirements}

The physical design of the NRCOC must support the necessary communication, analysis and decision-making activities of its personnel. Therefore, the equipment, the space planning, and the physical detail refinements must all be coordinated into a setting development that reaches the highest level of efficiency and function possible. Much of this achievement will be gained through attention to special design requirements of particular work areas. In this performance/design program these are noted under each of the workspace titles. However, there are some general performance requirements that can be expected to apply throughout the NRCOC. Special exceptions, restrictions or modifications of these recomendations are noted under special area headings.

The spatial adjacencies for this operations center are dictated almost entirely by the types of communications needs among the various organizational teams. These have been analyzed in Chapter 2 and are sumuarized in Figure 11. Much of the in-use success of this facility, however, will be determined by how the spaces relate to each other on the design details level. For example, there are occasions where visual/ audio exchanges between spaces must be independently controlled in one or two way fashion. While situations like this could be handled in an exclusively architectural manner, it is undoubtedly better in this instance to rely on electronic communications aids to carry part of the burden. The availability and sophistication of these devices are in a rapid state of flux. Future developments in this field could make some of the recommended design solutions in this program out-of-date or non-preferred very shortly. In this event, it is the intention of the program's design or performance recommendation that should be respected, rather than adherence to physical specifications. Design intentions are stated explicitly in the detail sections, or generally implicit in the functional narratives for the different spaces.

\subsubsection{Illumination}

By virtue of their functions, workspaces within the NRCOC do not need exterior windows. Security concerns, in fact, suggest that they be avoided. Since personnel could be expected to occupy their workspaces for long periods of time in the event of a protracted incident, it becomes necessary to specify a general lighting approach that is not only functional, but conducive to personal mood maintenance under stressful working conditions.

Where possible, mixed incandescent/fluorescent systems are preferred over single systems, particularly in workspaces. All fluorescents in workspaces should either be recessed, boxed or integrated into ceiling or furnishing systems. Best overall color-rendering, important for interpretation of VDT color displays and psychological acceptance by personnel, is apt to be obtained with Delux cool white fluorescent tubes. 
All workstations should have adjustable incandescent task 1 ighting where possible. Particular care should be taken to avoid glare on the VDTs used widely in this operations center. Section 5.4 contains recommendations for illumination and other setting factors around VDTs.

\subsubsection{Acoustics}

The workspaces within this operations center support intensive human response to nuclear emergencies. Under such conditions, it can be expected that noise generated by human conversations will be from $10-20$ decibels greater than in similar office spaces. This means there will be a general need for additional acoustical treatments to ceilings, floors, and partitions beyond that normally recommended by standard industry references such as Ramsey and Sleeper (1981). Throughout the details sections, intended acoustical performance is sumarized by reference to the designated noise criterion (NC) curve for the space. This curve summarizes noise acceptability levels for sound frequencies that can interfere with speech intelligibility. Throughout the NRCOC, padded carpeting is specified where functionally appropriate and acoustically absorptive rubberized floor tiles are specified elsewhere. All open-plan-type office partitions are specified to have reduction coefficients of at least 0.85 . Standard office acoustical ceiling tiles are likely to result in only minimally satisfactory sound absorption, unless used in conjunc- tion with high performance materials nomally found in recording studio applications.

Security concerns for audio privacy in some areas dictate that HVAC ducts that interconnect these spaces be treated with internal acoustic baffles or external vent shields. The generic nature of this program requires that their exact form be left unspecified.

\subsubsection{Thermal and Air Quality}

Thermal conditions in interior spaces are primarily determined by the HVAC system, which is not covered in this program. However, some general recomendations for this facility's thermal performance can be deduced outside of pure engineering considerations.

- Because there is no need for exterior windows in any work areas, solar gain and seasonal extremes of the site should not become a problem for the thermal control system.

- All workspaces distinguished in this program should have individual thermostats, and there should be individual workstation control where noted. Different personnel in this center perform in varying sedentary modes, requiring individually adjustable controls. 
- Air exchange is a critical factor in workspaces that support stressful activities and that do not have exterior exposure. Again, normal office standards do not apply to an emergency response facility. The ventilating system should be able to provide air exchange at the normal rate of $25 \mathrm{ft}^{3} / \mathrm{min} /$ person in all spaces. It may be necessary to boost this to $30-40 \mathrm{ft}^{3} / \mathrm{min} /$ person in some areas. Increased requirements are noted in the Details text with their own justification.

- People who work under stress can be expected to smoke more heavily than usual. An ion-precipitator and magnetic filter should be installed in the HVAC system that supports all workspaces in this Operations Center.

- Radiant heating panels are not recommended for local heat delivery. Too many of this facility's occupants will be working for long periods at desks or VDTs, where the botton half of the body would be shielded from the radiant heat.

- This operations center will be subject to Federal office building temperature regulations/standards. But it should be remembered that the personnel here are doing nonstandard work. Their ability to continue to perform at high levels of cognitive ability makes thermal comfort mandatory in this setting. At the smallest level, this means adapting the clothing worn by each person. All workspaces should be provided with convenient jacket/sweater hangers near their occupant's assigned positions.

\subsubsection{Security, Symbolic, and Special}

The sensitive nature of this operations center demands that building security be of high priority in its final design. Although this can be primarily met through standard NRC security card procedures, several architectural precautions are also recommended.

- The operations center's air intake and exhaust vents should be positioned in a secure area, should not be next to one another, and should be protected by security screens attached with tamper-proof screws.

- Any external windows in circulation areas of the Operations Center should be of reflective glass or be treated in a manner that does not permit external daytime monitoring. These same windows should be equipped with nighttime blinds.

- Facilities for press gatherings during an emergency incident should not be located in the operations center or in nearby spaces that allow visitors to use the center's circulation areas. 
Symbolically, this operations center represents the NRCs full technical capability to manage emergency incidents. Nuclear power has prinarily become a publicly controversial issue over its real or perceived hazards, and the ability to mitigate those hazards rests with the NRC. Thus, the NRCOC needs to reflect the highest standards of professionalism and technical competence in its architectural details and interior finishes.

As a backdrop for television news shows or interviews, the interior of this operations center sends a message to the American public about the seriousness with which the NRC regards its response capability. This implies that high quality functionalism must be visibly predominant in the design. Technical capability, even when that capability resides solely in software, must be emphasized in the setting in which it is exercised.

State-of-the-art architectural and interiors treatments can help carry the message and image of state-of-the-art response competence. This is not a setting like corporate home offices. Those can too often reflect self-aggrandizement of their members' business skills. This center needs to visibly refrain from status concerns while actually achieving status through a highly visible commitment to its professional mission.

With respect to design, this means high quality, high functionality, and low stereotype in furnishings and finishes. The following are a few examples :

- All floor coverings should use dark tones. Dark tone surfaces will not show the dirt of protracted traffic patterns, and they will actually be kept freer of litter because most dropped items are more noticeable on a dark surface.

- No wall coverings should be used that are identified as "institutional" stereotypes. This means avoiding pale greens or buff colors, particularly.

- Dark wood panellings, the mainstays of upper-level corporate interiors, should be avoided. Patterned wallpapers and bold supergraphics should also not be used, as these carry more frivolous and/ or dated connotations.

- All luminaires need to be attractively boxed or hidden, except for personal adjustable task lighting. Hanging fluorescent fixtures in particular give a cheap and temporary appearance to a workspace.

- Door handles throughout the center should be lever rather than knob type. Lever-type handles allow the user to open the door with both hands full. Carrying coffee cups and documents on both hands occurs frequently in emergency operations centers. 


\subsection{Detail design programs}

\subsubsection{Executive Team briefing room}

For the number of individuals and functions outlined in the functional narrative, the floor space of the briefing room may be summarized as follows:

Executive Secretary Workstation Status Officer Workstation (+ Assistant) Briefing Area

Storage

Circulation Space

Total Estimated

\begin{aligned} $36 \mathrm{ft}^{2} \\ 42 \mathrm{ft}^{2}\left(+20 \mathrm{ft}^{2}\right) \\ 469 \mathrm{ft}^{2} \\ 24 \mathrm{ft}^{2} \\ 143 \mathrm{ft}^{2} \\$\hline\end{aligned}

$714 \mathrm{ft}^{2}\left(734 \mathrm{ft}^{2}\right)$

The Executive Secretary and Status Officer need to work closely together to handle the influx of calls to the Ex Team during an emergency. Their workstations should be close to one another, and allow visual, material and vocal exchange. However, there should be some physical separation between the workstations to ensure some personal privacy. The Executive Secretary, in addition, should be located in a position that facilitates the control of traffic (physically) into the briefing room and, visually, into the meeting chamber. Both the Executive Secretary and Status officer should be positioned within the Briefing Area so that they may have telephone conversations while briefings are in progress. Figure 14 shows a layout of these two workstations.

\subsubsection{Executive Secretary workstation}

The Executive Secretary's role is not so much secretarial in the proposed redesign as it is one of time/personal contact manager. This person should receive all calls directed to the Ex Team through the operations center switchboard. Other responsibilities should include managing the briefing room between sessions, arranging personal visits with the NRC Chair in the meeting chamber, and overseeing preparations for briefing of the Ex Team.

Illumination. The workstation should have a special task light--for word processing work--which can illuminate handwritten material. This can be a small "tensor type" lamp for the desk top. To reinforce the significance of the Executive Secretary's managerial role, it is recommended that the workstation be more brightly illuminated by incandescent spot lighting. This may be recessed ceiling canisters or track-type spots. The latter, if used, should be offset from directly above the workstation in order to provide high angle side lighting. Incandescents give more pleasant skin-tone renderings, are perceived as higher status lighting, and, when used to increase illumination about $10 \mathrm{fc}$ above background ambience, confer a greater sense of importance to the workstation position. 


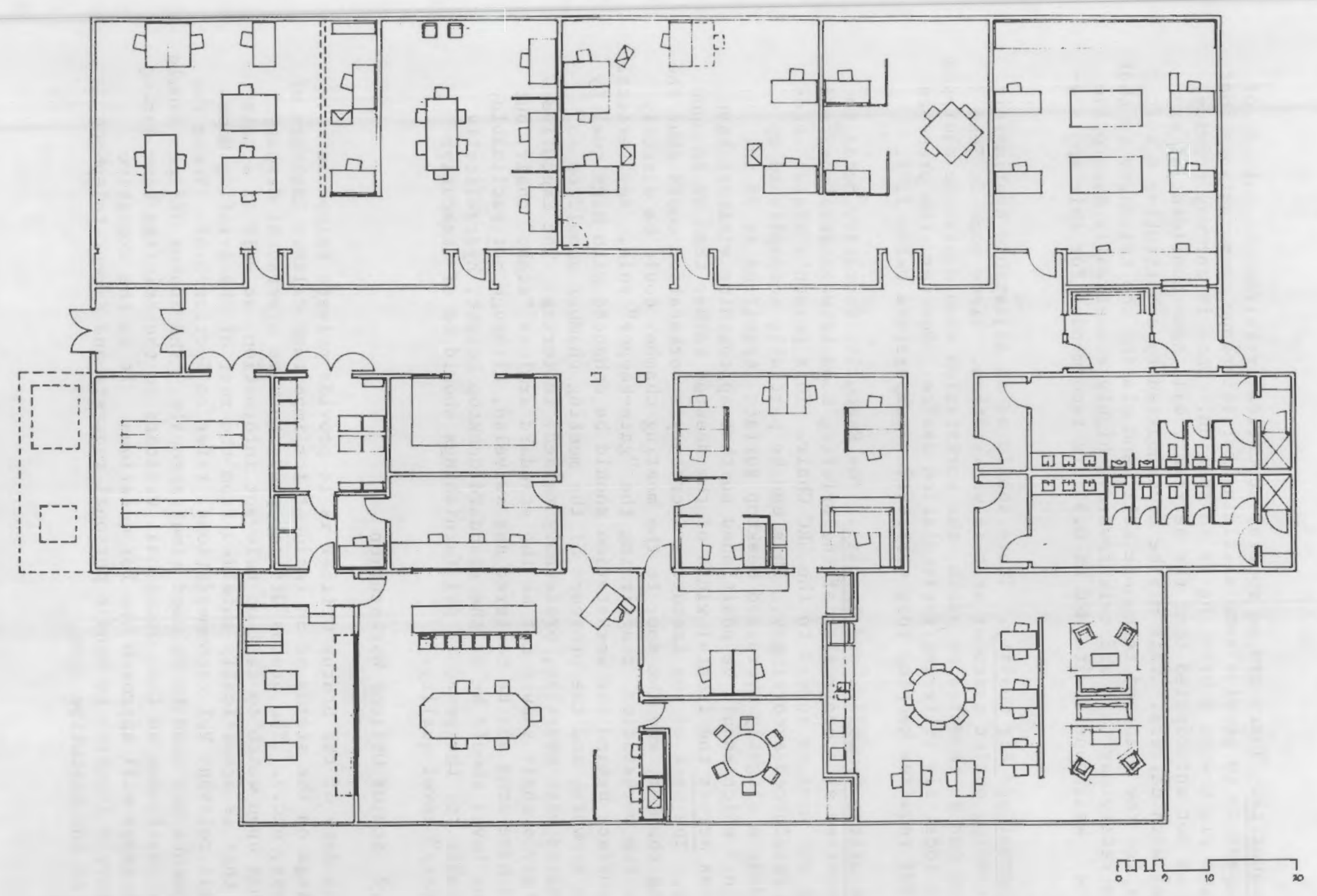

Figure 14 Furniture Layout 
Acoustics. There are no special acoustical requirements outside of the necessity to provide some shielding for telephone conversations that may take place when a briefing is in session. This is one-way privacy, as it is not anticipated that the secretary will have confidential exchanges with callers. This may be accommodated by substituting a soft buzzer for the standard telephone bell, and placing the telephone so that the secretary may turn and talk toward a highly acoustically absorptive surface. Wall panels with NRC of 0.95 are recommended for this application.

Thermal and Air Quality. There should be an adjustable heating/air conditioning outlet casement at this workstation. Since some Ex Team members can be expected to smoke, the workstation should also be equipped with a local air filtering/recirculation device. However, the presence of a VDT requires keeping this workstation temperature below $72^{\circ} \mathrm{F}$.

Security, Symbolic, and Special. The Executive Secretary needs to be perceived as a controller of the Briefing Room between sessions, and as one who manages access to the NRC Chair. This person's status needs to be reinforced accordingly. This can be partially accomplished by providing a slightly oversized desktop surface (specified at 36 in. $x 60$ in.) which should be positioned so that approaching visitors have to speak across the frontal width of the desktop rather than on an open corner. The back of the Executive Secretary's workstation could abut the meeting chamber, and the door to the meeting chamber could be directly beside the workstation, reaffirming the "gate-keeper" role. Any vertical wall surface behind the workstation should be enhanced with high quality framed artwork, and the presence of the meeting chamber should be so designated with oversize, preferably raised, lettering. The Executive Secretary's chair should not be the standard armless "steno" chair, but should have arms and be castered and swiveled, although not reclinable. Seating level should be at the standard desktop height, hydraulically adjustable for the person. All furnishings should be of "Executive Secretary" level quality.

\subsubsection{Status Officer Workstation}

The duty of the Status officer is to provide private telephone briefings on the status of an incident for important callers (members of congress, etc.). The Status officer needs to have a personal display terminal upon which to call up relevant information, as well as a telephone that is acoustically shielded from the rest of the Briefing Room. (For all relevant VDT recommendations, refer to Section 5.4). These two instruments may need to be used simultaneously. The Status officer should not be positioned so that occasional visitors to the Briefing Room during an emergency will approach him for questions. It is the Executive Secretary's function to handle personal requests and direct telephone calls to the Executive Team. 
Recent experience with exercises in the present NRCOC has indicated that the Status officer may require an assistant either temporarily or permanently assigned to the workstation. The duty of the assistant could be to help maintain an up-to-date information $\log$ while the Status officer is employed in a lengthy telephone call. The final justification for this additional position may well rest with the performance of the proposed SIM system. However, any potential enlargement of the Status Officer workstation to accommodate an assistant could probably be accomplished in another $20 \mathrm{ft}^{2}$, as indicated in the space summary table.

Illumination. The Status officer needs to be able to maintain 50$70 \mathrm{fc}$ illumination on his desk top regardless of the activity in the briefing area. His workstation should be equipped with a built-in fluorescent lamp over the desk writing area, and an incandescent elbow-type adjustable task 1 amp.

Acoustics. The workstation should provide acoustical shielding for the Status Officer's telephone conversations. The need for aural privacy is symetrical here. It is just as important that conversations are not overheard by others in the Briefing Room as it is that conversations are not disturbed by briefing activities. Therefore, the workstation should be separated from the briefing area by a $7 \mathrm{ft}$. high panel with an NRC of 0.85 . Adjacent wall surface should be treated with equally absorptive materials.

Thermal and Air Quality. There should be an adjustable heating/air conditioning outlet casement at this workstation. However, the presence of a VDT requires keeping this workstation temperature below $72^{\circ}$. Since some Ex Team members can be expected to smoke, the workstation should also be equipped with a local air filtering/recirculation device.

Security, Symbolic and Special. The Status Officer's primary role is to provide additional information for people who have a special "need to know." While most of these instances will be telephone exchanges, the appearance of the Status officer's workstation needs to reflect an image of competence and high-level access within the NRC. One way this can be achieved is by giving this workstation a more technical appearance than other parts of the Briefing Room. The acoustical shielding should be obvious rather than hidden in the workstation enclosure. Furthermore, some sight separation from traffic flow is desirable. For example, it should not be possible to enter the workstation operational space directly from the major circulation path of the Briefing Room. The work chair of the Status Officer should be castered, swiveled, and reclinable. It should have breathable upholstery and exceptional lumbar support. Although the Status officer does not need the storage space that a desk provides, there should be at least the amount of visual obstruction into the workstation space that a desk fronted onto the circulation space would provide. The appearance of high level functioning within the organization is enhanced by decreasing casual visual penetration into the workstation. The workstation does not require any special color treatments outside of those intended for the occupant. In this case, lack of woodgrain appliques can be used to increase the sense of Lechnical functioning. 


\subsubsection{Briefing Area}

The briefing area is the main work area of the Executive Team. It is used for all briefings and most discussions of the Ex Team. In short, it is the management center of an emergency response operation. The Briefing Area needs to comfortably seat the members of the Ex Team, plus members of the Liaison Team and directors of analysis teams. The seating should be divided in the following manner (see also Figure 14, p. 55).

The Ex Team should be seated around an oversize elliptical or elongated octahedral work table with one end reserved for the NRC Chair. This requires a table size of approximately 4-5 ft. width by $12 \mathrm{ft}$. length. The table should be equipped with 12 arm chairs that are castered, swiveled and reclinable. One--reserved for the NRC Chair-should be distinctively different from the rest. All the arm chairs here should reflect executive level functioning, which means shoulder-height back rests. The NRC Chair's seating can utilize a higher backrest and different color or upholstery material to achieve the necessary distinction. The end opposite the Chair should be reserved for presentors at briefings. Six to eight side chairs alongside the briefing area should be reserved for liaisons, analysis team directors, and visitors when they are present. These chairs should be positioned so as to allow easy viewing to the end of the table opposite the chair, yet be far enough away from the Ex Team members so as not to disturb them ( $5 \mathrm{ft}$. is usually sufficient). They should not be positioned so as to block slide projection or map displays at the end of the table opposite the Chair. These chairs may be divided between both 1onger sides of the Ex Team work table. No one should ever be seated behind the NRC Chair.

The briefing area should be equipped with a $2 \mathrm{ft}$. deep $\times 12 \mathrm{ft}$. long $\times 3 \mathrm{ft}$. high storage credenza that can fulfill the following functions:

a. It can house SIM system VDTs at both ends, with one end positioned near the NRC Chair. These monitors should be positioned so as to be visible to Ex Team members at the conference table.

b. It can house a small $\left(3 \mathrm{ft}^{3}\right)$ refrigerator for use by $\mathrm{Ex}$ Team members.

c. It can provide storage for miscellaneous supplies such as map pins, markers, tablets, thermos coffee services, etc. used in briefings.

The briefing area can be accommodated in 450-500 $\mathrm{ft}^{2}$. However, it is desirable to make it more rectangular in aspect ratio so as to help focus briefings on either presentations or the Chair's direction. An aspect ratio of ranging from $1.2: 1$ to 1.5 to 1 is recommended. 
The briefing area should be arranged so that the presentors' end of the conference table is in proximity to a wall treated for rearprojections from an adjacent projection room. The projection room itself should be capable of film and multiple slide projection. The briefing area wall should be equipped with interchangeable tackable and marking pen surfaces, as well as recesses for TV, connected videotape machine and another pair of current status monitors. The latter should be positioned so that it may be concurrently viewed by individuals who may have some difficulty seeing the storage credenza monitors. Screen, tackable, and marking surfaces should be instantly interchangeable, and should be approximately $4 \mathrm{ft}$. high $x 10 \mathrm{ft}$. wide, beginning at $36 \mathrm{in}$. above the briefing area floor.

Illumination. Illumination of the Briefing Area should support critical paperwork on the conference table surface, and yet be controlable for slides or graphic displays during presentations. Rheostated downward incandescents are recommended. These can be recessed, spot canister, or track lights. It should be possible to illuminate/dim the end of the briefing area opposite the Chair independently of the remaining lights. A mixed luminaire system is feasible here, with recessed fluorescents providing general area illumination, and the rheostated incandescents providing the extra illumination necessary for more critical tasks. The two systems should be independently controlled from at least two places in the Briefing Room, one of which is convenient to the Executive Secretary's workstation. Fluorescents should be specified as deluxe cool white, and be equipped with "eggcrate" diffusers to minimize glare. Illumination from fluorescent luminaires alone should be in the 40-50 fc range. The rheostated incandescents should provide illumination to 70-100 fc in the manner described above.

The intention of these illumination recommendations is to provide a system that can support general task work such as discussion and reading, as well as critical inspection of documents, analyses and presentations. These kinds of tasks appear at variable intervals during an emergency operation. Daylight fluorescents are more acceptable to people for long-term use, and have less likelihood of undesirable mood reactions attributed to some fluorescent installations. A mixed system is generally judged to be most acceptable aesthetically and functionally to individuals in an office setting.

Acoustics. The acoustics of the Briefing Area must be outstanding in the sense of speech intelligibility. This means that Briefing Area background noise resulting from HVAC equipment or other personnel in the NRCOC should not exceed requirements of noise criterion (NC) curve 30. This may require soundproofing in the walls of this area. It is also important that reverberation time be kept below $1.0 \mathrm{sec}$, yet above 0.5 sec for optimum combination of speech intelligibility and room "liveness" for the occupants. This will require more absorptive ceiling treatment than the standard acoustical tile, and sound-deadening board or similar absorptive treatments on the walls around the briefing area. This treatment can be combined with the requirement for additional tackable surface for graphic displays. 
Thermal and Air Quality. There should be provision for air exchange at the rate of at least $40 \mathrm{ft}^{3} / \mathrm{min} /$ person. Since Ex Team members or others may be expected to smoke, there should be provision for a portable ion air-filter if it is not possible to provide one in the general HVAC system. There is no special need for local heating/air conditioning of this area.

Security, Symbolic and Special. The briefing area is that place where some of the critical information about emergency response is received and integrated. It is vital that the Ex Team be able to discuss issues, receive information, and weigh alternatives in the least distracting atmosphere possible. From a security perspective:

- No one should be able to look into the briefing area from any other area except the Secretary's and Status Officer's workstations and the acoustically separate workstations of the Analysis Team Directors. No person should have unauthorized entry to these workstations.

- See requirements for Secretary's workstation as playing role of manager of outside individuals' visits to briefing area.

Symbolically, the briefing area is second in status only to the meeting chamber. Furnishing should be of executive-level quality. This should include liberal use of light wood wall paneling or trim and appropriate padded carpeting. The latter can aid the acoustics, but is not a substitute for additional ceiling treatment. Colors can be to preference of the occupants or administrator in charge, but highly saturated colors and bold graphic treatments are not recommended. Conference and briefing areas are more likely to be viewed and perceived as such if they are treated with mid-range achromatic finishes or darker warm colors and earth tones.

\subsubsection{Executive Team Meeting Chamber}

The meeting chamber is reserved for sensitive deliberations that demand the withdrawal of the Ex Team from the briefing room. It is meant to be occupied for short periods of time when the NRC Chair finds it necessary to discuss exceptional measures for direction and control of the emergency response. The meeting chamber should be an extremely secure, quiet, and private room adjoining the briefing room whose access is reserved almost exclusively to the Ex Team.

The meeting chamber needs to be large enough to comfortably, but snugly, hold the Ex Team. This means seating for six. Since it is the intention for the meeting chamber to be an occasional "discussion only" place, the seating arrangement and furnishings should reflect this distinction.

The meeting chamber should be approximately $100-200 \mathrm{ft}^{2}$ with an a spect ratio of $1.0-1.25: 1$. Seating should be by an executive chair and upholstered side chairs arranged around a 12-18 in. high (i.e. coffeecable height) $5 \mathrm{ft}$. diameter table. 
Illumination. Illumination in the meeting chamber should be indirect, by valanced fluorescents about the edges of the room, except for rheostated downward incandescents focused directly over the table surface. Deluxe warm white tubes are recommended for the indirect lighting. Recessed spots are probably most suitable for the latter installation. The intention is to provide a gentle edge illumination which visually expands the small space, while providing for additional illumination over the focal area of discussion. Background illumination should be approximately $10 \mathrm{fc}$ with the rheostated spots providing $70 \mathrm{fc}$ on the table surface.

Acoustic. The acoustics of the meeting chamber should be conducive to quiet discussion and the extreme privacy this space demands. All four walls and the ceiling should be acoustically treated to bring ambient background noise to meet the NC 25 curve. Reverberation time should be lowered to approximately 0.5 second.

Temperature and Air Quality. Because this space is small, there should be an additional "silent" ventilating fan connected to the same circuit as the background lights. Thermal comfort may be enhanced here by the addition of a radiant wall panel near the deliberations table.

Security, Symbolic and Special. Security for the meeting chamber is provided through its extreme visual and acoustic privacy. All walls should be equipped with internal insulation and constructed so as to prevent sound transmission (e.g. double studding). There should be no visual access to this space from any adjacent areas. All entry/exit is via one door in the briefing room.

Symbolically, the meeting chamber is the most private and reserved access area in the operations center. Admission here is only by and in the presence of the NRC Chair. Furnishings and carpeting should reflect this special status. The upholstered side chairs should not be the 1 ight and movable kind. The NRC Chair should have a more distinctive chair for his personal use. None of these chairs should be castered, swiveled, or reclinable.

Because of the small size, the walls and ceiling need to be light in color. An achromatic or primarily monochromatic color treatment is recommended, although one wall could be treated in a contrasting shade. Wood trim soffits would be acceptable additions, as are other embellishments that preserve the dignity and decorum of this space, e.g., wainscotting, paneling. The intention is that the space not appear stark, nor should it be warm and cozy. It is a highly professional, private, deliberative space reserved for the special use of one person, whose decision-making is vital to any emergency response.

Special requirements for this space include a telephone placed in a small storage cabinet for the express use of the NRC Chair. The storage cabinet should be large enough for a few other office items or supplies. There is no requirement for a video monitor in this space. 
Care should be taken to provide a low table surface that does not produce reflected glare from the overhead incandescent fixtures. Since it is not intended for reading material to be placed on this table, there is no special requirement for avoiding contrast with text materials.

\subsubsection{Liaison Team Room}

This workspace is for the Congressional Affairs and Public Affairs Liaisons. (Under this design proposal, the workstation of the State/ Federal Liaison has been shifted to the Protective Measures Team.)

This workspace should provide access to the briefing room through the select court. It is the duty of these Liaisons to ensure consistency among information releases provided to the outside. They need to confer with the NRC Chair on a periodic basis. The Liaisons should be able to enter the Briefing Room without using the major access corridor, but they should also be able to leave their workspace without crossing the briefing room. Estimated required floorspace for Liaisons' use is 120 $\mathrm{ft}^{2}$, with an aspect ratio of 1.0-1.2:1. Because of its location relative to the briefing room, this space could also serve as a private office during normal mode operations, or as a resource room to the Operations Area. As a resource room, it could provide storage for equipment and maps used only during emergency situations. The extra storage and floor space requirements are detailed in Appendix A.

Each 1 iaison needs to be equipped with a desk and separate telephone line (see Figure 14, p. 55). The desk chairs should have cut-back arms, breathable upholstery, and be swiveled and castered. The Liaisons' workspace need to be treated like a shared, two-person office, staffed by individuals whose telephone conversations and responsibilities are independent but whose outputs are tightly linked. Their desks could be arranged within modular, acoustically private workstations formed by a freestanding panel system, in order to enhance normal mode use.

Illumination. General workspace illumination is to be provided by recessed fluorescents to provide a desk-top illumination level of $60 \mathrm{fc}$. Each desk is also to be equipped with an adjustable elbow-style desk lamp or equivalent that can boost the illumination to $80 \mathrm{fc}$. The lamp should be adjustable so as to illuminate typewriter copy on a movable typewriter table in the workspace.

Acoustic. The workspace needs to be treated with standard acoustical ceiling tiles and commercial tight-weave carpeting to bring reverberation time to the $0.75-1.0 \mathrm{sec}$ earlier range and general sound level to meet NC curve 35. Further acoustical shielding may be necessary on wall surfaces that abut the briefing room.

The most important acoustic requirement in this workspace is to minimize the audio interference produced by the two occupants on each other. They spend considerable time on the phone in separate conversations, and these should be kept as private as possible. This is probably best achieved through sound absorptive panels between the workstations and localized absorptive surfaces around each telephone. 
Thermal and Air Quality. No special requirements beyond general ones of the operations center.

Security, Symbolic and Special. The Liaisons' work involves preparation and dissemination of information updates to special target groups. Any door to their workspace that accesses a major use corridor in the NRCOC should be lockable. Additionally, if there are relights into their space from NRCOC corridors or any other area, these should be one way from within the room, or treated so as to deter casual outside observation. It may be desirable to provide a two-way relight between the liaison's workspace and the Bridging Room, in order to allow impromptu visual signaling.

There is a special symbolic requirement that needs enhancement here. The Liaisons' task is to provide information about an emergency incident to the public and Congress, who have the "right to know." The office space should reflect this responsibility and be furnished to a suitable level of quality that reflects the importance of communication here. This means providing commercial trade carpeting and middle management level furnishings. The color scheme should be associated with trust, and competence and should stimulate reassurance. Color norms suggest that a dichromatic color scheme may be appropriate here--perhaps cream or 1 ight gray with a pale yellow or tan. Beyond this consideration, lighter colors should be used to make this small enclosed space seem larger for its occupants.

\subsubsection{Analysis Team Directors' Workspace}

The three Analysis Team Directors have a special relationship to the Ex Team. They are the means by which the results of the different teams' efforts reacn the Ex Team. They are the technical experts called upon to advise the Ex Team during its deliberations. The AT Directors make formal presentations to the Ex Team and maintain an informal availability with them. The AT Directors must, however, be able to be in fairly close contact with their own teams when needed.

The AT Directors require a workspace directly adjacent to the briefing room. They should be able to enter/exit their workspace without entering the briefing room. They should also be able to enter/exit the briefing room without using the common NRCOC corridor.

The AT Directors need aided two-way voice connection with the Briefing Area. They also require two-way visual connection with the Briefing Area.

If the AT Directors' workspace is to be given two-way visual and audio connections with the briefing area, there should be a partial glass partition wall separating the two spaces. A visual connection between the spaces could be enhanced by having the floor of the AT Directors' workspace raised by one or two steps. This way, they would be able to maintain easy visibility vis-a-vis the Ex Team when they responded to queries. Although there are some potentially disturbing 
status implications in such an arrangement of relative heights, the purpose of the elevation is to make the AT Directors immediately available to the Ex Team for queries without them having to leave their workspace. By remaining within an acoustically separate workspace, the AT Directors can maintain intermittent contact with their teams while still being immediately available to the Ex Team.

Space requirements for the three AT Directors' workspace should be approximately $160 \mathrm{ft}^{2}$ in a room aspect ratio that is dependent on the necessity of visual connection. In order to maintain visual contact with the Ex Team, the Directors need to sit abreast of one another along the partial glass wall (see Figure 14, p. 55). This requires a more rectangular space. If the AT directors are seated along the Briefing Room wall, their seating positions must allow them to see not only the Ex Team but also any information displays that are projected for Ex Team briefings. The critical viewing angle is the angle that is subtended from the nearest AT Director's seat to the nearest side of the screen. If head rotation is disregarded (for comfort reasons) this angle should not be greater than $60^{\circ}$. In the present generic design accompanying this program, the angle is kept below $40^{\circ}$ for the near side of the screen.

Each of the AT directors needs to be provided with a separate telephone line and movable VDT for accessing status board information. A line printer can be interconnected to these if desired. In addition, each director will need to be voice-linked with the Ex Tean briefing area. This can be done independently with plug-in headsets or through a speaker phone in the AT Director workspace. Acoustic qualities of extant speaker phones and the possibility that all three AT Directors will not be involved in the same conversation combine to make connectable head sets the preferred choice at this point.

Illumination. Deluxe cool white fluorescents recessed behind egg-crate diffusers are recommended to give an overall $70 \mathrm{fc}$ at desktop level. In addition, each workstation should be equipped with an adjustable elbow-type desk lamp.

Note that this illumination should be able to be lowered to $20 \mathrm{fc}$ if visual exchange between the briefing area and AT Directors' workstation is desired. In this case, either certain fluorescents must be separately switched or replaced with rheostated incandescents. The intention here is to avoid glare or light pollution conditions from the AT Directors' workstation onto the briefing area through the glass divider.

Luminaire installation needs to be especially sensitive to avoid potential glare on the VDT's, light exchange between areas and potential direct exposure to briefing room occupants. Other satisfactory systems may be obtained with a recessed luminous ceiling system or ambient light fixtures concealed in the tops of modularized workstation panels that are used to define the separate workstations. 
Acoustics. The major acoustic requirements of this space regard isolating it sufficiently from the briefing room and ensuring some degree of audio separation for each of the AT Directors. One AT Director may be speaking with the Ex Team while another is conferring with his Deputy Director. The two conversations should not interfere. Part of the solution here is technical--in the nature of the voice 1 ink between this workspace and the briefing area. Part of it also requires partial separation of the work desks and their associated telephones, so that the occupants can at least turn and talk toward an absorptive surface.

It is recommended that the workspace be treated with acoustical ceilings. Floor treatment should entail commercial grade carpeting, and any modularized panels should have an NRC of at least 0.85 . In addition, it may be necessary to specially treat vertical surfaces around telephones with exceptionally highly absorptive material like 2 in. SONEX or equivalent. NC curve 35 is the recommended performance level.

Thermal and Air Quality. This room should have separately adjustable heating and ventilation controls for the comfort of its occupants. Since it can be expected to be occupied for long periods of time, there should also be the possibility for a portable air filtration unit if one is not built into the building's HVAC system.

Security, Symbolic and Special. Special security needs here are guaranteed by ensuring audio privacy between this room and all adjacent spaces. This especially means that conversations between the AT Directors and Ex Team should not be heard by persons standing at the door that connects this workspace with the rest of the operations center.

The AT Directors are the technical managers of the analyses that provide the emergency response. They are equivalent to "vice-presidents in charge of . . " in most corporate structures, and their furnishings should reflect this. High-quality open-plan type office modules should be used to guarantee an acceptable combination of function and symbolic authority.

There are several special requirements for this workspace. The desk chairs need to be ergonomically excellent, which includes being castered, swiveled, reclinable and with breathable upholstery. Back support should extend to the upper shoulder region.

There are no special needs for documentation or materials storage at these workstations, but each one should be arranged so as to allow efficient use of its VDT. Each workstation will need at least $15 \mathrm{ft}^{2}$ of horizontal work surface, primarily for laying out reference documents.

The partial glass wall or interior window(s) connecting this workspace with the briefing area should be angled slightly toward the briefing area so as to improve visibility for Ex Team members by reducing any reflections due to the briefing area lighting system. There should also be blinds provided (on the briefing room side) so as to visually close the two spaces if desired. 
Personnel from any of the analysis teams can be expected to enter the AT Directors' workspace at variable times. The workspace door used by them should be placed so that visits to each of the team directors disturb the others in this space as little as possible.

\subsubsection{Operations Room}

\subsubsection{General Requirements}

The operations area provides the "nerve network" for the NRC operations center. Communications Support receives and routes all incoming and outgoing calls on commercial lines. Current Status is responsible for all communications with the affected site via dedicated lines. The information obtained and integrated by Current Status is the basis for all actions of the analysis teams. The physical design of these two groups' settings is thus critically dependent on the nature of voice/electronic communication aids used by their personnel. The final form of these devices is necessarily uncertain at this time. Therefore, implementation of this particular part of the design program will demand close attention to the intention of the requirements.

With the proper electronic aids, there is no need for the Operations Area to be near the Executive Team space or the analysis teams. Although Current Status is the source of all information, and operates as a magnet to operations center personnel, it would be better for efficient operations if the Current Status staff could do their jobs without the "assistance" or interested observation of others. This should be reflected in the placement of the operations area within the general plan.

Illumination. The Operations Area needs to be equipped with recessed deluxe cool or warm white fluorescents arranged and switched so that ambient illumination may be varied from 20-70 fc over the area as a whole and over the subspace allocated to each of the two teams. This will provide a combination of flexibility and changeability that will accommodate normal and emergency modes, and help alleviate the "claustrophobia" that often accompanies working for long stressful hours in interior spaces. A combined fluorescent/incandescent system may also be used, but the advantage would be primarily aesthetic. If chosen, the incandescents should not be used to substitute for the indivdually adjustable task lighting.

Acoustics. Presently, the operations area is a considerable noise generator. This is due both to its placement in plan and the speakerphones utilized by Current Status. Ideally, an operations area like this should be relatively quiet, since this enhances the professional capability of all involved to carry out their assigned tasks.

Therefore, the Operations Area should use soundproofing on surrounding walls if necessary to bring ambient background building noise to meet NC curve 35. Besides the acoustical shielding for the workstations already discussed, additional acoustical ceiling and floor covering material should be used to bring the reverberation time of this space to between 
0.75 and $1.0 \mathrm{sec}$. It may also be advantageous to "advertise" the expected quiet conditions of this space by running a $1-2 \mathrm{ft}$. band of highly absorptive material (such as 2 in. SONEX or equivalent) at the wall-ceiling juncture around the entire room. This becomes both a functional means and visual reinforcer of the expected sonic decorum.

Thermal and Air Quality. In this space, air and thermal adjustments are best handled at the level of the CS modules. However, the space as a whole would benefit from programed daily variation in its thermostat control, particularly in the normal mode. This will help offset the "thermal boredom" that occurs, which can significantly degrade monitoring tasks. A programed variation from $\pm 3^{\circ} \mathrm{F}$ around the federal acceptable norm is recommended.

Security: Symbolic and Special. Symbolically, the operations area is the most visible statement of function to the outside world that the NRC is equipped to handle a nuclear emergency. It must look like a control center with significant technical capabilities at its disposal. It is apt to become the single most frequently photographed room to accompany any news story.

Insofar as security is concerned:

- The Operations space should not be accessible by the most public or visitor-used circulation route in the center.

- The Operations space should not be equipped with relights.

- The Duty officer's station should be equipped with a hidden, silent alarm that would indicate at the nearest securicy station if assistance is needed.

It should be finished with dark commercial carpeting or high-profile radial floor tiles. Floor, wall, and ceiling finishes should be achromatic, allowing the modular furniture, panels, and task lamps to carry the coloring. Those colors should be highly saturated, bright, and either blue or orange hues, based on color association norms. Wood-grain surfaces of any kind should be avoided.

At least $15 \mathrm{ft}^{2}$ of tackable wall surface should be provided on two opposing walls of the space, all of it above $42 \mathrm{in}$. from the floor. This will permit the posting of site and region maps, helping the CS teams develop a visual as well as audio connection with events in the outside world.

\subsubsection{Communications Support Area}

In the new design, the Duty officer should be accommodated at one workstation during both normal and emergency modes. 
The Duty officer requires approximately $40 \mathrm{ft}^{2}$ of operational space (see Figure 14, p. 55). His horizontal work surface must accommodate his indicator panel, switchboard, telephone and cassette recorder. With the exception of the switchboard, each of these can be supported within $1 \mathrm{ft}^{2}$ of work surface. The existing switchboard should be replaced with a newer, more efficient type of device that pertnits easier switching of calls.

Workstation arrangement should be in the form of an inverted, asymmetric U (see Figure 14, p. 55). The longer return should be on the DO's right (preferred) side. This return should be at 23-25 in. floor height, and should be $18 \mathrm{in}$. deep by $42 \mathrm{in.} \mathrm{long.} \mathrm{Frontal} \mathrm{worksurface} \mathrm{should} \mathrm{be}$ 30 in. $x 72$ in. at standard desk height. Left (non-preferred) return should be $18 \mathrm{in.} \times 24 \mathrm{in}$. at $23-25 \mathrm{in}$. height. This return is intended for additional upright manual storage. This would free the immediate frontal work surface for spreading out manuals in use.

The indicator panel should be placed on the frontal right quarter, and the switchboard on the right return. The telephone may go either on the frontal right quarter or on the right return. Manuals most often used by the Duty Officer should be stored upright on the frontal left quarter. Less used manuals and other materials may go on the left return. The intention of this arrangement is to "zone" the Duty Officer's workstation into "response" and "reference" areas. The frontal area needs to be left available for spreading out manuals while on the phone.

Work space materials around the duty officer should be matte-finished to reduce glare and brightness contrast on printed materials. The chair of the Duty officer needs to be one of the best ergonomically designed desk chairs available on the market. This means that it should use a "star" base, be "instantly" adjustable in height (via gas/hydraulic tube), have breathable fabric upholstery, cut-back arms, and utilize a recliner mechanism that does not lift the user's feet from the floor. The chair should also provide exceptional thigh, lumbar and shoulder support. This chair ought to be a "dedicated" chair for this workspace.

In addition to the general illumination provided in the operations area, the Duty Officer's workstation should provide two adjustable elbow-type task lights (or equivalent). One should provide extra illumination on the frontal work surface. The other should provide illumination over the non-preferred shoulder of the Duty Officer. This will allow the Duty officer to enjoy confortable recreational reading while maintaining his monitoring task.

The Duty Officer needs to be kept thermally comfortable for the long duty periods he maintains. His workstation should be equipped with local low level radiant/convective heating adjustable by the Duty Officer, and work surface fan that is adjustable for position and direction.

There are no special acoustic requirements for this station outside of those discussed in the preceding section for the room as a whole. 
The Duty Officer's workstation needs to be out of the circulation path yet open to the operations area around it. His workstation should not be visually enclosed. It needs to be very convenient to the multichannel receiver, whose tapes are changed by the Duty officer. The workstation should not be located near Current Status personnel, but it can be adjacent to the two phone operators who come on duty in an emergency mode.

In addition, the following equipment should be sited for access by the Duty officer.

- A line printer, which is used during routine operations, should also be convenient to the Duty officer station, although it does not need to be integrated into the Duty officer station.

- A VDT which controls what is printed by the line printer. This unit should be adjacent to the line printer. It is used during normal monitoring operations of the NRCOC.

- A storage cabinet for equipment and materials, such as hand-held emergency 1 ights, office supplies, etc. This should be a vertical bookshelf type storage unit, approximately $4 \mathrm{ft}$. wide $x$ $6 \mathrm{ft}$. high $\times 12$ in. deep.

The two phone operators need to be accommodated in an integrated workstation area where they can work in a back-to-back position with respect to each other. This will be necessary to counteract the task stress placed on these operators during a real emergency. This requires more space, but it allows freedom of movement while maintaining coordination. Botn operators should be able to be accommodated in $50-60 \mathrm{ft}^{2}$ of floor space.

The operators should have their switchboards placed directly in front of tnem. Enough desktop surface should be provided on both right and left frontal quarters to allow convenient and safe placement of coffee cups or fast food. Each operator should be equipped with one adjustable elbowtype task 1 amp.

Chairs should be of exceptional ergonomic design. This means castered, swiveled, reclinable, with cutback arms and breathable upholstery. Since the operators will be spending most of their duty hours at the switchboard, the chairs should provide additional lumbar and thigh support.

The workstation module of the operators should be equipped with a low-level (i.e., below desktop) radiant heating unit and desktop fan, both adjustable by the operators.

The operators' workstation can be considered to produce significant conversational noise into the operations area. Therefore, this workstation should be shielded on at least two sides with acoustically absorptive panels to $6 \mathrm{ft}$. in height. Another side needs to be left open to provide visual escape for the operators, although this could be treated with an acoustic panel to $42 \mathrm{in}$. height without creating undue enclosure. 
All surfaces should be matte finish, and local bulkhead colors should be light and desaturated. Chairs may be bright and contrasting. The intention of final color selection should be to provide an enclosed space that is not overly confining, is mildly warm and stimulating, and has occasional places of bright color interest.

The phone operators' workstation should be located nearby or adjacent to the DO's workstation, in a position that puts them out of operations area circulation, yet visually open to such movement. This will also help alleviate their job stress.

\subsubsection{Current Status Area}

The key workstations for the Status Information Management System (SIMS) described in Section 5.0 are in the CS area. This system would utilize a pre-established incident profile that would be continually updated by the HPN and ENS directors. Any parts of this profile could be accessed at any time from designated VDTs throughout the operations center.

Data entry would be performed at twinned triple workstation configurations that reflect the information flow graphically represented in Figure 2. These information flows are organized along HPN and ENS lines, respectively.

In each flow, a single communicator handles conversations with the site via a headset, and enters data directly into the system through his/her own VDT. The Director of each line monitors the conversation, suggests questions to the communicator through his/her own headset, and also checks the developing profile. The Director of one line can commicate face to face with the Director of the other line. Each Director transfers the information electronically to his line's status board operator (SBO) who performs final entry into the status board computer memory. The Directors maintain headset communications with either SBO to ensure redundancy.

The setting requirements here are for two sets of three VDT workstations (six total) where only two of the workstations have face-to-face contact adjacency. The other workstations, relying as they do on headset comminications, should be acoustically shielded from each other and the rest of the operations area. They should not be visually isolated.

If the workstations are conceived as modular components within an "open-plan" configuration, it should be possible to accommodate each VDT station within a maximum $6 \mathrm{ft}$. x $6 \mathrm{ft}$. operational envelope, which would require $216 \mathrm{ft}^{2}$ total for six stations. The circulation factor should be increased by $5-10 \%$ to account for the increased traffic these will receive.

Since Current Status workstation procedures will rely intensively on VDTs, the reader is referred to the summary section on VDT design requirements in Section 5.4 of this report. The special detail recommendations included here are intended as additions to that section and the operations area requirements in general. 
Illumination. Since ambient lighting in the CS area should be kept below the $50 \mathrm{fc}$ maximum, around VDTs, each workstation should be equipped with an elbow-type auxiliary task lamp.

Acoustics. Necessary acoustic isolation of the workstations requires installation of highly absorptive (at least NRC 0.85 ) partitions to 84 in. height on two sides of each module. A suitably treated wall can serve as one of these. the need for visual rest stipulates that at least 90 degrees of the surrounding area be visually open to the individual from the seated work position. If this requires looking over panels, then those panels should not be greater than $31 \mathrm{in}$. in height, based on the 50 th percentile of the adult Anerican male population. The high acoustic panels, therefore, should not be placed in the direction of the preferred view.

Thermal and Air Quality. These are the same as for the operations area as a whole (note special VDT maximum temperature considerations). a whole.

Security, Symbolic and Special. These are for the operations area as

\subsubsection{Reactor Safety Team Room}

The RS team is a large but variable (10-14 member) group that functions in a loosely knit manner.

They will be best accommodated in 400-500 $\mathrm{ft}^{2}$ of open floor space of approximately $1: 1$ aspect ratio. They should work within an "open plan" type furnishings system. This system should not impede visual sight lines among seated team personnel. Therefore, all modular panels are not to exceed $42 \mathrm{in}$. in height, unless they occur at a location where a particular workstation will not be obscured.

As the local individual in charge, the Deputy Director needs to be the most accessible member of the team in the workspace. He needs a seated workstation equipped with $12 \mathrm{ft}^{2}$ of desk height work surface and a VDT. He should also have one adjustable elbow-type task lamp or equivalent.

The functional narrative describes the tean membership and specialities. Their spatial layout should not conflict with the following proximity diagram (see, also, Figure 14, p. 55).

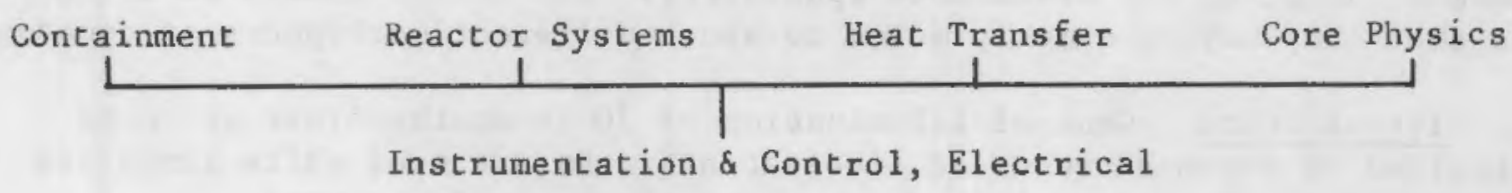


The Reactor Systems analysts (3) are the "centroid" of the analysis team. They work together and require approximately $50 \mathrm{ft}^{2}$ of single work surface area at 27 in. height.

The Containment Analyst should work in close proximity to the Reactor Systems Analysts. This person requires $15 \mathrm{ft}^{2}$ of single work surface area at $27 \mathrm{in.} \mathrm{height} \mathrm{with} \mathrm{one} \mathrm{adjustable} \mathrm{task} \mathrm{lamp.}$

There is a less proximate relationship between Reactor Systems analysts and the Heat Transfer analyst. Work surface and task lamp requirements for the Heat Transfer analyst are the same as for Containment analyst, above.

There is a close working relationship between the Core Physics analyst and the Heat Transfer analyst. Their work stations should be adjacent or in close proximity to each other. The requirements for work surface and task lamp are the same as for the Heat Transfer analyst.

The Instrumentation \& Control and Electrical Systems analysts (two individuals) work extremely closely together. Their work stations can be combined into one unit. They require greater-than-normal work surface $\left(24 \mathrm{ft}^{2}\right.$ ) area due to the large diagrams they customarily handle for both. This should be provided at desktop height (27 in.).

In the RS Team workspace, there is also need for a free standing VDT station with line printer. This should be positioned so that it is most accessible to the Containment, Reactor Systems, and Core Physics analysts. Two table top microfiche card readers should also be provided on a separate conference table, unless they are stored on movable stands.

Generally, the personnel of the RS Team need work tables more than they need desks. Even though work stations may be assigned to a given individual, there is a great deal of ebb and flow among positions during emergency work. For this reason, "circulation" space ought to be increased by a factor of $50 \%$ over what would be normally provided for a typical 10-person office.

There are no significant permanent storage concerns for this team space. Temporary storage of documents and manuals should be provided by having 12 linear feet of 12 i.a. deep adjustable shelving at three roughly equivalent locations on the room walls. Each wall should also have $25 \mathrm{ft}^{2}$ of tackable surface above $42 \mathrm{in}$. floor height, allowing easy posting of diagrams.

All chairs in this space should be castered and swiveled with cutback or no arms, and breathable upholstery. All chairs should be alike, so that they may be quickly moved to about different workspaces on demand.

Illumination. General illumination of $70 \mathrm{fc}$ on the floor is to be provided by overhead recessed fluorescents. Deluxe cool white lamps are recomended. Eggcrate diffusers or equivalent should be used. 
In addition, there should be secondary ceiling track lighting fixtures that can selectively illuminate tackable wall areas and major work surfaces. Their addition should bring the illumination on those surfaces to $100 \mathrm{fc}$. Controls for these should be placed as near as possible to the area to be lit.

Acoustics. The increased conversational level in this space, coupled with the lack of high interior partitions can be expected to provide noise problems. Highly absorptive ceiling tiles are required. Floor covering of either commercial grade carpeting or preferably high-profile radial tiles, is also recommended.

Under emergency use, noise level in this space should not exceed NC curve 50. This may require the installation of absorptive wa11 coverings, which could be used to provide the tackable surface mentioned earlier.

Thermal and Air Quality. Air exchange should be capable of being boosted through additional recessed fans to $50 \mathrm{ft}^{3} / \mathrm{min} /$ person in this workspace.

There are no requirements for local wS heating.

Security, Symbolic and Special. The RS Team space needs to enhance the functional efficiency of the team members above all else. It is in this space that critical technical analysis will be made that are the basis for the Executive Team's recommendations.

There is little opportunity for color enhancement, except through floor covering and chair fabrics. Cool colors are recommended, perhaps a bright, highly saturated green for the seat coverings and a dark green for the carpeting or tiles. Wall surfaces are to be light, achromatic creams or grays.

\subsubsection{Safeguards Team Room}

As security specialists, the Safeguards Team coordinates the emergency response of the NRC to that of local, State and Federal law enforcement. As noted earlier, this team may be accomnodated in an area of the Reactor Safety Team space, since the RS and Safeguards Teams usually do not operate simultaneously. Although it is improbable, two or more safeguards incidents may occur at the same time. If this results in a necessary increase in the number of Safeguards Team members, it should be possible to either enlarge the Safeguards Team area, or successfully utilize Reactor Safety Team space. One implication of the latter is a necessity for extra phone jacks in the RS Team space.

Safeguards Team members spend considerable time in telephone conversations. They also refer to site and regional maps in their assessment of the situation. They will require $300 \mathrm{ft}^{2}$ of floor space, depending on how their telephone stations can be combined with their group discussion requirements. 
The Sg Team space should be provided with one oversize conference table, rectangular in form, capable of seating 6-8 individuals (see Figure 14, p. 55). The chairs for this table should be standard side chairs with fabric backs and seats, that are easily movable.

There need to be 3-4 telephone stations, one of which may be accommodated at the conference table. Bringing one telephone station to the table requires more table area to effectively separate it. placing the others away from the table requires more floor space. An ideal solution may allow the telephones to be used both at the table and at one or two nearby stations. Plug-in sets would be necessary, and the telephone lines would have to be integrated into the table supports. Any telephone station designed solely as such should have $5 \mathrm{ft}^{2}$ of associated writing space.

Il lumination. Recessed fluorescents with diffusers are recommended to bring ambient illumination to $70 \mathrm{fc}$ at floor level. An additional row of adjustable track 1 ights should be placed over the table area. These should bring illumination on the table to at least $100 \mathrm{fc}$ if all are focused on it. These same track fixtures can be used to provide increased illumination for a nearby tackable wall surface (12 $\mathrm{ft}^{2}$ ).

Acoustics. Acoustic requirements for the $\mathrm{Sg}$ Team space are more stringent than for the RS Team space, with additional high absorptive material to be placed around any telephone station not located at the conference table. At the minimum, this should provide a surface, not more than $2 \mathrm{ft}$. away, that the user may talk toward while on the phone. The appropriate acoustic performance curve for this space is NC 40.

\section{Thermal and Air Quality. Same as for RS space.}

Security, Symbolic and Special. Although the Sg Team may be most cost effectively accommodated in space associated with that of the RS Team, the former is a distinct organizational entity. Its area should be treated in a corresponding distinguishing manner. This is perhaps best accomplished through use of the different style of side chair covered with a different color fabric.

\subsubsection{Protective Measures Team Space}

\subsubsection{General Requirements}

The Protective Measures Team is the largest (14) and most internally complex of the analysis teams. Because it is broken into two sub-teams, it is perhaps best accommodated in two adjoining spaces. One of these, the Radiological Analysis Team ( $R A$ ), should require about $400 \mathrm{ft}^{2}$; and the other, the Protective Action Analysis Team (PAA) about $200 \mathrm{ft}^{2}$.

Refer to the functional narrative for these team compositions. Each will be discussed separately in this detail description. 


\subsubsection{Radiological Analysis Team Area}

The members of this team should all have assigned work stations, with the possible exception of the team leader, who moves around among team members (see Figure 14, p. 55). As the communication links in Figure 4 show, the Dose Assessment analyst is the central figure in the information flow. The Dose Assessment work station should be equipped with VDT and oversize (36 in.x72 in.) desk-height work surface.

The Source Term Analyst ( 1 person) and Meterologist ( 2 persons) positions also use one VDT each. They work independently of each other and each provides information to the Dose Assessment Analyst. The Source Term Analyst may also receive information by hand from the RS Team. This analyst's workstation should be the most convenient one to the RS team in the Protective Measures Tean space.

The Source Term analyst requires a standard ( $30 \mathrm{in.x} 60 \mathrm{in.}$ ) desk height work surface with adjacent VDT. The Meterologist requires two slightly oversize ( 34 in.x 60 in.) work surfaces with one VDT on a movable support that can be made convenient to each. These two positions do not need to be visually or acoustically separate from each other.

Offsite Environmental and Hydrology may be treated as two noninteracting modular, single person work stations, each requiring a standard 30 in.x 60 in. desk height work surface. Onsite Health Physics has the same physical work station space requirement as each of the two above, but this position is infrequently required in emergencies or exercises. The space for this position may be best gained by oversizing one of the above or combining the two into a three-person work station that utilizes a continuous work surface that can be shared by its occupants, if there is a space problem.

The RA Team area may be furnished with open-plan-type modular components. There are no special storage requirements. All partition panels should have noise reduction coefficients of 0.85 .

The RA Team members do not have strong particular requirements for either visual or acoustical isolation from one another. Therefore, all panel heights should be kept to no greater than $31 \mathrm{in.}$ or $42 \mathrm{in..}$ However, the VDT stations require lower ambient illumination, and this could be partially gained by using $6 \mathrm{ft}$. panel partitions around part of the Source Term, Dose Assessment, and Meterology positions.

Illumination. General illumination of $70 \mathrm{fc}$ is to be provided by recessed fluorescents (deluxe cool or warm white tubes) equipped with egg-crate type diffusers. Each work station position should also be equipped with an adjustable, elbowtype task lamp (or equivalent). 
Acoustics. The operating mode of the RA Team does not lend itself to large amounts of conversational noise. However, emergency operations usually generate such conditions, so the RA Team space should be equipped with the same floor and ceiling absorptive treatments as the RS Team space. Again, the appropriate acoustic performance curve for this space is $\mathrm{NC} 50$.

\section{Thermal and Air Quality. Same as for RS Team.}

Security, Symbolic and Special. These are similar to the RS Team space. However, because these individuals spend more time at tables or desks, all chairs should be equipped with cut-back arms and be castered, $s$ wiveled, reclinable and with breathable fabric upholstery. Furnishing color should be different from the RS Team space. Again, a bright $s$ aturated, cool color is recommended for the seating, with similar color trim on achromatic panels. A darker color of the same hue as the seating may be appropriate for the floor covering. Wall and ceiling finishes should be the same as the RS Team space.

The RA Team area requires Current Status monitors mounted so as to be visible to all. Wall or suspended ceiling mountings are the preferred choices.

\subsubsection{Protective Action Analysis Area}

This area should adjoin the Radiological Analysis Team area with at least a $4 \mathrm{ft}$. wide connecting opening (for two-way traffic). There is no need for an interior door.

The PAA works differently as a team. It makes extensive use of site maps and the licensee's emergency plans. There is also frequent discussion between the two Protective Action Analysts, and frequent telephone conversations by the two State Liaisons.

Thus, the PAA area is best thought of as being zoned into two types of spaces: an acoustically shielded work station for the telephones and a large conference table space for protective action analysis and discussion. This is perhaps best accommodated in a space $1: 1$ aspect ratio, using open-plan-type partitions to achieve the zoning.

The telephone work station for the State Liaisons should be semienclosed $6 \mathrm{ft}$. high partitions on at least two sides. These should have panels with noise reduction coefficients of at least 0.85 . Each 1 iaison should have an associated $30 \mathrm{in.x} 60 \mathrm{in}$. desk-height work surface. Seating should be as for the RA Team members in the adjoining space.

The conference area needs to be equipped with a square aspect table of $4 \mathrm{ft}$. on a side, no more than $26 \mathrm{in}$. high. The intention here is to provide a lower than normal table that will allow easier map inspection. It should be equipped with four armless chairs that are castered, swiveled, and have reclining backs and breathable upholstery. Approximately $10 \mathrm{ft}^{2}$ of tackable wall surface should be located near the table. 
Illumination. The same fluorescent ceiling fixtures and illumination level as for the RA Team space may be used. There should, however, be the addition of recessed canister or similar type incandescent spot fixtures over the conference table. Each telephone station area is to have an integral task lamp.

Acoustics. The conversational noise generated by the PAA Team should not disturb the RA Team in the adjoining space. It is recommended that all wall surfaces around the conference table be treated with absorptive materials, and that the same absorptive floor covering and ceiling treatment be extended from the RA Team area into this space. Acoustic performance of this space should meet NC curve 45.

\section{Thermal and Air Quality. Same as for the RA Team area.}

Security, Symbolic and Special. Same as for the RA Team area. Although the PAA is a special subteam, it does not require distinctive color treatment. The area should have its own Current Status monitors, however. These can be wall mounted so as to be visible throughout the area.

\subsubsection{Response Coordination and Reception Areas}

\subsubsection{Functional Narrative}

The Response Coordination area is the staging and homework area for administrative and logistics support groups of the Response Coordination Tean. It is especially important for this team to provide support for the Analysis and Executive Teams at the center. The RC Team needs its own staging area from which to initiate requests to outside agencies for support of NRC response to a nuclear emergency. Provision also need to be made for the possibility that the Status Information Display System might fail. Specifically, a temporary power outage or line surge could damage the computers in the center during an emergency. This would require that information produced by the Current Status Team and work of the analysis teams be transcribed, duplicated and distributed throughout the NRCOC by the RC Team so that the emergency response could continue.

The Reception Area is the entry area to the operations center. All staff entry takes place here and visitors are cleared with security to wait for their host in the center to receive them. The reception area needs to be very near, if not contiguous with, the Response Coordination area. This is because during an emergency, all supplies (including meals) brought into the operations center are handled by the RC Team. $\mathrm{Placing}$ these areas adjacent to one another can greatly aid the task of the RC Team to bring necessary support items into the center with ease and efficiency. 


\subsubsection{Detail Description}

This space can afford a latitude of aspect ratios, from $1: 1$ to $1: 1.5$, depending on the exact type of office equipment ultimately assigned to it.

The space needs to support, at the minimum, four separate standard desk-type workstations and a security station for the vestibule (see Figure 14, p. 55). It should also contain storage of office supplies necessary to keep the center running during any emergency incident.

The RC area needs to be an open-plan office area of approximately $600 \mathrm{ft}^{2}$, dependent on final storage and equipment requirements.

Al 1 four work-desks should be of standard 30 in.x 60 in. size, and two of these should be equipped with typing returns. Since all of these desks will be occupied for shorter periods of time, they do not need the more costly kinds of desk chairs specified elsewhere. However, all desk chairs should be armed, swiveled and castered, with breathable upholstery. The chairs at the typing desks should also be hydraulically adjustable in height.

The RC area should also be equipped with two $4 \mathrm{ft} . \mathrm{x} 8 \mathrm{ft}$. work tables, and eight easily movable side chairs (may be stackable). Each workstation should have a telephone.

If the Response Coordination Area is partially open to the vestibule, the security station can be positioned so that it becomes part of the general workspace. Security staff will require one desk, slightly oversize at 36 in.x 66 in., equipped with desk chair as described above.

There should be a $30 \mathrm{in}$. deep countertop at 40-41 in. height separating that part of the vestibule from the RC area at the security station. Security staff should also be equipped with an upholstered stool (with back support) so that entry monitoring may be made while seated.

The security station needs two telephones, one on the counter and one on the desk.

Illumination. General workspace illumination in the Response Coordination and Reception Areas is to be provided by boxed or recessed fluorescents with deluxe cool white tubes to provide a desk top illumination level of $60 \mathrm{fc}$. Each desk is to be equipped with an auxiliary desk lamp. The desks with typing returns need lamps adjustable to illuminate upright typing copy.

In addition, there should be a row of recessed downward spot incandescents located over the security station counter. This is to help aid skin-tone rendering and identification of cards by security staff. Combined illumination here should be $80 \mathrm{fc}$ at countertop level. 
Acoustics. There are no exceptional acoustics requirements for this space outside of those for similar office arrangements. The appropriate preference curve is NC 50. The ceiling of the entire space should be treated with standard acoustical tile. The wall area directly behind and around the typing desks should received similar covering, or acoustic panels with NRCs of 0.85 should be installed on two sides of these workstations. Carpeting in this space is desirable but not strictly necessary. However, the floor covering should be at least high-profile rubberized radial tiles or equivalent, as specified for all hallways in the operations center.

Thermal and Air Quality. The proximity of the entryway can be expected to make the security station and vestibule one of the colder parts of the operations center. Additional, fan-forced wall heaters or some equivalent auxiliary heater would help keep these spaces thermally comfortable during winter months. There should be standard air exchange of no less than $40 \mathrm{ft}^{3} / \mathrm{min} /$ person for these areas.

Security, Symbolic and Special. If metal detection is desired at the entry into the operations center, it should be built in to the vestibule area, with an interlock circuit to prevent the final door into the operations center from opening (see description of vestibule following). There should be adequate storage provided behind the counter, where visitors may leave cameras or other items not allowed into the operations center.

These areas provide a visitor's first glimpse into the operations center. They should be finished so as to reflect the proficiency of the center as a whole as well as being supportive to an often harried RC Team. This implies light-colored wall finishes of noninstitutional colors. Light tan or cream would be appropriate. The countertop should be light stained wood or wood-grained laminate. Floor covering in the reception area should be dark so as not to dirty easily. The Response Coordination can utilize exterior windows to give it a lighter, airy contrast to the necessarily more enclosed spaces deeper in the center. Turning $25 \%$ of any exterior wall over to window space should be sufficient.

Special Requirements: Reception Area. In this program, the reception area is considered to be a special requirement function of the Response Coordination area.

The Reception area is the vestibule and entry space for all individuals into the operations center. This area should be much more rectilinear in aspect ratio (about 2-2.25:1) so as to organize circulation with respect to a security station on one side. Depending on the amount of seating area desired, it will require a floor space of from 140-250 $\mathrm{ft}^{2}$. Bench or chair seating should be provided for four people. 
The Reception area should be equipped with both an outer door to the general circulation space of the building and an inner door to the operations center. The inner door can be card or buzzer controlled (from the security station). This door should be equipped with a relight into the main corridor. Both doors should be visible from the security station, but the station is better located nearer the outer door, to aid early identification. All other area requirements are the same as for the Response Coordination area.

\subsubsection{Ready Room}

\subsubsection{Functional Narrative}

The ready room is a recommended addition to the types of spaces currently in use in the NRC operations center. The ready room is meant to be both a lounge for working personnel, a staging area for staff just coming on duty and, during exercises, an area from which exercise controllers can operate.

As a lounge, the ready room offers an opportunity for personnel to escape for a few minutes the extremely stressful working situation of an actual emergency. As a staging area, the ready room allows newly arrived individuals the opportunity to get acquainted with a situation and become oriented to the current status before going to their work stations.

It is extremely important that individuals who are analyzing and managing an emergency situation have temporary "escape" or "break" opportunities. These times usually come naturally with the development of an emergency incident. But to make the most of them, it is mandatory that a worker be able to leave the workstation space itself. The simple opportunity to temporarily remove oneself physically from a stressful place is an effective substitute for the inability to control the temporal demands of the work. The ready room fulfills the need to leave a workstation, remaining close at hand yet out of the way of other working groups.

Some staff of the center may only be called in to handle special situations that arise during an incident. These individuals will need a place where they can acquaint themselves with the current status, and where they may receive informal briefings from their co-workers. This activity should not all take place in the actual workspaces, as it is liable to disturb the activities there. The ready room thus provides a temporary, neutral area for such orientation activities.

Additionally, the ready room can be seen as a temporary retreat area for visitors to the operations center. Although visitors in the center may not be problematic during all phases of an incident, some times may become so demanding that it becomes desirable for visitors to be out of the way without actually having to leave. The ready room becomes a logical place to make visitors unobtrusive yet still feel they are a part of things. 


\subsubsection{Detail Description}

The ready room needs to accommodate 15-20 people on "coffee-break" activities and have associated food preparation and storage facilities. The room will contain these functional areas: the food preparation and storage area, the eating area, and the lounging area (see Figure 14, p. 55).

Food Preparation and Storage Area. Staff of the operations center tend to send out for fast foods, or leave foodstuffs such as special teas or coffees onsite to use during an incident. Supporting the preparation of snacks or reheating of processed foods is thus much more important than incorporating the vending of similar items.

The food preparation area should have a single continuous counter of 10-12 ft. length. There should be continuous base cabinet storage underneath, with at least 1 drawer cabinet for flatware and utensils. From $1 / 4-1 / 3$ of the way from one end, there should be a $30 \mathrm{in}$. double sink equipped with a garbage disposal. Approximately 6-8 lineal feet of overhead cabinets should also be included. Several narrower cabinets are preferred to fewer wider ones, as it is more likely that the different personnel in the operations center will want to keep their foodstuffs somewhat separate.

The food preparation area should contain a $16 \mathrm{ft}^{3}$ refrigerator/ freezer combination, a microwave oven of $1.5 \mathrm{ft}^{3}$ capacity, and a twoburner hotplate. The latter two should be mounted appropriately on the counter top. (It may be necessary to shield or place the microwave in a special cabinet.)

Recommended floorspace allotment: $80-100 \mathrm{ft}^{2}$.

Eating and Lounging Areas. This area needs to accomodate a variety of informal activities. People will wish to eat either singly or in small, changing groups. This area should be equipped with one round table of $6 \mathrm{ft}$. diameter (capable of seating 8 comfortably). In addition, there should be 4-5 two-person tables of approximately $2 \mathrm{ft} . x 4 \mathrm{ft}$. dimensions. These tables should all be of the same type so that they may be moved together upon user demand. Floorspace allotment for this furnicure is approximately $70 \mathrm{ft}^{2}$ for tables plus $300 \mathrm{ft}^{2}$ for circulation, for a total of $370 \mathrm{ft}^{2}$. This allotment will provide adequate workspace for four exercise controllers and a VDT connected to the Status Information Management System. Phone jacks should be provided in this area to accomnodate one phone for each exercise controller.

The lounge area itself should be furthest from the food preparation area. This area is foreseen as one in which plate-type meals are not consumed. It is meant for quieter rest moments.

The lounge area should consist of 2-3 smaller territories defined by informal furniture groupings. Each grouping should include two overstuffed residential-type arm chairs and one three- or two-person sofa, organized around s low coffee table. Space should further be defined by means of low, overhanging lamps over the coffee tables. The intention 
here is to create a space within a space where the user may come to feel a second degree of removal from the stressful workspace. Such a feeling of separation is enhanced by the use of high-backed sofas and chairs, and area rugs that further define a separate floor space.

Floor space allotment for this space is 2 or 3 areas of $90 \mathrm{ft}^{2}$ or 180-270 $\mathrm{ft}^{2}$. In addition, the lounge area should provide for 8 lineal feet of 4-ft.-high bookshelf storage along one wall. There needs to be a ceiling-suspended current status monitor positioned so as to be visible from within the entire eating/lounge area.

Illumination. The lighting treatment of the ready room should reinforce its spatial subdivision into food preparation, eating and lounging areas.

Illumination in the food preparation area should come from boxed ceiling fluorescents using deluxe warm white tubes sufficient to produce $60 \mathrm{fc}$ on the countertop.

Illumination in the eating area should utilize a combination of indirect fluorescents (soft white-natural tubes) and recessed incandescent fixtures. Together these should provide $50 \mathrm{fc}$ on the tabletops. The mixed system here will be much more aesthetically acceptable, and provide the necessary--better color rendering of the food. Ideally, these should be low overhead lanps over each table, but movement of tables in this area makes this impractical unless the fixtures are swagged for alternative locations.

General illumination in the lounge area should be by ceiling incandescent track lighting that are rheostated and separately switched for each furniture grouping. This is in addition to the low hanging lamp over each table. The track lighting should be sufficient to bring illumination in each area through a range of 10-45 fc on the floor.

Acoustics. The ready room needs to be perceived as a quieter space in order to enhance the sense of respite or escape from the workplace. Ambient noise under normal occupancy should not exceed NC curves 35-40. High-profile radial floor tiles or padded 1 inoleum is recommended for the food preparation and eating areas. The radial tiles provide greater acoustic absorbency and decreased breakage of dropped items. Padded comerical carpeting is specified for the lounge area. The ceiling should be of high-performance acoustical tiles. The walls of the lounge area should be additionally treated with absorptive covering such as sound-deadening board, which may be treated in such a manner so as to produce a maximum amount of tackable wall space.

Thermal and Aix Quality Requirements. There should be an auxiliary exhaust fan placed in the food-preparation area. General air exchange in the ready room should be no less than $40 \mathrm{ft}^{3} / \mathrm{min} /$ person. If the ready room is equipped with windows (see next section), the windows should be operable. 
Security, Symbolic and Special. The ready room needs no additional security precautions as long as it is in the security envelope of the center as a whole. Security here is enhanced, however, by not having a variety of vending machines in this area.

As a place of retreat and individual replenishment, the ready room needs to appear as supportive and noninstitutional as possible. Colors should be those associated with relaxation and the enjoyment of appetite. This means that oranges and reds are recommended for the food preparation area. The lounge area should be treated with muted earth tones. One interior wall should be treated with an extensive "nature-theme" supergraphic or photomural. The furniture selected should have rounded edges rather than rectilinear ones, and the low coffee tables should be round or oval in shape. The extensive use of light to medium wood grain trims or surfaces is recommended throughout the entire ready room.

If there is one space in the operations center that should have extensive window wall, it is the ready room. Windows offer a strong sense of psychological escape to the occupants of spaces--especially when such people are involved in stressful tasks.

The ready room should have at least a $30-50 \%$ window wall on one side. Window coverings of louver drapes or horizonal blinds should also be provided. Both of these allow for a wide range of occupant response to ambient sunlight.

The aspect ratio of the room as a whole would be square rather than rectangular, as this allows a greater possible separations among the different seating areas: $1: 1.0-1: 1.25$ is recommended.

\subsubsection{Support Spaces}

\subsubsection{Copy/Fax Room}

This room will hold copy and telefax machines. It needs to be approximately 100-120 $\mathrm{ft}^{2}$ in size with acceptable aspect ratios from $1: 1$ to $4: 1$. The room needs $50-70 \mathrm{fc}$ on the copy surface, perhaps best provided by overhead recessed or boxed fluorescents using deluxe cool white tubes.

Air exchange in this room needs to be increased to $60 \mathrm{ft}^{3} / \mathrm{min} / \mathrm{person}$ minimum when in use. The room should also be equipped with a separate thermostat since many copy machines require cooler than usual ambient temperatures to deter heat buildup.

The room will be noisy during machine operation. Both the ceilings and upper walls should be treated with acoustical tile so as to bring the ambient noise spectrum to no greater than NC 60 standards during normal use. This will probably also require the installation of carpeting or high-profile rubberized tiles as floor covering. 
This room needs to be equipped with lockable storage for copy supplies. About 30-35 lineal feet of cabinet shelf space should be sufficient. Final furniture specifications depends on the selecting copy machines.

\subsubsection{Phone Room}

The phone room contains the switching equipment for the operations center phone systems. A new system is presently being planned, which will require double the floor space presently required. The new phone room should contain $240-250 \mathrm{ft}^{2}$ in approximately $1: 1$ aspect ratio.

Illumination should be by overhead fluorescent using standard cool white tubes to produce $50 \mathrm{fc}$ on the floor. There are no special acoustics, thermal or ventilation requirements.

The switching equipment in this room may be installed up to 1000 feet away from the Duty officer's console. This implies that the phone room itself may not need to be in building space dedicated to the center.

\subsubsection{Restrooms}

The operations center needs restroom facilities for men and women that are conveniently accessible via the major circulation path. They should be in especially close proximity to the Operations room and the ready room.

The restrooms need to be equipped with three sinks each. Men's facilities need a total of 4-6 toilet/urinal fixtures, and women's facilities need 4-5 toilets. Each restroom should also have a single shower with drying area. The shower and drying area should be equipped with lockable privacy door and auxiliary exhaust fan and infra-red ceiling heater. Each restroom should provide lockable towel storage and a laundry hamper for used towels.

General illumination in the restrooms should be by recessed or boxed ceiling fluorescents (deluxe warm white tubes) and recessed incandescent spots in a mixed system. It is particularly important to provide incandescant spots over the counter/sink grooming area.

The intention of the mixed system is to provide more naturalistic rendering of skin tones in the restroom and to enhance the visual aesthetics of the area. In the working environment of an emergency response center, trips to the restroom become "mini-breaks" for often exhausted personnel. It can be helpful to treat the restroom area in a fashion that allows the users to regain a positive self-image during their visits. This is aided by the following design amenities: 
Floor and walls ought to be of the same material. Small, (2 in.x 2 in.) dark, earthtone tiles are recommended. This provides a greater sense of protective enclosure.

- Light wood grain laminate partitions are preferred over the standard metal kind. These are much less likely to receive graffiti.

- Mirrors for the grooming area that are bronze-toned help make the viewer look and feel healthier.

- High-performance acoustical ceiling panels should be installed to control reverberation time.

\subsubsection{Computer Room}

The operations center needs a dedicated space for its computer support system and for the storage of extra VDTs that may be needed as replacements or for extended workstations in an emergency. This room should be conveniently located to the analysis team spaces. Actual floor space requirements are difficult to project before the computer system is specified, but 200-400 $\mathrm{ft}^{2}$ should be the lower and upper bounds of the necessary range. This room will also require special heating and ventilating controls.

Illumination should be by boxed or recessed overhead fluorescents (deluxe cool white tubes). Acoustical treatment is by standard acoustical ceiling tiles and the high-profile radial floor tiles recommended for all hallways in the center.

\subsubsection{Hallways and Circulation Areas}

The major circulation corridor of this center is specified to have greater than standard width. Standard width for an upper-level privacy corridor is $7-7.5 \mathrm{ft}$. Here, the privacy corridor should have a width of approximately $10 \mathrm{ft}$, equivalent to a main corridor for ground floor level. The rationale for this is threefold:

- Much emergency response work involves face-to-face communication. A $10 \mathrm{ft}$. corridor allows two pairs of people, walking abreast, to pass each other in opposite directions without impeding passage or disturbing the other's conversation.

- The major corridor can expect to receive extremely heavy cross-traffic under peak operational demands.

- The major corridor will be used to transport oversize operations manuals in carts to one or more analysis team rooms or to the briefing room. The use of these should not impede communication of personnel walking abreast in the corridor. 
Illumination in the corridors should be provided by recessed overhead fluorescents to provide 20-30 fc on the floor. These should be placed so that the longest dimension lies across the corridor direction. This increases the sense of corridor width, and helps deter the exaggerated linear perspective often encountered in interior hallways. The intention here is to use a minor treatment that enhances spaciousness, which in turn helps prevent the "pressure cooker" feeling that develops when working for prolonged periods in enclosed spaces under heavy cognitive task demands.

One conspicuous feature of the circulation space included in this design is an oversize $\left(\approx 250 \mathrm{ft}^{2}\right)$ select court that buffers the intense circulation around the Executive Team and Operations areas. The rationale for use of a select court in the manner proposed here is fourfold.

- If the operations center is on the top floor of a building, it provides an opportunity to bring daylight (via skylight) into a set of spaces that would normally be totally enclosed.

- The use of a court separate from a main corridor allows ad hoc circulation among the surrounding spaces to be unhindered by a very different circulation pattern originating in other parts of the center.

- The use of a court as a "fore space" to the Executive Team areas enhances their privacy and deters casual entry into the ET briefing room. It is no longer as opportune to simply "pop in" while on a task that takes one through the major circulation path.

- The court can operate as a "staging area" for briefing preparations without disturbing ET deliberations.

\subsubsection{Reception Area}

The Reception area should be equipped with both an outer door to the general circulation space of the building and an inner door to the operations center. The inner door can be card or buzzer controlled (from the security station). This door should be equipped with a relight into the main corridor. Both doors should be visible from the security station, but the station is better located nearer the outer door, to aid early identification. All other area requirements are the same as for the Response Coordination area. 


\section{REFERENCES}

Hannan, J. and Himes, J. Mitre Corp. Conceptual Design of the NRC Headquarters Operations Center: User Needs for Radiological and Meteorological Data. NUREG/CR-1739, December 1980.

Phoenix Associates Inc. Operations Center Meteorological and Dose Assessment Acquisition System. NUREG/CR-2371, October 1981.

Ramsey, C. G., and Sleeper, H. R. Architectural Graphic Standards. New York: John Wiley, 1981.

U.S. Nuclear Regulatory Commission, NRC Incident Response Plan. NUREG0728 , September 1980.

U.S. Nuclear Regulatory Commission. Report to Congress on NRC Emergency Communications. NUREG-0729, September 1980.

U.S. Nuclear Regulatory Commission. Report to Congress on the Acquisition of Reactor Data from the NRC Operations Center. NUREG-0730, September 1980 .

U.S. Nuclear Regulatory Commission. Agency Procedures for the Incident Response Plan. NUREG-0845 (Draft), September 1981. 



\section{Appendix A}

ANALYSIS OF SPACE REQUIRED FOR NRC OPERATIONS CENTER

Executive Team space includes:

Briefing Room

$714 \mathrm{ft}^{2}$

Meeting Chamber

$121 \mathrm{ft}^{2}$

Liaisons Workspace

$118 \mathrm{ft}^{2}$

Analys is Team Directors Workspace

$162 \mathrm{ft}^{2}$

Operations area

includes

Communications Support

$160 \mathrm{ft}^{2}$

Current Status

$200 \mathrm{ft}^{2}$

Reactor Safety

Team space

(in one room)

$412 \mathrm{ft} \mathrm{t}^{2}$

Safeguards

Team space

(in one room that may interconnect with the Reactor

Safety Team space)

$302 \mathrm{ft}^{2}$

Protective

Measures Team space

(in two interconnecting rooms)

$530 \mathrm{fr}^{2}$

Response Coordination

Team space

(in one room)

$636 \mathrm{ft}^{2}$

This brings the overall estimated square footage requirement of the NRC Operations Center to $3355 \mathrm{ft}^{2}$ exclusive of corridors, restrooms, other storage facilities, ready room, machine support rooms and any calculation for "building factor." 


\section{Secretary}

136 in. $x 60$ in. desk with 36 in. $x 18$ in. return for either return for either electric typewriter or CRT/keyboard

$19.5 \mathrm{ft}^{2}$

1 swiveled, castered armchair with operational space requirement e

1 coat tree @ $1.8 \mathrm{ft} . \times 1.8 \mathrm{ft}$.

1 wastebasket @ $1.2 \mathrm{ft} . \times 2 \mathrm{ft}$.

$10.5 \mathrm{ft}^{2}$

Sum $\quad 36.0 \mathrm{ft}^{2}$

\section{Status Officer}

1 VDT desk e so in. x 60 in.

1 swivel armchair with workarea \&

1 wastebasket \& $1.2 \mathrm{ft} . x 2 \mathrm{Et}$.

1 storage cabinet a $1.5 \mathrm{ft}$. $\times 3 \mathrm{ft}$.

1 acoustic partition e. $5 \mathrm{ft} . \times 16 \mathrm{ft}$.

(possible assistant's chair and phone station)

$15.0 \mathrm{ft}^{2}$

$12.25 \mathrm{ft}^{2}$

$2.4 \mathrm{ft}^{2}$

$4.50 f t^{2}$

$8.0 \mathrm{ft}^{2}$

$\left(\underline{20.0} \mathrm{ft}^{2}\right)$

Sum $\quad 42.2 \mathrm{ft}^{2}$

$\left(62.2 \mathrm{ft}^{2}\right)$

\section{Briefing Area}

1 conference table (octahedral or elliptical) for $12 \max$ @ 27 lineal inches/person one end reserved for NRC Chair, one end open $5 \mathrm{ft}$. wide $x 12 \mathrm{ft}$. long

12 swivel arm chairs o $12 \mathrm{ft}^{2} /$ chair

8 side chairs e $1.5 \mathrm{ft} . \times 2.5 \mathrm{ft}$./chair

circulation space around table: $5 \mathrm{ft}$. deep on each of 3 sides

briefing area at foot of table $15 \mathrm{ft}, x 6 \mathrm{ft}$.

$60.0 \mathrm{ft}^{2}$

$144.0 \mathrm{ft}^{2}$

$30.0 \mathrm{ft}^{2}$

$145.0 \mathrm{ft}^{2}$

$90.0 \mathrm{ft}^{2}$

$12 \mathrm{ft}$. $\mathrm{x} 2 \mathrm{ft}$. counter/divider/storage credenza

Sum $\quad 469.0 \mathrm{ft}^{2}$

$24.0 \mathrm{ft}^{2}$

briefing room circulation e $25 \%$ of $493 \mathrm{ft}^{2}$

Total $571.0 \mathrm{ft}^{2}$

$143.0 \mathrm{ft}^{2}$

Total Floor Space Requirement

$714.0 \mathrm{ft}^{2}$

$\left(734.0 \mathrm{ft}^{2}\right)$ 
1 conference table e $5 \mathrm{ft}$. diameter, 12-18 in. high

6 upholstered medium weight side chairs @ $12 \mathrm{ft}^{2}$ each

1 storage (telephone) cabinet (a) $3 \mathrm{ft} . x 1.5 \mathrm{ft}$.

circulation e. .25 of above

$$
\begin{array}{r}
20.0 \mathrm{ft}^{2} \\
72.0 \mathrm{ft}^{2} \\
4.5 \mathrm{ft}^{2} \\
24.0 \mathrm{ft}^{2} \\
121.0 \mathrm{ft}^{2}
\end{array}
$$

Total

Liaison Team Room/OPS Area Resource Room

2 liaisons desks @ $2.5 \mathrm{ft} . \times 5 \mathrm{ft}$.

$25.0 \mathrm{ft}^{2}$

21 iaisons swiveled, castered armchairs

(d) $12.25 \mathrm{ft}^{2}$ operational space/chair

1 wastebasket @

1 map cabinet a $3.5 \mathrm{ft} . \times 4.5$

3 electronics cabinets @ $1.5 \mathrm{ft} . \times 4 \mathrm{ft}$.

1 medium size safe (d $3.5 \mathrm{ft}$. $33 \mathrm{ft}$.

1 typewriter table (moveable) @ $1.5 \mathrm{ft} . x 3.5 \mathrm{ft}$.

$25.0 \mathrm{ft}^{2}$

$2.4 \mathrm{ft}^{2}$

$15.75 \mathrm{ft}^{2}$

$6.75 \mathrm{ft}^{2}$

$10.5 \mathrm{ft}^{2}$

$5.25 \mathrm{ft}^{2}$

circulation @. 30 of above

$90.65 \mathrm{ft}^{2}$

$\underline{27.2} \mathrm{ft}^{2}$

Tota1

$118.0 \mathrm{ft}^{2}$

\section{Analysis Team Directors Workspace}

3 executive desks 34 in. $x 72$ in. or equivalent countertop worksurface

3 swiveled, castered desk chairs

$$
\text { (a) } 12.25 \mathrm{ft}^{2} / \text { chair }
$$

2 wastebaskets $2.4 \mathrm{ft}^{2}$ each

3 VDTs on moveable stands

(e) $2.5 \mathrm{ft}$. $\times 3 \mathrm{ft}$. each

3 side chairs $1.5 \mathrm{ft} . \times 2.5 \mathrm{ft}$. each

1 line printer (optional) e $1.5 \mathrm{ft} . \times 2.5 \mathrm{ft}$.

$50.5 \mathrm{ft}^{2}$

$37.0 \mathrm{ft}^{2}$

$5.0 \mathrm{ft}^{2}$

$22.5 \mathrm{ft}^{2}$

$11.25 \mathrm{ft}^{2}$

$3.75 \mathrm{ft}^{2}$

circulation at .25 of above

$130.0 \mathrm{ft}^{2}$ $32.5 \mathrm{ft}^{2}$

Tot 81

$162.50 \mathrm{ft}^{2}$ 


\section{Duty Officer Workstation}

frontal work surface (desk) @ $2.5 \mathrm{ft} . \mathrm{x} 6 \mathrm{ft}$.

$15.0 \mathrm{ft}^{2}$ right return @ $1.5 \mathrm{ft}$. $\times 3.5 \mathrm{ft}$. $5.25 f t^{2}$ left return @ $1.5 \mathrm{ft} . \mathrm{x} 2 \mathrm{ft}$.

1 topline ergonomic desk chair w/operational space o $3.0 \mathrm{ft}^{2}$

1 wastebasket @

\section{Two Phone Operators Workstations}

1 desks @ $2.5 \mathrm{ft} . \mathrm{x} 5 \mathrm{ft}$.

2 swivel, castered armchairs @ $12.25 \mathrm{ft}^{2}$ each

$25.0 \mathrm{ft}^{2}$

2 acoustic panels $0.5 \mathrm{ft}$. $x$ 15 ft.

\section{Other Equipment}

1 multi-channel recorder e $2 \mathrm{ft} . \mathrm{x} 3.5 \mathrm{ft}$.

1 moveable VDT on stand (d $2.5 \mathrm{ft} . \times 3 \mathrm{ft}$.

1 steno chair @ $1.5 \mathrm{ft} . \times 1.5 \mathrm{ft}$.

1 line printer a $1.5 \mathrm{ft} . x 2.5 \mathrm{ft}$.

1 storage cabinet @ $1 \mathrm{ft} . x 4 \mathrm{ft} . x 6 \mathrm{ft}$. $\mathrm{h}$

$7.0 \mathrm{ft}^{2}$

$7.5 \mathrm{ft}^{2}$

$3.0 \mathrm{ft}^{2}$

$3.75 \mathrm{ft}^{2}$

$4.0 \mathrm{ft}^{2}$

$25.25 \mathrm{ft}^{2}$

Total

$120.0 \mathrm{ft}^{2}$

$36.0 \mathrm{ft}^{2}$

Total

$156.0 \mathrm{ft}^{2}$

(or approx. $160.0 \mathrm{ft}^{2}$ ) 
OPERATIONS AREA: CURRENT STATUS

\section{Director/Deputy Workstation}

2 VDT type desks @ $2.5 \mathrm{ft} . \times 5 \mathrm{ft}$.

2 exec arm chairs $12.25 \mathrm{ft}^{2}$ each

2 side chairs a $2 \mathrm{ft}$. $x 2 \mathrm{ft}$. each

2 wastebaskets e $2.4 \mathrm{ft}^{2}$ each

$25.0 \mathrm{ft}^{2}$

$24.5 \mathrm{ft} 2$

$8.0 \mathrm{ft}^{2}$

$4.8 \mathrm{ft}^{2}$

$62.3 \mathrm{ft}^{2}$

\section{Two Communicators Workstations}

2 VDT type desks @ $2.5 \mathrm{ft} . \times 5 \mathrm{ft}$.

2 swivel arm chairs e $12.25 \mathrm{ft}^{2}$ each

$25.0 \mathrm{ft}^{2}$

$\underline{24.5} \mathrm{ft}^{2}$

$49.5 \mathrm{ft}^{2}$

\section{Two Status Board Operator Workstations}

2 VD'Ts on stands \& $2.5 \mathrm{ft} . x 3 \mathrm{ft}$.

2 swivel arm chairs @ $12.25 \mathrm{ft}^{2}$ each

$15.0 \mathrm{ft}^{2}$

$24.5 \mathrm{ft}^{2}$

$39.5 \mathrm{ft}^{2}$

circulation .30 of above

Total

$151.30 \mathrm{ft} \mathrm{t}^{2}$

circulation e. 30 of above $45.39 \mathrm{ft}^{2}$

Total

$196.7 \mathrm{ft}^{2}$

(or approx. 200.0 $\mathrm{ft}^{2}$ )

Total estimated floor space for Operations Area

$160 \mathrm{ft}^{2} \times 200 \mathrm{ft}^{2}=360.0 \mathrm{ft}^{2}$ 
Deputy Director Workstation

1 VDT desk @ $2.5 \mathrm{ft} . \mathrm{x} 5 \mathrm{ft}$.

1 swivel chair @ $12.25 \mathrm{ft}^{2}$ ops. space

$12.5 \mathrm{ft}^{2}$

$12.25 \mathrm{ft}^{2}$

Reactor Systems Workstation (3 Analysts)

$24 \mathrm{ft} . \times 6 \mathrm{ft}$. conference tables or equivalent $48.0 \mathrm{ft}^{2}$

3 swivel chairs a $9 \mathrm{ft}^{2}$ ops. space each $27.0 \mathrm{ft}^{2}$

Containment Workstation (1 Analyst)

1 table @ $3 \mathrm{ft} . x 5 \mathrm{ft}$.

1 swivel chair @ $12.25 \mathrm{ft}^{2}$ ops. space

$15.0 \mathrm{ft}^{2}$

$12.25 \mathrm{ft}^{2}$

Heat Transfer/Core Physics Workstation (2 Analysts)

2 tables $3 \mathrm{ft} . \times 5 \mathrm{ft}$.

2 swivel chairs e $12.25 \mathrm{ft}^{2}$ each

$30.0 \mathrm{ft}^{2}$

$24.5 \mathrm{ft}^{2}$

Instrumentation \& Control Electrical Workstation (2 Analysts)

1 conference table d $4 \mathrm{ft}$. $x 6 \mathrm{ft}$.

$24.0 \mathrm{ft}^{2}$

2 swivel chairs a $9 \mathrm{ft}^{2}$ ops. space each

$18.0 \mathrm{ft}^{2}$

\section{One Free Station}

VDT w/stand e $2.5 \mathrm{ft} . \times 3 \mathrm{ft}$.

line printer \& $1.5 \mathrm{ft}$. $\times 2.5 \mathrm{ft}$.

1 steno chair e $1.5 \mathrm{ft} . \times 1.5 \mathrm{ft}$.

$15.0 \mathrm{ft}^{2}$

$3.75 \mathrm{ft}^{2}$

$3.0 \mathrm{ft}^{2}$

Other

wall mounted storage shelves in three locations, each 12 linear feet $x 12$ in. deep in three $4 \mathrm{ft}$. long shelves--floorspace requirement:

$\underline{12.0} \mathrm{ft}^{2}$

circulation at $2 \times .30$ or .60 of above,

$257.25 \mathrm{ft}^{2}$

(see Detail section 7.2 .6 )

$154.35 \mathrm{ft}^{2}$

Total

$411.6 \mathrm{ft}^{2}$ 


\section{Conference Area}

1 conference table @ $3.5 \mathrm{ft} . \times 8 \mathrm{ft}$.

$28.0 \mathrm{ft}^{2}$

6 side chairs @ $2 \mathrm{ft} . \times 2 \mathrm{ft}$. operational space around table in $4 \mathrm{ft}$. band 2 extra side chairs d $2 \mathrm{ft}$. $\mathrm{x} 2 \mathrm{ft}$.

$24.0 \mathrm{ft}^{2}$

$92.0 \mathrm{ft}^{2}$

$8.0 \mathrm{ft}^{2}$

$152.0 \mathrm{ft}^{2}$

\section{Three Telephone Stations}

3 desks a $2.5 \mathrm{ft}$. $x 5 \mathrm{ft}$.

3 swivel chairs @ $12.25 \mathrm{ft}^{2}$ ops. space each

2 freestanding acoustic panels a 84 in. $h \times .5 \mathrm{ft} . \times 12 \mathrm{ft}$.

circulation @ .30 of above

$37.50 \mathrm{ft}^{2}$

$36.75 \mathrm{ft}^{2}$

$6.0 \mathrm{ft}^{2}$

$80.25 \mathrm{ft}^{2}$

Total $232.25 \mathrm{ft}^{2}$

$70.00 \mathrm{ft}^{2}$

Total $302.25 \mathrm{ft}^{2}$ 
Dose Assessment Workstation

$13 \mathrm{ft}$. $x 3 \mathrm{ft}$. desk

1 VDT on stand $2.5 \mathrm{ft} . \mathrm{x} 3 \mathrm{ft}$.

$18.0 \mathrm{ft}^{2}$

l swivel arm chair inc. ops. space

\section{Source Term Workstation}

$12.5 \mathrm{ft} . \times 5 \mathrm{ft}$. desk c

$12.5 \mathrm{ft}^{2}$

1 VDT on stand e $2.5 \mathrm{ft} . \times 3 \mathrm{ft}$.

$7.5 \mathrm{ft}^{2}$

1 swivel arm chair incl. ops. space

\section{Meteorology Workstation}

2 desks @ $2 \mathrm{ft} .10 \mathrm{in.} x 5 \mathrm{ft}$.

1 VDT on stand e $2.5 \mathrm{ft} . \times 3 \mathrm{ft}$.

$18.0 \mathrm{ft}^{2}$

$7.5 \mathrm{ft}^{2}$

2 swivel arm chairs ops. spaces

$24.5 \mathrm{ft}^{2}$

Offsite Environmental and Hydrology

$22.5 \mathrm{ft} . \times 5 \mathrm{ft}$. desks

$25.0 \mathrm{ft}^{2}$

2 swivel arm chairs ops. space

$24.5 \mathrm{ft}^{2}$

Occasional Onsite HP Workstation

$12.5 \mathrm{ft} . \times 5 \mathrm{ft}$. desk

$25.0 \mathrm{ft}^{2}$

1 swivel artn chair ops. space

$12.25 \mathrm{ft}^{2}$

estimated floor space for acoustic panels $.5 \mathrm{ft} . x 74 \mathrm{ft}$. $37.0 \mathrm{ft}^{2}$

circulation at .50 of above (twice normal)

Total

$244.0 \mathrm{ft}^{2}$ $122.0 \mathrm{ft}^{2}$

Total

$366.0 \mathrm{ft}^{2}$ 
PROTECTIVE ACTION ANALYSIS TEAM

\section{Two State Liaisons Workstations}

$22.5 \mathrm{ft} . \times 5 \mathrm{ft}$. desks

2 swivel chairs @ 12.25 ops. space each

1 wastebasket ef $1.2 \mathrm{ft} . \times 2 \mathrm{ft}$.

acoustic partitions @.5 ft. x $20 \mathrm{ft}$.

$25.0 \mathrm{ft}^{2}$

$24.5 \mathrm{ft}^{2}$

$2.4 \mathrm{ft}^{2}$

$10.0 \mathrm{ft}^{2}$

\section{Conference Area}

1 square/round table $4 \mathrm{ft}$. $\times 4 \mathrm{ft}$. (or $4 \mathrm{ft} . \mathrm{d}$ )

$16.0 \mathrm{ft}^{2}$

4 side chairs $2 \mathrm{ft} . \times 2 \mathrm{ft}$.

$16.0 \mathrm{ft}^{2}$

$2 \mathrm{ft}$. operational space based around table

$32.0 \mathrm{ft}^{2}$

circulation at .30 of above

Total

$125.9 \mathrm{ft}^{2}$

$38.0 \mathrm{ft}^{2}$

Total for RA and PAA Teams

$530.0 \mathrm{ft}^{2}$ 


\section{Desk Workstations}

2 desks @ 30 in. $x 60$ in.

2 desks @ 30 in. $x 60$ in. with typing returns (d) 18 in. $x 34$ in.

4 swivel desk chairs @ 12.25 ops. space each

4 wastebaskets e $2.4 \mathrm{ft}^{2}$ each

operational space around desks

2 work tables @ 27 in. $h, 4 \mathrm{ft} . x 8 \mathrm{ft}$.

8 stackable side chairs \& $1.8 \mathrm{ft} . \mathrm{x} 2.2 \mathrm{ft}$. each

operational space around tables

$25.0 \mathrm{ft}^{2}$

$34.0 \mathrm{ft}^{2}$

$49.0 \mathrm{ft}^{2}$

$9.6 \mathrm{ft}^{2}$

$74.0 \mathrm{ft}^{2}$

$64.0 \mathrm{ft}^{2}$

$32.0 \mathrm{ft}^{2}$

$170.0 \mathrm{ft}^{2}$

\section{Security Station}

1 desk @ 36 in. x 66 in.

l swivel chair @ 12.25 ops. space

1 wastebasket

$16.5 \mathrm{ft}^{2}$

$12.25 \mathrm{ft}^{2}$

$2.4 \mathrm{ft}^{2}$

circulation space a .30 of above

$489.0 \mathrm{ft}^{2}$

$147.0 \mathrm{ft}^{2}$

Total

$636.0 \mathrm{ft}^{2}$ 
No. of

Copies

OFFSITE

A. A. Churm

DOE Patent Division

9800 S. Cass Avenue

Argonne, IL 60439

218 U.S. Nuclear Regulatory Commission

Division of Technical Information and Document Control

7920 Norfolk Avenue

Bethesda, MD 20014

2 DOE Technical Information Center

ONSITE

32 Pacific Northwest Laboratory

A. E. Desrosiers (25)

Technical Information (5)

Publishing Information (2) 


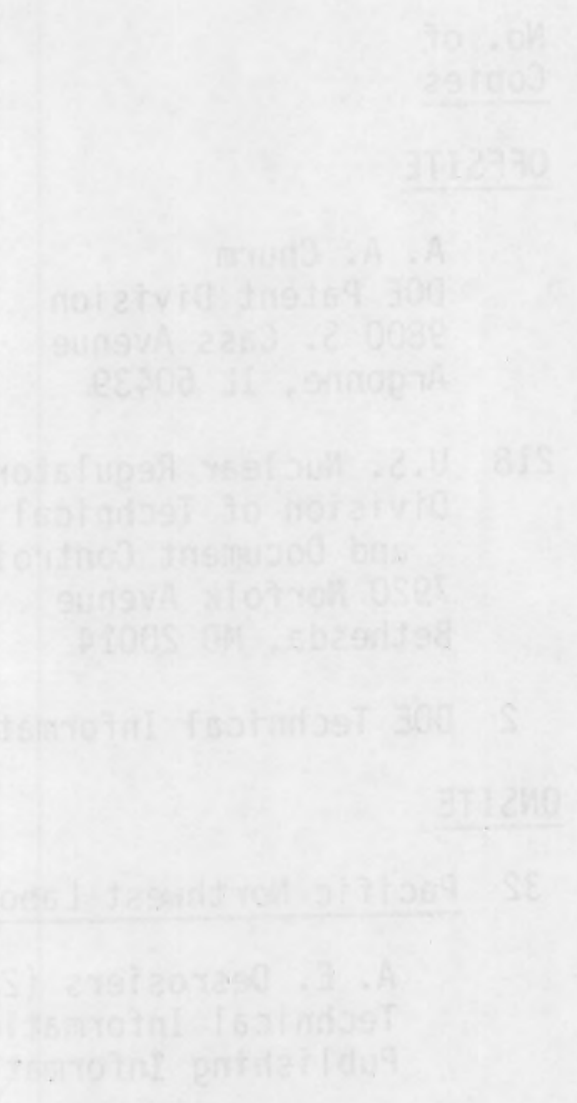




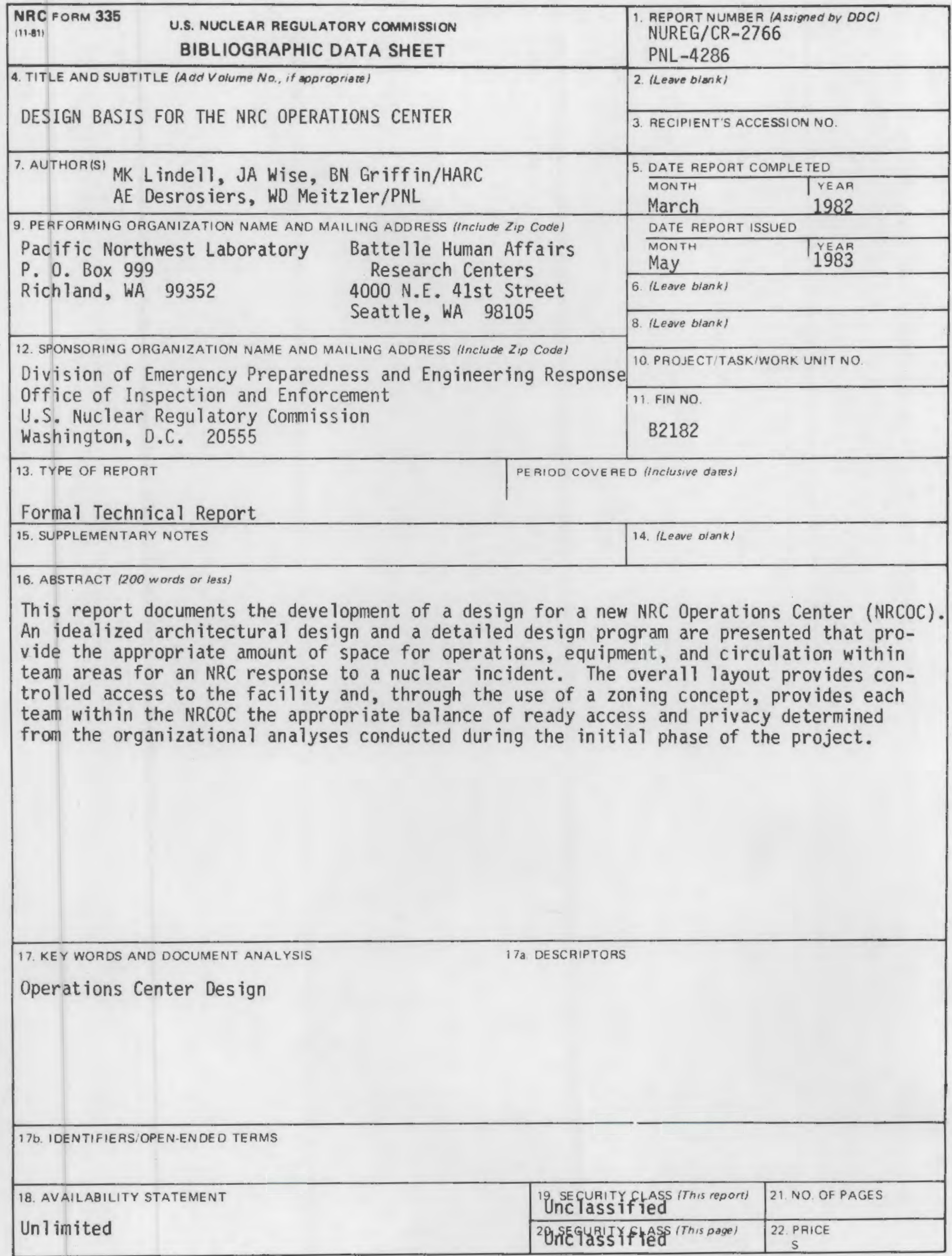




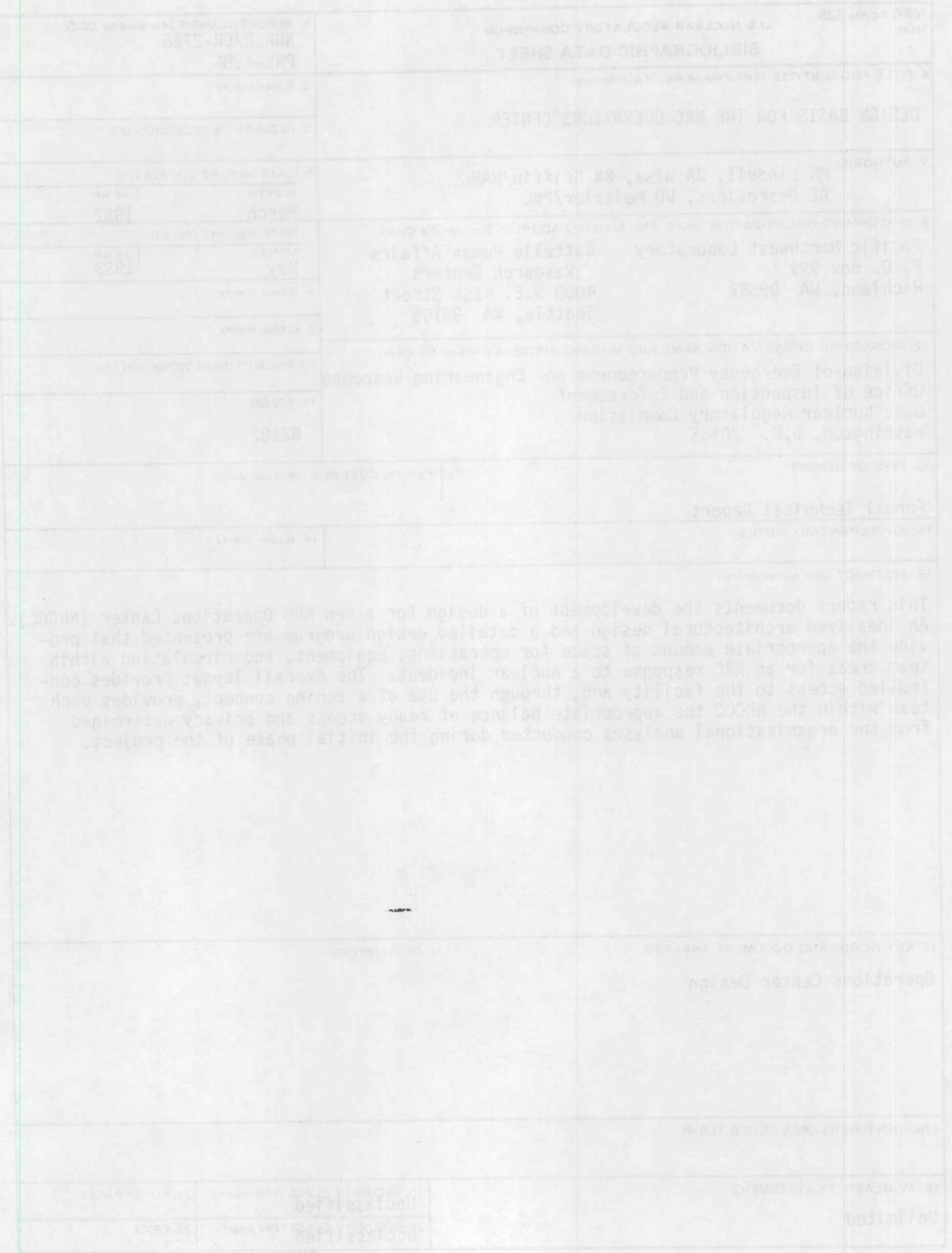

